Portland State University

PDXScholar

Fall 11-16-2015

\title{
Transport of Heat Activated Persulfate and Its Application for In-situ Chemical Oxidation of Residual Trichloroethylene
}

Lauren Dekker Quig

Portland State University

Follow this and additional works at: https://pdxscholar.library.pdx.edu/open_access_etds

Part of the Civil and Environmental Engineering Commons Let us know how access to this document benefits you.

Recommended Citation

Quig, Lauren Dekker, "Transport of Heat Activated Persulfate and Its Application for In-situ Chemical Oxidation of Residual Trichloroethylene" (2015). Dissertations and Theses. Paper 2629.

https://doi.org/10.15760/etd.2625

This Thesis is brought to you for free and open access. It has been accepted for inclusion in Dissertations and Theses by an authorized administrator of PDXScholar. Please contact us if we can make this document more accessible: pdxscholar@pdx.edu. 
Transport of Heat Activated Persulfate and Its Application for In-situ Chemical Oxidation of Residual Trichloroethylene

by

Lauren Dekker Quig

A thesis submitted in partial fulfillment of the

requirements for the degree of

Master of Science

in

Civil and Environmental Engineering

Thesis Committee:

Gwynn Johnson, Chair

Scott Wells

William Fish

Portland State University

2015 
Abstract

In situ chemical oxidation is a promising technology for the remediation of persistent subsurface contamination. Increasingly, the persulfate ion is being studied for use in these systems, both on its own as a strong oxidant and as the precursor to the even more reactive sulfate radical. Persulfate has been shown to treat a wide range of contaminants, from traditional Superfund contaminants such as chlorinated solvents to emerging pharmaceutical contaminants. Additionally, persulfate ISCO can be tailored to site and pollutant specific characteristics based on the method of persulfate activation (e.g., energy and catalysis activation) to the sulfate radical. Thermal activation of persulfate is particularly promising because it can be easily controlled, requires no additional reagents, and commonly creates only non-toxic end products. While persulfate in-situ chemical oxidation technology is being commercially used, a mechanistic study of the physical and chemical processes controlling the effectiveness of this remedial approach is not well documented in the literature. Published work characterizing persulfate ISCO largely focuses on reactions in aqueous, batch systems, which fail to provide crucial design data when working with ever transient, multi-phase groundwater systems.

The purpose of this research was twofold. Initial studies characterized the overall transport behavior of unactivated and thermally-activated persulfate $\left(20,60\right.$, and $\left.90^{\circ} \mathrm{C}\right)$ in one-dimensional soil column systems packed with a natural sandy porous media. This necessitated the development of a flow-through, temperature-controlled, continuous- 
injection system for the delivery of heat-activated persulfate. Finally, as a proof of concept, experiments were conducted to investigate persulfate ISCO as a remedial approach for residual-phase trichloroethylene (TCE), a commonly detected, persistent subsurface contaminant.

At all activation temperatures investigated, persulfate exhibited ideal transport behavior with negligible differences in the observed breakthrough curves of persulfate ion and nonreactive tracers in miscible displacement experiments. Additionally, moment analysis of the breakthrough curves measured for persulfate ion in solution indicated negligible interaction of persulfate with the sandy material under steady-state flow (average retardation factor equaled $1.00 \pm 0.021$ ). Persulfate ISCO for residual-phase trichloroethylene (TCE) was characterized at two flow rates, $0.2 \mathrm{~mL} / \mathrm{min}$ and $0.5 \mathrm{~mL} / \mathrm{min}$, resulting in two degrees of apparent persulfate activation, $39.5 \%$ and $24.6 \%$, respectively. Both ISCO soil column systems showed an initial, long-term plateau in effluent concentrations measured for TCE indicating steady-state dissolution of pure phase TCE. Effluent concentrations of TCE began decreasing after 75 and 100 pore volumes (normalized for the residual fraction of TCE in individual soil columns) in the $39.5 \%$ and $24.6 \%$ activated persulfate columns as compared to 110 pore volumes in the control study (flushed with electrolyte only). Pseudo first-order rate constants for the decreasing TCE concentrations were calculated using log-linear regression analysis. The measured reaction rate constants for the control, the $0.2 \mathrm{~mL} / \mathrm{min}$ (39.5\% activation) study, and the $0.5 \mathrm{~mL} / \mathrm{min}$ (24.6\% activation) study equaled $0.044,0.063$, and $0.083 \mathrm{hr}^{-1}$, respectively. 
Additionally, moment analysis of the complete dissolution of TCE in the persulfate/activated persulfate remediation systems indicated approximately $33 \%$ degradation/oxidation of TCE mass present.

As shown by this and other work, persulfate has enormous potential as a subsurface remediation technology. A more thorough understanding of the physical and chemical mechanisms controlling the behavior and application of persulfate in the subsurface, especially under transient conditions, is necessary for the growth of this technology. By characterizing heat-activated persulfate under dynamic conditions, describing the overall transport of persulfate/activated persulfate in a natural porous media, as well as a proof of concept for the ISCO treatment of a residual nonaqueous phase liquid, this work aids in improving the implementation of persulfate ISCO systems. 


\section{Table of Contents}

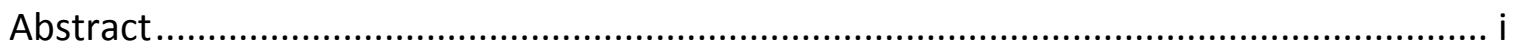

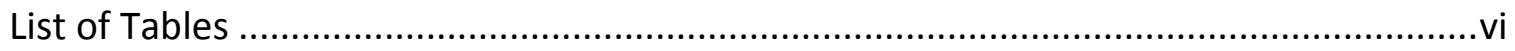

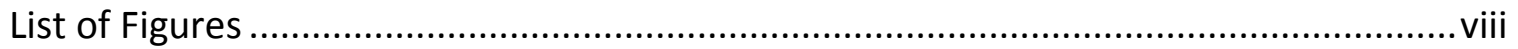

List of Symbols and Abbreviations ........................................................................... ix

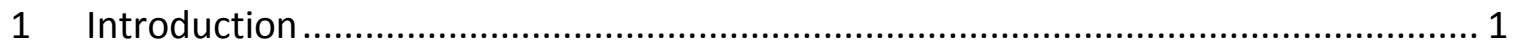

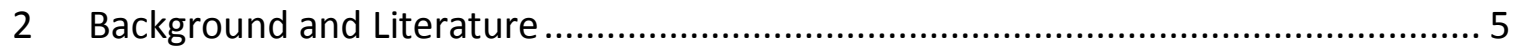

2.1 Persistent Groundwater Contamination ...................................................... 5

2.2 In Situ Chemical Oxidation Treatment Technologies ......................................... 6

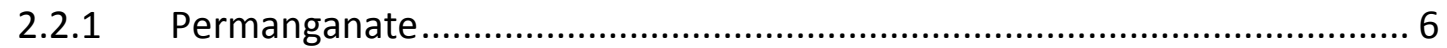

2.2.2 Hydrogen peroxide/Fenton's Reagent ..................................................... 7

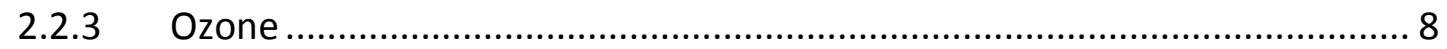

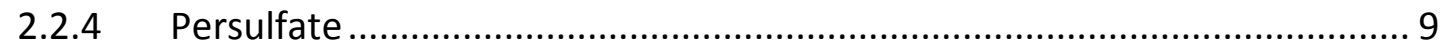

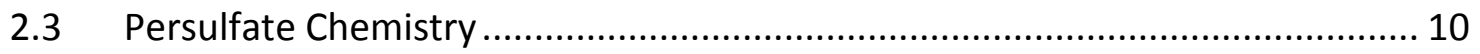

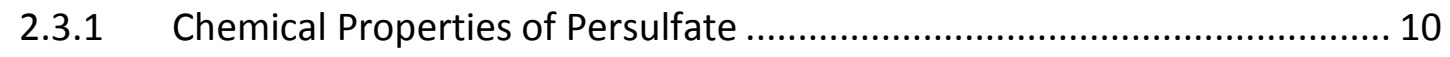

2.3.2 Methods of Persulfate Activation ........................................................... 11

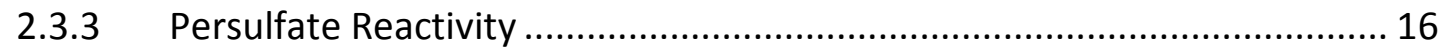

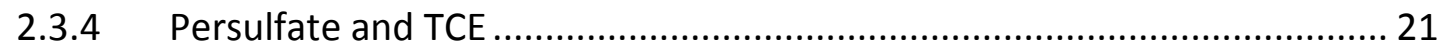

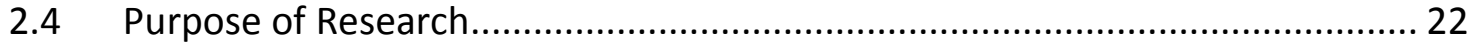

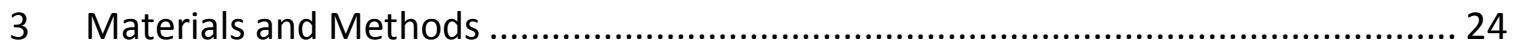

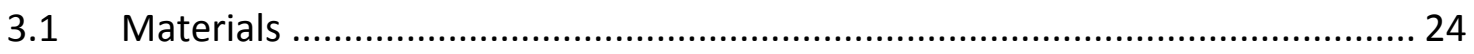

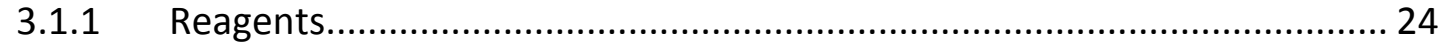

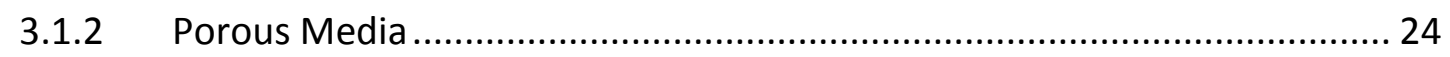

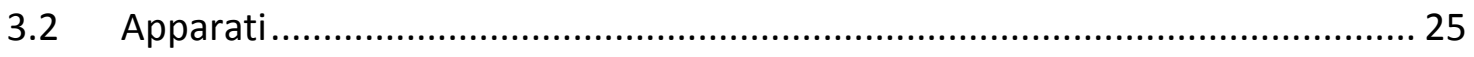

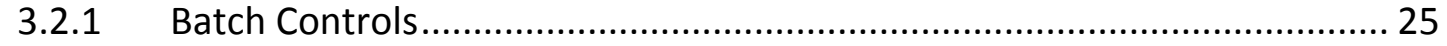

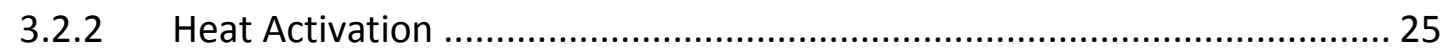

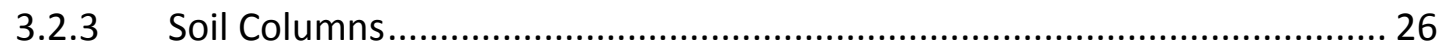

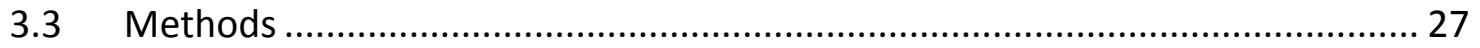

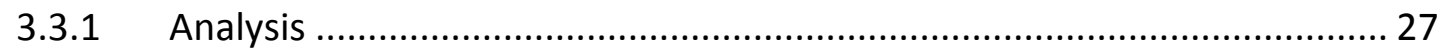

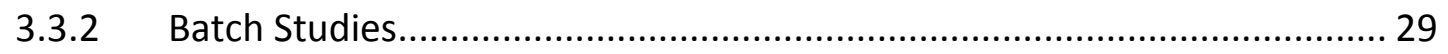




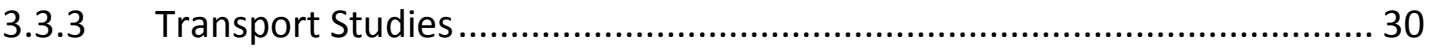

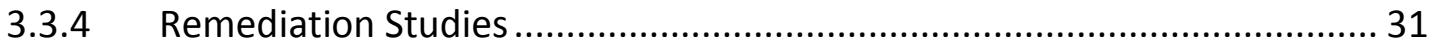

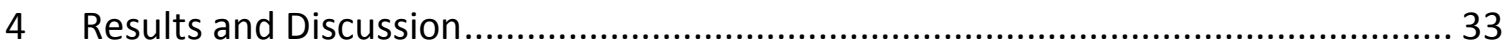

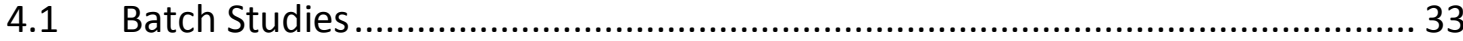

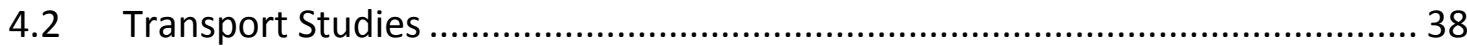

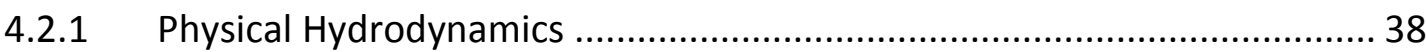

4.2.2 Temperature Effects ........................................................................... 44

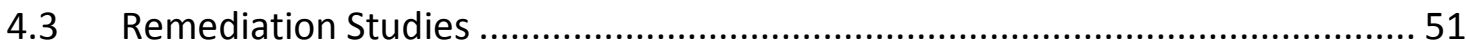

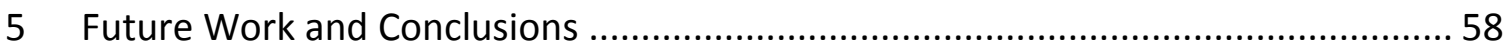

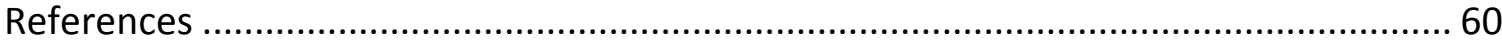

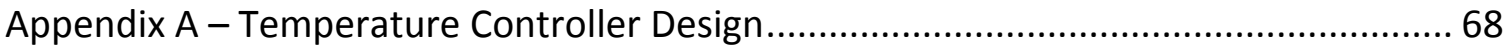

Appendix B - Experimental Set-up ………………………......................................... 70

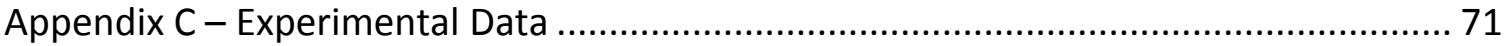


List of Tables

Table 1: Select groundwater contaminants and their properties ................................ 5

Table 2: Redox half-reactions and potentials for common ISCO species [44] ................. 11

Table 3: Percent mass recovery of persulfate after 9 day batch experiment under a range of conditions. Standard error given for batch reactors containing Accusand.

Table 4: Relevant experimental values for NRTs performed over the course of experimentation in column packings $\mathrm{A}$ and $\mathrm{B}$.

Table 5: Relevant experimental values from thermal activation transport studies done in column A

Table 6: Apparent activation gains observed after persulfate has left the heated reservoir in elevated temperature studies.....

Table 7: System properties for remediation studies 52

Table 8: Mass removal for remediation studies 53

Table 9: Activation gains observed after persulfate has left the heated reservoir in transport and remediation studies 
List of Figures

Figure 1: Relative concentration over time for persulfate activated at 60 and $90^{\circ} \mathrm{C}$ in a batch system.

Figure 2: Relative concentration over time for persulfate and sulfate activated at $90^{\circ} \mathrm{C}$ in a batch system.. 35

Figure 3: Persulfate concentration in batch reactors after 9 days, normalized to starting concentration $\mathrm{C}_{\mathrm{o}}$

Figure 4a-b: (a) Arrival waves and (b) elution waves for three separate nonreactive tracers in column packing $A$.

Figure 5a-c: Arrival and inverted elution waves for (a) NRT 1A, (b) NRT 2A, and (c) NRT 3A..

Figure 6a-c: (a) Arrival wave (b) elution wave and (c) arrival and inverted elution waves for nonreactive tracer in column packing $B$.

Figure 7a-b: (a) Arrival and (b) elution waves for representative NRTs in column packings $A$ and $B$.....

Figure 8a-b: Comparison of (a) arrival and (b) elution waves for persulfate at three different activation temperatures in column A. .

Figure 9a-f: Arrival and elution wave comparisons and reproducibility for all thermal activation studies done in column A.

Figure 10a-b: Comparison of (a) arrival and (b) elution waves for $20^{\circ} \mathrm{C}$ PS-2 and NRT $2 \mathrm{~A}$

Figure 11: Transport of persulfate (PS), sulfate $\left(\mathrm{SO}_{4}\right)$, and total sulfate species $\left(\mathrm{PS}+\mathrm{SO}_{4}\right)$ as measured in $\mathrm{PS} 60^{\circ} \mathrm{C}-3$. 50

Figure 12: Relative concentration of TCE versus dimensionless time in pore volumes scaled for initial residual TCE content.

Figure 13 a-c: Modeled pseudo-first order dissolution for three TCE transport studies. 55 
Figure 14a-c: Concentration of persulfate and sulfate as measured at the effluent of the heated reservoir ("Reservoir") and in the column effluent ("Effluent") as compared to measured concentration of initial persulfate stock concentration ("Initial PS"). ............ 56 
List of Symbols and Abbreviations

\begin{tabular}{|c|c|}
\hline ATSDR & Agency of Toxic Substances and Disease Registry \\
\hline BPA & Bisphenol A \\
\hline BTEX & Benzene, toluene, ethylene, and xylenes \\
\hline $\mathrm{C}$ & Aqueous phase concentration \\
\hline$C_{0}$ & Initial aqueous concentration \\
\hline$d_{50}$ & Median particle diameter \\
\hline DEHP & Di-(2-ethylhexyl)phthalate \\
\hline $\mathrm{E}^{0}$ & Standard oxidation-reduction potential \\
\hline GC & Gas chromatography \\
\hline ISCO & In situ chemical oxidation \\
\hline $\mathrm{k}$ & First-order or pseudo first-order rate constant, units of inverse time \\
\hline LDL & Lower detection limit \\
\hline $\mathrm{MCL}$ & Maximum contaminant level \\
\hline MTBE & Methyl tert-butyl ether \\
\hline NAWQA & National Water-Quality Assessment Program \\
\hline NRT & Nonreactive Tracer \\
\hline PAH & Polycyclic aromatic hydrocarbon \\
\hline PCB & Polychlorinated biphenyl \\
\hline PCE & Tetrachloroethylene \\
\hline PFAA & Perfluoroalkyl acids \\
\hline PFBA & Pentafluorobenzoic acid \\
\hline $\mathrm{ppb}$ & Parts per billion \\
\hline ppm & Parts per million \\
\hline PS & Persulfate \\
\hline PV & Pore volume \\
\hline $\mathrm{R}$ & Ideal gas constant, $8.314 \mathrm{~kJ} \mathrm{~K}^{-1} \mathrm{~mol}^{-1}$ \\
\hline $\mathrm{T}$ & Absolute temperature, in Kelvin \\
\hline TCE & Trichloroethylene \\
\hline UV & Ultra-violet \\
\hline ZVI & Zero-valent iron \\
\hline
\end{tabular}


1 Introduction

Though hidden from sight, aquifer systems are an absolutely vital source of freshwater. Exempting the freshwater stored in glaciers and ice caps, there is nearly 100 times more freshwater stored in aquifers as compared to surface water [1]. Approximately 25 to $40 \%$ of the world's drinking water [2] and nearly $45 \%$ of water for irrigation [3] comes from subsurface systems. The top three groundwater users -China, India, and the United States - pull nearly a quarter of all their water from aquifer systems, withdrawing a combined 475 billion $\mathrm{m}^{3}$ of water per year [4]. With such a heavy dependence on subsurface systems, maintaining the health of aquifers is paramount to providing clean water for residential, agricultural, and industrial uses. Unfortunately, the inherent and complex physical qualities of groundwater systems and the wide variety of pollutants migrating to the subsurface make aquifers difficult to monitor, and when contaminated, a challenge to clean up.

A wide variety of natural occurring and anthropogenic compounds have been found at concerning levels in subsurface systems. The Agency of Toxic Substances and Disease Registry (ATSDR) lists some of the most concerning environmental pollutants at priority Superfund sites. In the top twenty contaminants of concern, a range of chemical classes are represented, including heavy metals, large organic compounds, oil and gas contaminants, and pesticides [5]. In a survey of over 6,000 drinking water wells in the United States, the National Water-Quality Assessment Program (NAWQA) found 22\% had 
levels of contaminants that are of concern for human health, ranging from agricultural based nitrates, to anthropogenic volatile organic compounds, to naturally occurring radon [6]. This large array of contaminant classes and associated chemistry significantly increases the difficulty in developing effective treatments for contaminated aquifer systems.

Complicating the maintenance and remediation of subsurface systems further, a focus on science and research was not prevalent until the 1970s [7] as the environmental movement gained traction in the United States and around the world. Though the technology continues to develop, traditional remedial approaches for subsurface contamination such as pump and treat and soil vapor extraction are often ineffective, time consuming, costly, and may not be appropriate for all contaminant classes ([7][9]). For example, the Baird and McGuire Superfund site in Holbrook, Massachusetts has had a pump and treat system in place since 1993 with no plans to end operation any time soon [10]. Costs for environmental cleanup at hazardous waste sites in the United States are projected as high as $\$ 250$ billion dollars between 2004 and 2033 for an estimated 294,000 sites [11]. With the sheer cost and volume of necessary remediation, treatment options that are cost effective, quick, and robust are more and more vital.

In situ chemical oxidation (ISCO) is a remediation technology that has gained increasing attention in recent years. ISCO systems inject a chemical oxidant directly into the subsurface to treat recalcitrant contaminant zones, either by complete mineralization of the pollutant or degradation to less harmful byproducts. There are four oxidants 
commonly used: hydrogen peroxide $\left(\mathrm{H}_{2} \mathrm{O}_{2}\right.$ or Fenton's reagent), permanganate $\left(\mathrm{MnO}_{4}{ }^{-}\right)$, ozone $\left(\mathrm{O}_{3}\right)$, and more recently, persulfate $\left(\mathrm{S}_{2} \mathrm{O}_{8}{ }^{2-}\right)$. These compounds are all effective oxidizers, and two (peroxide and persulfate) can be activated to produce even stronger oxidant radical species, i.e., the hydroxyl radical $(\bullet \mathrm{OH})$ and the sulfate radical $\left(\mathrm{SO}_{4}{ }^{-} \bullet\right)$, respectively [8]. Research has shown that physical, chemical, and biological heterogeneities inherent to contaminated subsurface systems often require various and different ISCO technologies to be employed. Understanding the advantages and disadvantages of each treatment approach is crucial to designing the most effective system for remediation.

In situ chemical oxidation has been proven to successfully degrade a wide array of contaminants at the bench scale. Primarily it has been shown to degrade volatile organic compounds [12], chlorinated solvents ([9], [13]-[17]), polycyclic aromatic hydrocarbons ([8], [9], [18], [19]), aromatic compounds, petroleum products (e.g., benzene, toluene, ethylbenzene, and xylene) [9], poly-chlorinated biphenyls, pesticides ([20], [21]), and emerging contaminants such as pharmaceuticals and other personal care products ([22][24]). A majority of these studies have been done in batch systems, and few examine the effectiveness of the technology under dynamic (transport) conditions (i.e., in soil column systems) ([25]-[28]). Unfortunately, pilot- and field-scale studies are scarce in the literature, although some research results are available in conference proceedings and industry technical reports ([8], [9]). Though batch studies provide relevant insight for characterizing the overall applicability of ISCO for the remediation of commonly found 
subsurface pollutants, more peer-reviewed work under dynamic (transport) conditions is vital to the development of working, full-scale, ISCO treatment systems.

As one of the newest chemical oxidants to be employed in ISCO systems, research characterizing the applicability and effectiveness of persulfate and/or activated persulfate for the remediation of common contaminants found in subsurface systems is needed. Though some knowledge from other chemical oxidant technologies is transferrable, particularly associated with permanganate treatment technologies [8], there are significant gaps in the understanding of persulfate's chemical oxidation behavior. For example, the effectiveness of ISCO using persulfate and its applicability to contaminated subsurface systems is expected to be a function of the various methods of persulfate activation (e.g., iron, biochar, $\mathrm{pH}$, ultraviolet light, and heat), the complexities of subsurface environments, and the properties of common contaminants of concern.

This study aims to characterize the overall transport behavior of persulfate and heat-activated persulfate in a natural porous media. Soil column studies were conducted to investigate the physical and chemical processes controlling the transport of persulfate and activated persulfate under different degrees of activation as a function of activation temperature. This research included the design of a temperature-controlled flow apparatus to deliver a steady-state concentration of thermally-activated persulfate to a soil column system. Additionally, the effectiveness of thermally-activated persulfate as an in situ chemical oxidant for the remediation of residual trichloroethylene (TCE) in a natural porous media was characterized in a flow-through soil column system. 


\section{Background and Literature}

\subsection{Persistent Groundwater Contamination}

As water becomes an ever more precious resource, the cleanup of contaminated aquifers for human use is becoming more vital. More than $80 \%$ of Superfund sites in the United States have degraded the health of local aquifers, and some 500 more sites have the possibility to adversely affect nearby supply wells [29]. The most common classes of contaminants found at Superfund sites are volatile organic compounds (e.g., trichloroethylene and tetrachloroethylene), semi-volatile organics (e.g., polycyclic aromatic hydrocarbons), and heavy metals [30]. Data for some representative subsurface contaminants are shown in Table 1.

Table 1: Select groundwater contaminants and their properties

\begin{tabular}{|l|c|c|c|c|}
\hline \multicolumn{1}{|c|}{ Contaminant } & $\begin{array}{c}\text { ATSDR } \\
\text { Rank [5] }\end{array}$ & $\begin{array}{c}\text { Percent } \\
\text { Frequency [5] }\end{array}$ & $\begin{array}{c}\text { US Drinking } \\
\text { Water MCL [31] }{ }^{2}\end{array}$ & $\begin{array}{c}\text { Example Adverse } \\
\text { Health Effects [31] }\end{array}$ \\
\hline Arsenic & 1 & $86.2 \%$ & $0.010 \mathrm{ppm}$ & $\begin{array}{l}\text { Skin irritation, } \\
\text { paralysis carcinogen }\end{array}$ \\
\hline $\begin{array}{l}\text { Polychlorinated } \\
\text { Biphenyls (PCBs) }\end{array}$ & 5 & $41.4 \%$ & $0.050 \mathrm{ppb}$ & Hearing/vision \\
problems, cancer, \\
\hline Benzene
\end{tabular}


As indicated by the high frequency of many of these pollutants, many Superfund sites are contaminated with multiple and diverse compounds. This makes cleanup even more complex, and stresses the need for treatment technologies that are effective on a wide variety of compounds. While the sheer number and complexity of contaminated sites is troubling enough, many of the pollutants at these sites also exhibit high toxicity to humans at low levels.

\subsection{In Situ Chemical Oxidation Treatment Technologies}

One treatment technology that has been increasingly studied in recent years is insitu chemical oxidation (ISCO). ISCO involves the injection of a chemical oxidant species into the subsurface to degrade recalcitrant compounds susceptible to redox reactions. The oxidant species work by removing electrons from the contaminant of concern (COC), either breaking the compound down completely or transforming it into less hazardous products. The most common oxidants currently used are hydrogen peroxide $\left(\mathrm{H}_{2} \mathrm{O}_{2}\right.$ or Fenton's reagent), permanganate $\left(\mathrm{MnO}_{4}{ }^{-}\right)$, ozone $\left(\mathrm{O}_{3}\right)$, and more recently, persulfate $\left(\mathrm{S}_{2} \mathrm{O}_{8}{ }^{2-}\right)$. As with any technique, each method has its advantages and disadvantages. For reference, some of the benefits and challenges of the prominent ISCO technologies are listed below.

\subsubsection{Permanganate}

Permanganate is the most widely studied chemical oxidant, with literature describing the process from bench to the field scale (e.g., [7], [8], [27], [30], [32]-[34]). 
Different half reactions dominate under different $\mathrm{pH}$ conditions, but all cases involve the oxidation of manganese present in permanganate. Permanganate has been shown to be highly effective with chlorinated alkenes, both in the aqueous and nonaqueous phase, but less so with alkanes, aromatics, and polychlorinated biphenyls. The reactivity of the permanganate ion is broad, but nonspecific. In the subsurface, this often means that permanganate use is inefficient, as the oxidant is lost to side reactions driven by natural oxidant demand. Due to its high solubility, permanganate can be injected at high concentrations, leading to density driven transport that has been shown to improve its distribution in subsurface systems [35]. A wide variety of aquifer systems, from fractured bedrock to clay-silts (e.g., [8], [30], [34]), have been successfully treated with permanganate, however, there are several byproducts, particularly solid $\mathrm{MnO}_{2}$ and gaseous $\mathrm{CO}_{2}$, that can lead to inefficient mass transfer associated with decreases in the matrix permeability [36]. While subsurface biomes appear to recover quickly after permanganate ISCO, there is little data on long-term impacts to groundwater quality due to process byproducts ([8], [37]).

\subsubsection{Hydrogen peroxide/Fenton's Reagent}

Hydrogen peroxide when activated with ferrous iron $\left(\mathrm{Fe}^{2+}\right)$ can produce the hydroxyl radical $(\bullet \mathrm{OH})$, an incredibly reactive, non-specific oxidant. The high degree of reactivity means that the radical can break down a wide variety of contaminants. For example, radical chain reactions can form new radical and ion species, such as the superoxide radical $\left(\bullet \mathrm{O}_{2}{ }^{-}\right)$, and peroxide anions $\left(\mathrm{HO}_{2}^{-}\right)$, which may act as reducing agents 
in the subsurface. Because of these reductive species, hydrogen peroxide systems could be designed to treat pollutants susceptible to both oxidation and reduction [8].

The rapid rate of both peroxide breakdown and radical reaction means that the long-term persistence of the oxidant in the subsurface post application is not a concern; however, that high reactivity and rapid reaction rate can make the oxidant mixture difficult to deliver far past the injection site. For example, researchers have shown that while the hydroxyl radical is highly reactive to a wide range of chemical species, it has a tendency to be scavenged by other compounds in the subsurface ([38], [39]). Additionally, some subsurface sites employing peroxide ISCO have reported higher contaminant levels after treatment due to mobilization of nonaqueous phase liquids and migration of heavy metals (e.g., [8], [34], [37]). Researchers have also reported that large quantities of heat and gas can be produced on the application of hydrogen peroxide/Fenton's reagent, causing the melting of ISCO equipment, asphalt buckling, and even fire ([34], [40]). While these byproducts can be dangerous, they have also been shown to contribute to an increase in mass transfer between the contaminant and oxidant [37].

\subsubsection{Ozone}

Ozone has been injected as a subsurface treatment similar to air sparging. Ozone has relatively broad reactivity, and in combination with water or hydrogen peroxide can form the hydroxyl radical as well. This broad reactivity means that ozone reacts 
nonspecifically in the subsurface, and it is often consumed in non-productive side reactions by more readily-oxidized aquifer materials (e.g., cationic metals) rather than the contaminant of concern ([8], [34], [41]). Research has shown that ozone is more reactive in the gas phase, making it a valuable tool for treatment in the unsaturated zone while ozone's low aqueous solubility makes it less effective for treating contaminants in the saturated zone [8]. When injected as a gas, the formation of air channels in the subsurface is essentially random, limiting the extent of ozone delivery to target areas of concern ([41], [42]). Additionally, special equipment (e.g., 316 stainless steel and Teflon seals and gaskets) is often needed due to ozone's corrosive effect at the high pressures needed for injection as other common materials (e.g., galvanized steel, natural rubbers, polypropylene) are prone to ozone cracking and oxidation [43] . Ozone is also a regulated air pollutant and can increase volatilization of subsurface contaminants as well, making vapor control an important part of any field-scale treatment design [8].

\subsubsection{Persulfate}

Persulfate, or peroxydisulfate, is the most recent compound being investigated for remediation purposes. Its strong oxidant properties have been well characterized in the literature (e.g., [8], [9], [44] and sources therein). For in situ chemical oxidation, persulfate is an attractive reagent for several reasons, in part because of the high oxidizing potential associated with both persulfate and its associated decomposition products. While unactivated persulfate itself has a high standard potential, upon activation, persulfate decomposes to form the even more active sulfate radical $\left(\mathrm{SO}^{-} \bullet^{-}\right)$. The persulfate ion is 
also a promising technology because of the multiple ways that activation to the sulfate radical can occur. This allows for tailoring to a specific site and compound for more effective remediation.

\subsection{Persulfate Chemistry}

\subsubsection{Chemical Properties of Persulfate}

Several characteristics of persulfate make it particularly attractive as an aquifer remedial technology. In particular, it is readily available in a salt form as sodium, potassium, or ammonium, although the sodium salt is preferred due to its high aqueous solubility and low environmental impact. With a solubility of $73 \mathrm{~g} / \mathrm{L}$ at $25^{\circ} \mathrm{C}$ [45], highly concentrated solutions of sodium persulfate can be created, facilitating density driven mass transport in the subsurface. The byproducts of oxidation-reduction reactions with sodium persulfate are sodium and sulfate ions, two compounds without enforceable water quality standards ([46], [47]). On a weight basis persulfate is also cost-competitive at approximately $\$ 1.20 / \mathrm{lb}$. [8]. Persulfate is highly stable at ambient temperatures, with a half-life of approximately 50 days when no activation sources are present at $20^{\circ} \mathrm{C}$ in aqueous solution [48].

For comparison, the relevant redox reactions and reduction potentials of persulfate, the sulfate radical, and other chemical oxidants are given in Table 2. Of the common oxidants used for ISCO, only the hydroxyl radical has a higher redox potential than that of the sulfate radical. 
Table 2: Redox half-reactions and potentials for common ISCO species [44]

\begin{tabular}{|l|c|c|}
\hline \multicolumn{1}{|c|}{ Compound } & Redox Half Reaction & $\begin{array}{c}\text { Redox } \\
\text { Potential, E }\end{array}$ \\
\hline Persulfate & $\mathrm{S}_{2} \mathrm{O}_{8}^{2-}+2 e^{-} \rightarrow 2 \mathrm{SO}_{4}^{2-}$ & $2.01 \mathrm{~V}$ \\
\hline Sulfate Radical & $\mathrm{SO}_{4}^{-} \bullet+e^{-} \rightarrow \mathrm{SO}_{4}^{2-}$ & $2.60 \mathrm{~V}$ \\
\hline Hydrogen Peroxide & $\mathrm{H}_{2} \mathrm{O}_{2}+2 \mathrm{H}^{+}+2 e^{-} \rightarrow 2 \mathrm{H}_{2} \mathrm{O}$ & $1.77 \mathrm{~V}$ \\
\hline Hydroxyl Radical & $\mathrm{OH} \cdot+e^{-} \rightarrow \mathrm{OH}^{-}$ & $2.70 \mathrm{~V}$ \\
\hline $\begin{array}{l}\text { Permanganate (natural } \\
\text { pH) }\end{array}$ & $\mathrm{MnO}_{4}^{-}+4 \mathrm{H}^{+}+3 e^{-} \rightarrow \mathrm{MnO}_{2}\left(\mathrm{~s}+2 \mathrm{H}_{2} \mathrm{O}\right.$ & $1.70 \mathrm{~V}$ \\
\hline Ozone & $\mathrm{O}_{3(\mathrm{~g})}+2 \mathrm{H}^{+} \rightarrow \mathrm{O}_{2(\mathrm{~g})}+\mathrm{H}_{2} \mathrm{O}$ & $2.07 \mathrm{~V}$ \\
\hline
\end{tabular}

\subsubsection{Methods of Persulfate Activation}

Zhang et al. [44] categorized the activation methods of persulfate into two primary types: energy activation and catalyzer activation. The former indicates a system where energy is applied, as heat, radiation, or photochemically, to encourage the breakdown of persulfate to sulfate radicals. The latter, catalyzer activation, refers to processes that use another chemical species, generally transition metals, acids, or bases, to create sulfate radicals.

Energy activation systems work by providing enough energy, through heat or light, to sever the peroxy (oxygen-oxygen) bond in the persulfate ion, generating two sulfate radicals, as shown in equation (1):

$$
\mathrm{S}_{2} \mathrm{O}_{8}^{2-} \stackrel{\text { heat } / h v}{\longrightarrow} 2 \mathrm{SO}_{4}^{-} \bullet
$$


Thermal activation has been studied largely at the bench scale, with promising results for a wide variety of environmental contaminants ([12], [14], [16], [22], [49]-[51]). Multiple studies have shown that higher temperatures led to a higher rate of decomposition of persulfate to form the sulfate radical ([12], [16], [48]). Studies have also shown that the reaction in equation (1) follows the Arrhenius equation (e.g., [48], [52]). While heat activation of persulfate under higher temperatures lead to a both higher potential for species oxidation and percent removal for most compounds, some researchers have shown that higher temperatures can release sulfate radicals too quickly to provide adequate remediation [9].

The characterization of heat-activated persulfate as a chemical oxidant are largely reported in the literature for batch systems, wherein researchers achieve thermal activation by simply heating the batch reservoir to temperature (e.g. [12], [22], [51], [53]). While characterizing the kinetics of chemical oxidation by persulfate, this method is highly unrepresentative of the technical approach necessary to employ persulfate as an in situ treatment technology in subsurface systems. For example, at the field scale it is likely that persulfate would be heat activated on the surface and then pumped into the subsurface, or that heating technologies (e.g., radio-wave heating or steam injection) would be applied to the aquifer following the injection of persulfate [16]. Ultraviolet light, most often a mercury lamp at $254 \mathrm{~nm}$, and even visible light have also been used to provide the energy needed for the reaction in equation (1) to go forward. However, due to the low penetrating power of these wavelengths, most work examines the UV- 
activation of persulfate for treatment of wastewater rather than subsurface contamination [44].

Outside of energy activation, the most common method of persulfate activation in ISCO systems is cationic metal catalysis. The generic reaction for persulfate activation by metal catalysis is shown in equation ((2), [44]):

$$
\mathrm{S}_{2} \mathrm{O}_{8}^{2-}+\mathrm{M}^{n+} \rightarrow \mathrm{M}^{(n+1)+}+\mathrm{SO}_{4}^{-} \cdot+\mathrm{SO}_{4}^{2-}
$$

Metal catalysis is slightly less efficient in its activation of persulfate, as only one sulfate radical is produced per persulfate ion. In addition, persulfate activation by metal catalysis suffers from scavenging of the sulfate radical by the same metals used for activation, as well as unproductive reactions of persulfate with metal cations as shown in equations (3) and (4), respectively [44].

$$
\begin{gathered}
\mathrm{SO}_{4}^{-} \cdot+\mathrm{M}^{n+} \rightarrow \mathrm{M}^{(n+1)+}+\mathrm{SO}_{4}^{2-} \\
\mathrm{S}_{2} \mathrm{O}_{8}^{2-}+2 \mathrm{M}^{n+} \longrightarrow 2 \mathrm{M}^{(n+1)+}+2 \mathrm{SO}_{4}^{2-}
\end{gathered}
$$

Clearly, these reactions can be incredibly detrimental to treatment efficiency when using metal-activated persulfate ISCO. Several researchers have investigated the proper balance of oxidant to activation method for persulfate ISCO [e.g., 26]. For example, on activating persulfate with iron, the use of chelating agents and sequential additions of ferrous iron have been studied to decrease the extent of those reactions in equations (3) and (4) by limiting available iron. Chelating agents can also recycle trivalent iron ( $\mathrm{Fe}^{3+}$ ) 
back to its divalent form $\left(\mathrm{Fe}^{2+}\right)$, thus increasing the amount of ferrous iron able to activate persulfate by reaction (2). Iron chelation not only affects the reactivity but is also necessary to keep iron in solution at concentrations that are viable for persulfate activation ([8], [44]).

Researchers have shown various metals can act to catalyze the activation of persulfate. For example, zero-valent iron (ZVI) has also been used with success to activate persulfate ([18], [54]-[56]), as well as several other metals, such as silver $\left(\mathrm{Ag}^{+}\right)$, cobalt $\left(\mathrm{Co}^{2+}\right)$, and nickel $\left(\mathrm{Ni}^{2+}\right)([33],[57],[58])$. Of those metals characterized in the literature, silver has been shown to be the most effective persulfate activator [33]; however, its environmental impacts far outweigh the benefits of increased activation efficiency. Iron is the most commonly employed metal activator for several reasons. It is largely prevalent in the subsurface and has low environmental toxicity. Additionally, much research has been done using iron as an activator in other systems, primarily for hydrogen peroxide (e.g., Fenton's reagent), and some of those application techniques are transferable to the application and remediation of subsurface systems using iron-activated persulfate ISCO. Unfortunately, iron has limiting transport behavior in the subsurface, and iron activation of persulfate above ground, prior to injection, can mean significant reductions in the amount of persistent radical reaching the contaminated zone. Researchers have shown naturally occurring iron may also be effective at persulfate activation, but that science is still in its infancy ([57]-[59]). 
While energy and iron activation are the most well studied activation methods for persulfate, another common technology is $\mathrm{pH}$-dependent activation. Alkaline activation is achieved by increasing the $\mathrm{pH}$ to highly basic conditions, generally with $\mathrm{pH}$ greater than 10. Equation (5) describes the activation of persulfate under these conditions [60].

$$
2 \mathrm{~S}_{2} \mathrm{O}_{8}^{2-}+2 \mathrm{H}_{2} \mathrm{O} \rightarrow 3 \mathrm{SO}_{4}^{2-}+\mathrm{SO}_{4}^{-} \bullet+\mathrm{O}_{2}^{-} \bullet+4 \mathrm{H}^{+}
$$

Under alkaline conditions, the hydroxyl radical can also be formed as shown in equation (6):

$$
\mathrm{SO}_{4}^{-} \bullet+\mathrm{OH}^{-} \longrightarrow \mathrm{OH} \bullet+\mathrm{SO}_{4}^{2-}
$$

The activation of persulfate under these conditions is very rapid, so much so that it can be difficult to treat far past the injection zone. The hydroxyl radical, while very powerful (i.e., a high redox potential), also has a very short half-life in the subsurface. The rapid reaction of both radicals, as well as the stoichiometry in reaction (5), makes alkaline activation less efficient than other activation methods ([9], [44]). However, because of ease of mixing and technology transfer from the more developed Fenton's reagent technologies, this is the most common activation method in field studies and commercial applications to date (e.g. [34], [61], [62]). Unfortunately, there is little peer-reviewed literature available describing these efforts, as most sites are done by commercial rather than academic enterprises. 


\subsubsection{Persulfate Reactivity}

Upon activation and regardless of activation method, persulfate is reactive with a broad range of common subsurface contaminants. As the sulfate radical is effective in withdrawing electrons, contaminants with substituent groups prone to electrophilic reactions are generally more susceptible to oxidation by the persulfate/sulfate radical system [44]. Persulfate has exhibited strong remediation potential for many of the key classes of compounds found at contaminated subsurface sites. This includes chlorinated alkanes and alkenes, polycyclic aromatic hydrocarbons, petroleum hydrocarbons, pesticides, and dyes. Promising research has also been done on some emerging contaminant classes, including endocrine disruptors, pharmaceuticals, and personal care product additives. Current research concerning persulfate treatment of some choice contaminant classes is discussed below.

\section{Halogenated Compounds}

As one of the more prevalent subsurface contaminants, a great deal of attention has been paid to ISCO treatment of halogenated compounds. For example, Costanza et al. showed in batch reservoirs that tetrachloroethylene (PCE) could be effectively mineralized to $\mathrm{CO}_{2}$ and chloride ions by persulfate activated above $50^{\circ} \mathrm{C}$. In soil slurries, they also observed a wide variation in PCE degradation (0\%-90\%) over 80 minutes of reaction time for several reference soils. The low degradation rates in some slurries are presumed to be due to those slurry soils containing large natural oxidant demand and a higher amount of reduced species all competing for sulfate radicals [17]. A similar range 
of removal efficiencies was seen for PCE when persulfate was activated by a basic oxygen furnace waste slag, with greater degradation efficiencies reported for increasing ratios of persulfate to activator species [63]. Pure, nonaqueous phase PCE was also treated in a column system simulating contamination in fractured bedrock, with maximum removal rates of $2600 \mathrm{mg} / \mathrm{L}$ per day when using iron-activated persulfate and a $1.8-20 \%$ removal of total tetrachloroethylene mass. Rebound occurred after persulfate injection ceased, and significant residual concentrations remained after treatment [28].

1,1,1-Trichloroethane, a particularly recalcitrant compound, was fully degraded after 2 hours by persulfate activated at $50^{\circ} \mathrm{C}$ when mixed in batch ratio of $100: 1$, though in field applications complete degradation would likely not occur due to competitive reactions with oxidizable material in the porous matrix [64]. Huang et al. treated a mixture of 59 VOCs with $1-5 \mathrm{~g} / \mathrm{L}$ of persulfate activated between $20^{\circ} \mathrm{C}$ and $40^{\circ} \mathrm{C}$ in batch systems. Their study results indicate that persulfate preferentially oxidized alkene and substituted phenyl compounds over alkanes, with 37 of 59 contaminants having $90 \%$ or greater removal efficiencies after 72 hours in solution with $5 \mathrm{~g} / \mathrm{L}$ of $40^{\circ} \mathrm{C}$ activated persulfate [50]. Discussion of the peer-reviewed literature for persulfate's degradation of trichloroethylene is discussed further on.

\section{Oil and Gas}

Contamination from oil and gas related products is prevalent throughout the United States, and is the site of many small scale ISCO field treatments [34]. Persulfate 
has proved an effective remediation tool for common contaminants found at these sites (e.g., MTBE, BTEX, PAHs, and other aromatic compounds). For example, Deng et al. [65] showed the impacts of different activation methods on the removal of MTBE, a legacy contaminant used as a gasoline additive. Heat $\left(40^{\circ} \mathrm{C}\right)$, iron, and alkaline-activated persulfate $(40.5 \mathrm{~g} / \mathrm{L})$ were able to degrade $100 \%$ of $1000 \mathrm{ppm}$ MTBE within 12,100 , and 600 hours, respectively. Only heat-activated persulfate also fully oxidized the degradation products of MTBE (within approximately $300 \mathrm{~h}$ ) [65]. Huang et al. [50] found the half-life of $5 \mathrm{ppm}$ MTBE to be less than one hour at an $8 \mathrm{~g} / \mathrm{L}$ persulfate dose when heated to $40^{\circ} \mathrm{C}$. Another study examined aqueous solutions and soil slurries spiked with BTEX and exposed to $24 \mathrm{~g} / \mathrm{L}$ persulfate activated by iron. They found half-lives for BTEX to be in the range of 3-7 days for solely aqueous systems as compared to 1-2 days in both the aqueous and sorbed-phase (i.e., soil slurries) [66]. Phenol was transformed into an insoluble polymer by persulfate at $70^{\circ} \mathrm{C}$, making it an effective treatment for contaminated wastewater [51]. Other studies have shown phenol-based compounds can be mineralized by room temperature persulfate reactions [67].

Studies examining complex matrices taken from contaminated sites illustrate how site dependent and variable persulfate treatment can be. Liao et al. [19] and Zhao et al. [49] examined persulfate-based remediation of PAHs in soils from a contaminated coking site. Of the 16 PAHs studied, Liao et al. found 80 to $87 \%$ degradation in both the aqueous and sorbed-phase, although some oxidation byproducts saw an increase in concentration over the treatment period. Longer treatment and higher oxidation doses were effective 
in removing those byproducts as well [19]. Zhao et al. [49] have shown that heat-activated persulfate $\left(60^{\circ} \mathrm{C}\right)$ effectively degraded over $99 \%$ of PAHs studied, while iron-activated persulfate degraded between 73 and $83 \%$ of PAHs studied. No oxidative effects were seen when persulfate was activated in alkaline conditions [49].

In one of the few pilot-scale studies available in the literature, 2000 liters of unactivated persulfate were injected into the subsurface to remediate a gasoline source zone. Ethylbenzene, naphthalene, and petroleum hydrocarbon concentrations were reduced by approximately $40 \%$ when taking into account rebound after treatment ended. Increased concentrations in $\mathrm{CO}_{2}$ indicate complete mineralization of contaminants [68]. In another study, sediment contaminated from oil-sand production with carboxylic acids was effectively treated by $10 \mathrm{~g} / \mathrm{L}$ persulfate at ambient temperature, with $100 \%$ mineralization within 110 days [69].

\section{Emerging Contaminants}

Activated persulfate has also been shown to be an effective treatment technology for new and emerging contaminants such as pharmaceuticals and additives to personal care products. In one study, between 60 and $100 \%$ of a saturated solution of ibuprofen was degraded using heat-activated persulfate at temperatures ranging from $50-70^{\circ} \mathrm{C}$ [69]. $\mathrm{Ji}$ et al. [24] showed the effects of iron-activated persulfate on the removal of two representative antibiotic compounds at micromolar concentrations, reaching maximum 
removal efficiencies of 95.8 and $74.7 \%$ after 4 hours. Other promising work has been done with other medications and antimicrobial products (e.g., [44], [70]-[72]).

Pharmaceuticals are not the only emerging contaminants that have proven responsive to persulfate oxidation. Bisphenol $\mathrm{A}(\mathrm{BPA})$, an endocrine disrupting compound found in plastics, was treated with a coupled system using ultrasound and a low concentration of persulfate. Persulfate alone was shown to completely breakdown 225 ppb BPA at $70^{\circ} \mathrm{C}$ within 60 minutes; paired with ultrasound, the same solution was degraded within 10 to 45 minutes [73]. In one of the few available column studies, a range of perfluoroalkyl acids (PFAAs), which are used as additives in flame retardants and other applications, were tested in a bench scale ISCO system [27]. While significant losses in mass were not observed, ISCO treatment appeared to increase sorption of the longer chain PFAAs when compared to transport behavior without oxidant present, likely due to changes in aqueous and soil chemistry $(\mathrm{pH}$, ionic strength, changing soil organic matter, etc.). The lack of transformation may indicate a need for process optimization, considering promising batch studies in the literature. Other studies have shown high degrees of mineralization of micromolar concentrations of PFAAs using persulfate in aqueous systems ([74]-[76]). Heat-activated persulfate was also used to treat mature landfill leachate with high concentrations of ammonia and refractory organic compounds (measured as chemical oxygen demand), with removal efficiencies of up to 91 and $100 \%$, respectively [77]. Polyvinyl alcohol, an additive in multiple industries from textiles to 
pharmaceuticals, was completely oxidized by both thermal- and iron-activated persulfate in 30 minutes and 2 hours, respectively [56].

\subsubsection{Persulfate and TCE}

Trichloroethylene (TCE) is one of the most commonly detected environmental contaminants and has been the focus of a great deal of ISCO and specifically persulfate ISCO. Most research has been done in batch systems with TCE aqueous-phase concentrations at approximately $60 \mathrm{mg} / \mathrm{L}$, a fraction of TCE's saturation concentration of $1100 \mathrm{mg} / \mathrm{L}$. A majority of available literature on the degradation of TCE using ISCO focuses on thermal- and iron-activation of persulfate, with promising results in both cases. With few exceptions ([25], [26]), the available peer-reviewed research characterizing persulfate ISCO of TCE have been conducted in batch systems. It may be of interest to note that most of that research has been done in purely aqueous phase TCE, rather than TCE-contaminated soil systems. There are some commercial examples of field treatment of TCE by persulfate, but the details are not available due to use of proprietary technologies (e.g., [34], [61], [62]). As other studies have illustrated the effects of soil properties and chemistry on remediation attempts employing ISCO, such as changes in fraction of soil organic carbon, microbe activity, and permeability ([28], [57], [78], [79]), it is clear that the physical, chemical, and biological heterogeneities associated with contaminated subsurface systems may require various and different ISCO remediation technologies to be employed. 


\subsection{Purpose of Research}

Persulfate ISCO is a very promising technology for a wide range of commonly found pollutants in subsurface systems. A review of the literature indicates a great deal of peer-reviewed data is lacking describing its chemistry and behavior on application in subsurface environments. The purpose of this work is to characterize the overall transport behavior and remediation effectiveness of persulfate and heat-activated persulfate in a natural porous media contaminated with pure, nonaqueous phase trichloroethylene. Heat activation of persulfate was chosen for this study due to its low environmental impact and ease of control and characterization. This research included batch studies and dynamic (transport) studies carried out in one-dimensional flow, packed soil columns. These results are expected to aide in the application and design of persulfate ISCO remediation technologies. This research was conducted in three stages: batch work on activated and unactivated persulfate; column work to investigate the overall transport behavior of activated and unactivated persulfate in natural porous media; and finally remediation studies under dynamic (transport) conditions, as proof of concept for a heatactivated persulfate ISCO treatment system. Batch work was done to quantify the degree and reaction kinetics of persulfate activation at elevated temperatures, i.e., $60^{\circ} \mathrm{C}$ and $90^{\circ} \mathrm{C}$. These batch studies included experiments to qualify the degree of mass losses of persulfate to mechanisms other than activation, such as volatilization or sorption/ interaction to natural sandy material and/or experimental apparati. Miscible displacement experiments were done in conjunction with nonreactive tracer experiments 
to determine the unique transport behavior of persulfate activated to different degrees at different activation temperatures $\left(20,60\right.$, and $\left.90^{\circ} \mathrm{C}\right)$.

Column studies were conducted with TCE established at residual concentrations and flushed with $10 \mathrm{mM}$, heat-activated persulfate at two flow rates, $0.2 \mathrm{~mL} / \mathrm{min}$ and 0.5 $\mathrm{mL} / \mathrm{min}$, resulting in two degrees of maximum apparent persulfate activation, $39.5 \%$ and $24.6 \%$, respectively. These final studies served as a proof of concept for a thermallyactivated persulfate ISCO remediation system for a dense nonaqueous phase liquid source zone. 


\section{Materials and Methods}

\subsection{Materials}

\subsubsection{Reagents}

Sodium persulfate $\left(\mathrm{Na}_{2} \mathrm{~S}_{2} \mathrm{O}_{8}, 98 \%\right)$ was sourced from Alfa Aesar (Ward Hill, MA). Potassium iodide $(\mathrm{KI}, 99 \%)$ and sodium bicarbonate $\left(\mathrm{NaHCO}_{3},>99.7 \%\right)$ for persulfate analysis were also purchased through Alfa Aesar. Calcium chloride dihydrate $\left(\mathrm{CaCl}_{2} \cdot 2 \mathrm{H}_{2} \mathrm{O}\right.$, $>99 \%)$ and sodium sulfate $\left(\mathrm{Na}_{2} \mathrm{SO}_{4},>95 \%\right)$ were obtained from Thermo Fisher Scientific (Waltham, MA). Sulfa4 Powder packs for sulfate $\left(\mathrm{SO}_{4}{ }^{2-}\right)$ analysis were obtained through Cole-Parmer (Vernon Hills, IL). Pentafluorobenzoic acid $\left(\mathrm{C}_{6} \mathrm{~F}_{5} \mathrm{CO}_{2} \mathrm{H}, 99 \%\right)$ was also purchased through Alfa Aesar. Trichloroethylene $\left(\mathrm{C}_{2} \mathrm{HCl}_{3,} \geq 99.5 \%\right)$ was purchased through Sigma-Aldrich (St. Louis, MO).

\subsubsection{Porous Media}

Accusand, a commercially available milled silica sand (Unimin Corporation, New Canaan, CT), was used as the representative porous media for both batch and column experiments. The $40 / 50$ mesh sand chosen has a $d_{50}$ of $0.39 \mathrm{~mm}$ and a particle density of $2.65 \mathrm{~g} / \mathrm{cm}^{3}$. Prior to use, all sand was cleaned via sonication and rinsed with nanopure water. Sand was sonicated for an hour, stirring every 5 minutes, in a Branson 2510 water bath sonicator (Branson Ultrasonics, Danbury, CT). The sand was then rinsed with approximately $10 \mathrm{~L}$ of nanopure water and allowed to air dry. 


\subsection{Apparati}

\subsubsection{Batch Controls}

For unactivated persulfate studies, $20-\mathrm{mL}$ glass scintillation vials fitted with HPDE screw caps were used as batch reactors. These reactors were placed horizontally on a wire rack and firmly secured to prevent damage. The wire rack with reactors was then placed on a Vibrax-VXR orbital shaker (IKA, Wilmington, NC) to agitate samples over the course of the experiment.

\subsubsection{Heat Activation}

A temperature controlled heating apparatus was designed and built to perform controlled, steady-state heat activation of persulfate at 60 and $90^{\circ} \mathrm{C}$. The heating reservoir was a $250-\mathrm{mL}$ flask fitted with a rubber stopper with ports drilled for inlet and outlet tubing as well as a K-type thermocouple. A programmable REX-C100 PID temperature controller (RKC USA, South Bend, IN) connected to the thermocouple then modified voltage input to a wired outlet. This built temperature controller was equipped with a standard plug, and as such was designed to be used with any bench-top heating element, controlling the temperature within $\pm 1^{\circ} \mathrm{C}$, after an initial 20 minute equilibration time. A Glas-col heating mantle (Terre Haute, IN) was used as the heating element for these experiments as it could easily be placed on a Thermix $120 \mathrm{~S}$ stir plate (Fisher Scientific) to allow for adequate mixing in the reservoir.

For column experiments, this same temperature-controlled system was used with modifications for inlet and outlet flow. Fresh $10 \mathrm{mM}$ persulfate was pumped into the 
heated $250-\mathrm{mL}$ reservoir at $0.5 \mathrm{~mL} / \mathrm{min}$ by an Acuflow Series II HPLC pump while heatactivated persulfate was drawn out at the same flowrate with a Q Pump (Fluid Metering Inc., Syosset, NY). This process was carried out for a minimum of two residence times (approximately 12 hours) to ensure a constant concentration of activated persulfate on the effluent end of the system. The Q pump was then switched out for a second Acuflow Series II HPLC pump during the injection and elution portions of the soil column experiments. This system behaved as a continuously-stirred tank reactor at steady-state, allowing the delivery of uniform concentrations of persulfate/activated persulfate as influent to the soil column systems.

\subsubsection{Soil Columns}

All flow-through experiments were conducted in vertically-positioned, 316stainless steel columns averaging $7.0 \mathrm{~cm}$ in length and $2.2 \mathrm{~cm}$ in diameter (Alltech Chromatography). Endcaps were fitted with $0.5-\mu \mathrm{m}$ thick porous frits and distribution plates to ensure uniform flow over the cross-sectional area of the column. All tubing and fittings for the HPLC pumps and soil columns were composed of 316-stainless steel. All soil columns were homogeneously dry-packed with clean Accusand. The dry packing included the positioning of discrete layers of sand, with scoring and weighted tamping between each layer to interlock those layers and ensure as much physical homogeneity as possible. For all soil column experiments, an Acuflow Series II HPLC pump delivered the injection and elution pulses. 


\subsection{Methods}

\subsubsection{Analysis}

A U-1800 UV-Visible spectrophotometer (Hitatchi, Tokyo, Japan) was used for analysis of PFBA, persulfate and sulfate concentration in both batch and column experiments. PFBA analysis during nonreactive tracer (NRT) experiments was conducted using the spectrophotometer at $226 \mathrm{~nm}$. Standardization of the UV-Vis for PFBA analysis included a minimum ten-point calibration curve, providing a concentration range from $525 \mathrm{mg} / \mathrm{L}$ to a lower detection limit of approximately $1 \mathrm{mg} / \mathrm{L}$. Sample and standards with concentrations above $175 \mathrm{mg} / \mathrm{L}$ were diluted to keep absorbance within the range of the UV-Vis.

Persulfate concentrations in solution were analyzed using a modified iodometric titration method [80]. Samples were diluted as needed, and then an aliquot of sample was added to a premade solution of potassium iodide $(\mathrm{KI})$ and sodium bicarbonate $\left(\mathrm{NaHCO}_{3}\right)$ at $100 \mathrm{~g} / \mathrm{L}$ and $5 \mathrm{~g} / \mathrm{L}$, respectively. The ratio of sample to $\mathrm{KI}-\mathrm{NaHCO}_{3}$ solution was held at 1:19 (m:m). After a 20-minute reaction time, three discrete measurements of sample absorbance were taken using with the UV-Vis set at a wavelength of $400 \mathrm{~nm}$. A minimum ten-point calibration curve was created on the day of analysis by serial dilutions of a stock sodium persulfate solution, detecting a range of approximately 50 to $1 \mathrm{mg} / \mathrm{L}$ of sodium persulfate after the 1:19 dilution associated with the iodometric method.

Sulfate was measured using Sulfa4 powder packs, a proprietary reagent mix. Samples were diluted below $70 \mathrm{mg} / \mathrm{L}$ sulfate as needed for a total sample volume of 10 
$\mathrm{mL}$. A single powder pack was then added, and the sample was allowed to sit undisturbed for a reaction period of 5 minutes. Three discrete absorbance measurements were then read on the UV-Vis set at $420 \mathrm{~nm}$, as recommended by EPA method 375.4 for sulfate analysis. A minimum seven point calibration curve was created on the day of analysis by serial dilutions of a stock sodium sulfate solution. These results along with persulfate analysis were used to establish a mass balance for the heat-activated persulfate/sulfate system.

Concentrations of TCE were measured in two ways, by UV-Vis spectroscopy and by gas chromatography (GC-FID). The UV-Vis was set to read at $242.5,400$, and $420 \mathrm{~nm}$ for TCE. The first wavelength was used in conjunction with a calibration curve to determine TCE concentration, while the second and third wavelengths were run to determine and correct for interference with persulfate and sulfate in solution, respectively. TCE analysis by direct-inject, gas chromatography was conducted on a Shimadzu (Tokyo, Japan) GC-17A gas chromatograph equipped with a flame ionization detector and an SPB-624 glass capillary column. Discrete direct inject, aqueous-phase samples were collected in 2-mL screw-cap glass vials, filled with as little headspace as possible to minimize losses to volatilization. Standardization of the UV-Vis and the gas chromatography systems for TCE analysis included an eight-point calibration curve. Sample blanks and/or check standards for the UV-Vis and the GC-FID were run on average every 10 samples. 


\subsubsection{Batch Studies}

Batch experiments were conducted to quantify the heat activation of persulfate at 60 and $90^{\circ} \mathrm{C}$. The heat activation system described previously was used with $200 \mathrm{~mL}$ of $10 \mathrm{mM}$ persulfate in $0.01 \mathrm{~N} \mathrm{CaCl}_{2}$. Ports for inlet and outlet tubing controlling flow in the temperature-controlled, heated reservoir were covered during all experiments to prevent loss due to evaporation. Samples were taken periodically over the duration of the experiment in $1 \mathrm{~mL}$ aliquots. The 60 and $90^{\circ} \mathrm{C}$ studies were conducted until concentrations of persulfate remaining in solution were at the method detection limit of approximately $1 \mathrm{mg} / \mathrm{L}$, requiring approximately 100 and 6 hours, respectively. All samples were analyzed for persulfate using the iodometric method to quantify the kinetics of persulfate degradation over time. For the batch experiment conducted at $90^{\circ} \mathrm{C}$, sulfate concentrations in solution over time were also determined as a mass balance for the heat activation of persulfate.

Control experiments were done on unactivated persulfate to determine any mass loss of persulfate due to mechanisms not related to heat activation, specifically interaction with porous media or reaction and sample vessels. Clean Accusand and a solution of sodium persulfate in a $1: 1$ mass ratio were added to $20-\mathrm{mL}$ batch reactors. $\mathrm{A}$ combination of concentrations (10 and $100 \mathrm{mM}$ persulfate) and background solutions (0.01 $\mathrm{N} \mathrm{CaCl}_{2}$ and DI water) were tested in five replicates for these controls. Each experiment included two replicate reactors containing only the persulfate solution. Reaction times were at minimum one week, after which an aliquot was taken from each 
reactor and analyzed for persulfate. Persulfate reactivity to Accusand and/or experimental apparati was determined by mass difference.

\subsubsection{Transport Studies}

Packed soil columns were saturated with $0.01 \mathrm{~N} \mathrm{CaCl}_{2}$ using an Acuflow Series II HPLC pump (SSI, State College, PA), beginning at an average linear pore-water velocity of $11.4 \mathrm{~cm} / \mathrm{hr}$ for the initial 24 hours, followed by an increase in the flow rate to $16.0 \mathrm{~cm} / \mathrm{hr}$ for an additional 24 hours, and then finally $22.8 \mathrm{~cm} / \mathrm{hr}$ until the total column weight remained constant for several days. Bulk density was calculated using the weight of packed media and the measured column volume. Porosity was estimated using the dry and saturated packed weights of each column system. Corrections for dead volume in the column system were made using the sand's bulk density and assuming a particle density of $2.65 \mathrm{~g} / \mathrm{cm}^{3}$.

Nonreactive tracer (NRT) experiments were performed after saturation on each column to qualify the effects of physical heterogeneities on the overall transport behavior through the porous media. These NRTs were conducted pre- and post-persulfate injections in each column both to establish reproducibility and to ensure no physical changes in the system over its experimental life. A solution of $500 \mathrm{mg} / \mathrm{L}$ pentafluorobenzoic acid (PFBA) in $0.01 \mathrm{~N} \mathrm{CaCl}_{2}$ was injected for approximately 10 pore volumes at $22.8 \mathrm{~cm} / \mathrm{hr}$, and then eluted with PFBA-free electrolyte $\left(0.01 \mathrm{~N} \mathrm{CaCl}_{2}\right)$ solution. Samples were collected in 5-mL polypropylene test tubes and analyzed for PFBA concentrations. 
Soil column experiments were performed at minimum in duplicate for heat activated persulfate at 20,60 , and $90^{\circ} \mathrm{C}$. Before injection, samples from the effluent of the heat activation system were taken to insure a constant concentration of activated persulfate had been reached. The column was then injected with the activated persulfate for a minimum of 10 pore volumes and eluted with persulfate-free $0.01 \mathrm{~N} \mathrm{CaCl}_{2}$ electrolyte solution. All samples were collected in glass scintillation vials, capped, and then placed in an ice bath to quench the activation reaction prior to analysis for persulfate. Additionally, a mass balance for the overall transport behavior of heat-activated persulfate $\left(60^{\circ} \mathrm{C}\right)$ in soil was performed by measuring both persulfate and the sulfate $\left(\mathrm{SO}_{4}{ }^{2-}\right)$ concentrations in the soil column effluent using Sulfa4 powder packs as described previously.

\subsubsection{Remediation Studies}

To determine the effectiveness of heat-activated persulfate for in-situ chemical oxidation of residual pure-phase organic liquid, a solution of persulfate/heat-activated persulfate was run through saturated soil columns with established residuals of TCE. Residuals of pure phase TCE were established by imbibing approximately $20 \mathrm{~mL}$ of pure TCE into the vertically-positioned, saturated soil column at an average injection flowrate of $0.3 \mathrm{~mL} / \mathrm{min}$ using a syringe pump equipped with a $50-\mathrm{mL}$ glass, gas-tight syringe. Effluent from the column was monitored for the first appearance of pure-phase TCE and imbibing continued for additional 30 minutes. A saturated aqueous-phase solution of TCE was then injected for approximately an hour in the reverse direction (i.e., vertically downward flow) using a dedicated Acuflow Series I HPLC pump at an average flowrate of 
$1 \mathrm{~mL} / \mathrm{min}$. The residual fraction of pure phase TCE in the soil column was determined by mass difference (e.g., soil column mass pre- and post-establishment of residual TCE). Finally, approximately ten pore volumes of a saturated aqueous-phase solution of TCE were injected to ensure equilibrium, steady-state conditions in the residual soil columns.

Remediation studies were conducted in two discrete residually-saturated soil columns using persulfate activated at $60^{\circ} \mathrm{C}$. Using the temperature-controlled system described previously, heat-activated persulfate was continuously injected into residual column $A$ at an average linear porewater velocity of $9.1 \mathrm{~cm} / \mathrm{hr}(0.2 \mathrm{~mL} / \mathrm{min})$ and into residual column B at $22.8 \mathrm{~cm} / \mathrm{hr}(0.5 \mathrm{~mL} / \mathrm{min})$. Samples of column effluent were collected in a 5-mL luerlock-tipped, glass, gas-tight syringe and analyzed by UV-Vis, GC-FID, or both. Specifically, an aliquot was collected for UV-Vis, persulfate, and sulfate analysis followed by a separate aliquot for GC-FID analysis. The non-GC aliquots were placed in an ice bath for a minimum of 5 minutes to quench the persulfate activation reaction and subsampled for TCE analysis by UV-Vis. The remaining sample was used for iodometric and Sulfa4 analysis of persulfate and sulfate, respectively. Persulfate was continually pumped through the system until the concentration of TCE in the effluent reached a lower detection limit of approximately $1 \mathrm{mg} / \mathrm{L}$. 


\section{Results and Discussion}

\subsection{Batch Studies}

Batch studies characterizing the kinetics of the heat activation of persulfate were conducted at both 60 and $90^{\circ} \mathrm{C}$. Pseudo first-order reaction rate coefficients were determined by regression analysis of the log-linear relative concentrations of persulfate over time (see Figure 1).

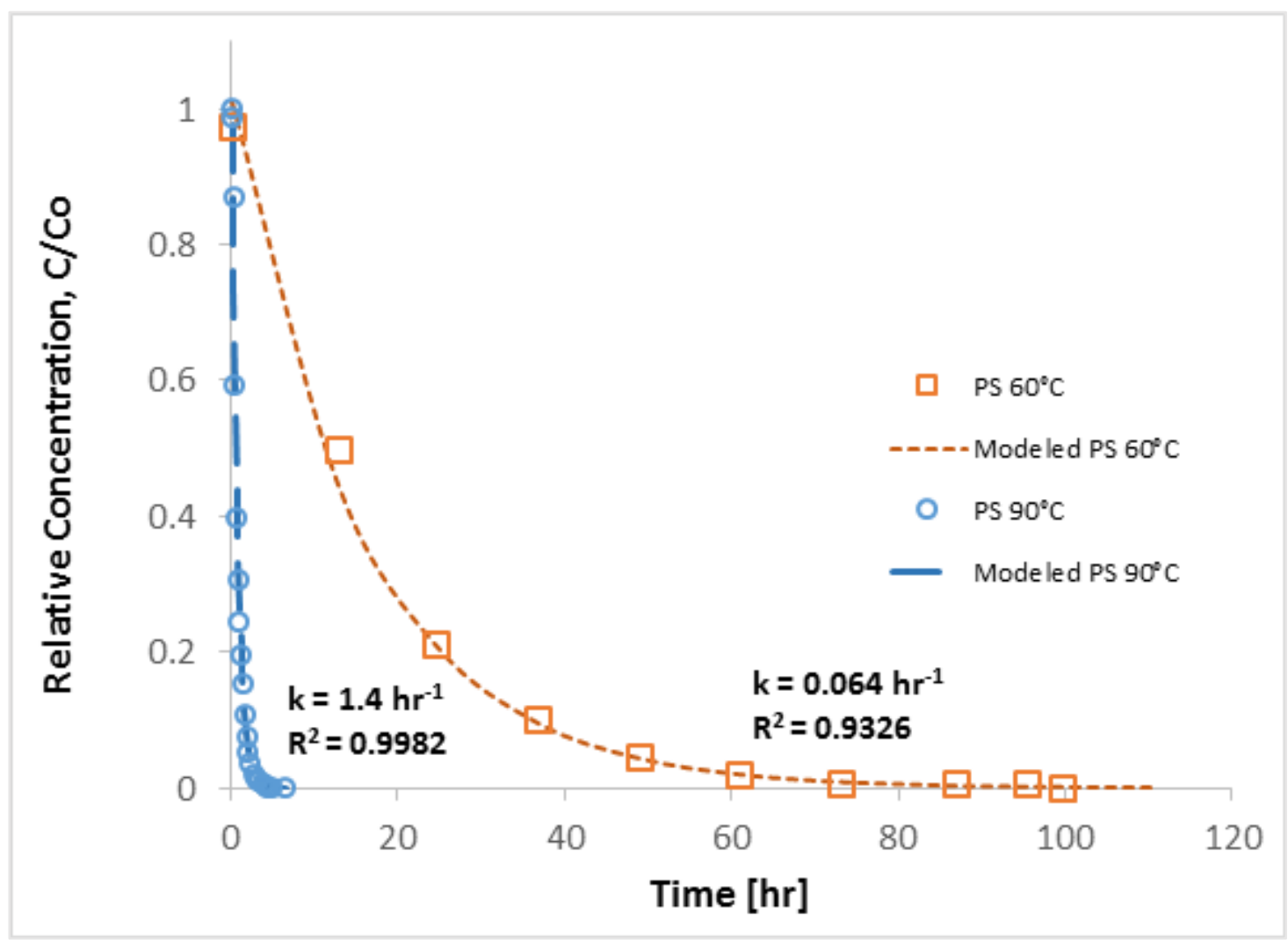

Figure 1: Relative concentration over time for persulfate activated at 60 and $90^{\circ} \mathrm{C}$ in a batch system. First order rate constants determined from log-linear regression analysis are $\mathrm{k}=0.064$ $h r^{-1}\left(R^{2}=0.9326\right)$ and $k=1.4 \mathrm{hr}^{-1}\left(R^{2}=0.9982\right)$ for 60 and $90^{\circ} \mathrm{C}$, respectively. 
Rate constants describing the kinetics of the thermal degradation of persulfate in batch equaled $0.064 \mathrm{hr}^{-1}\left(\mathrm{R}^{2}=0.9326\right)$ and $1.4 \mathrm{hr}^{-1}\left(\mathrm{R}^{2}=0.9982\right)$ for $60^{\circ} \mathrm{C}$ and $90^{\circ} \mathrm{C}$, respectively. Johnson et al. [48] describe an empirical relationship for the temperature dependence of the rate constant for thermal decomposition of persulfate as shown in equation (7):

$$
\ln k=(36.6 \pm 0.8)-\frac{134 \pm 2}{R T}
$$

where $\mathrm{k}=$ thermal degradation rate constant $\left[\mathrm{s}^{-1}\right]$

$$
\begin{aligned}
& \mathrm{R}=\text { ideal gas constant, } 8.314 \cdot 10^{-3} \mathrm{~kJ} \mathrm{~K}^{-1} \mathrm{~mol}^{-1} \\
& \mathrm{~T}=\text { absolute temperature }[\mathrm{K}]
\end{aligned}
$$

Using equation (7), the estimated rate constants for the heat activation of persulfate at 60 and $90^{\circ} \mathrm{C}$ equaled $0.028 \pm 0.0021 \mathrm{hr}^{-1}$ and $1.5 \pm 0.20 \mathrm{hr}^{-1}$, respectively. These rate constants correspond to half-lives of approximately 25 hours for activation at $60^{\circ} \mathrm{C}$ versus 28 minutes for activation at $90^{\circ} \mathrm{C}$, showing the sharp temperature dependence of persulfate thermolysis. Reaction rate constants determined from regression of experimental data measured in this study are consistent with the empirical relationship in equation (7), particularly the $90^{\circ} \mathrm{C}$ study.

For the batch experiment conducted at $90^{\circ} \mathrm{C}$, both sulfate and persulfate concentrations in solution over time were measured as a sulfate-species mass balance for the heat activation of persulfate. Figure 2 shows the relative concentration of persulfate as it degrades upon heat activation over time, as well as the resulting appearance of 


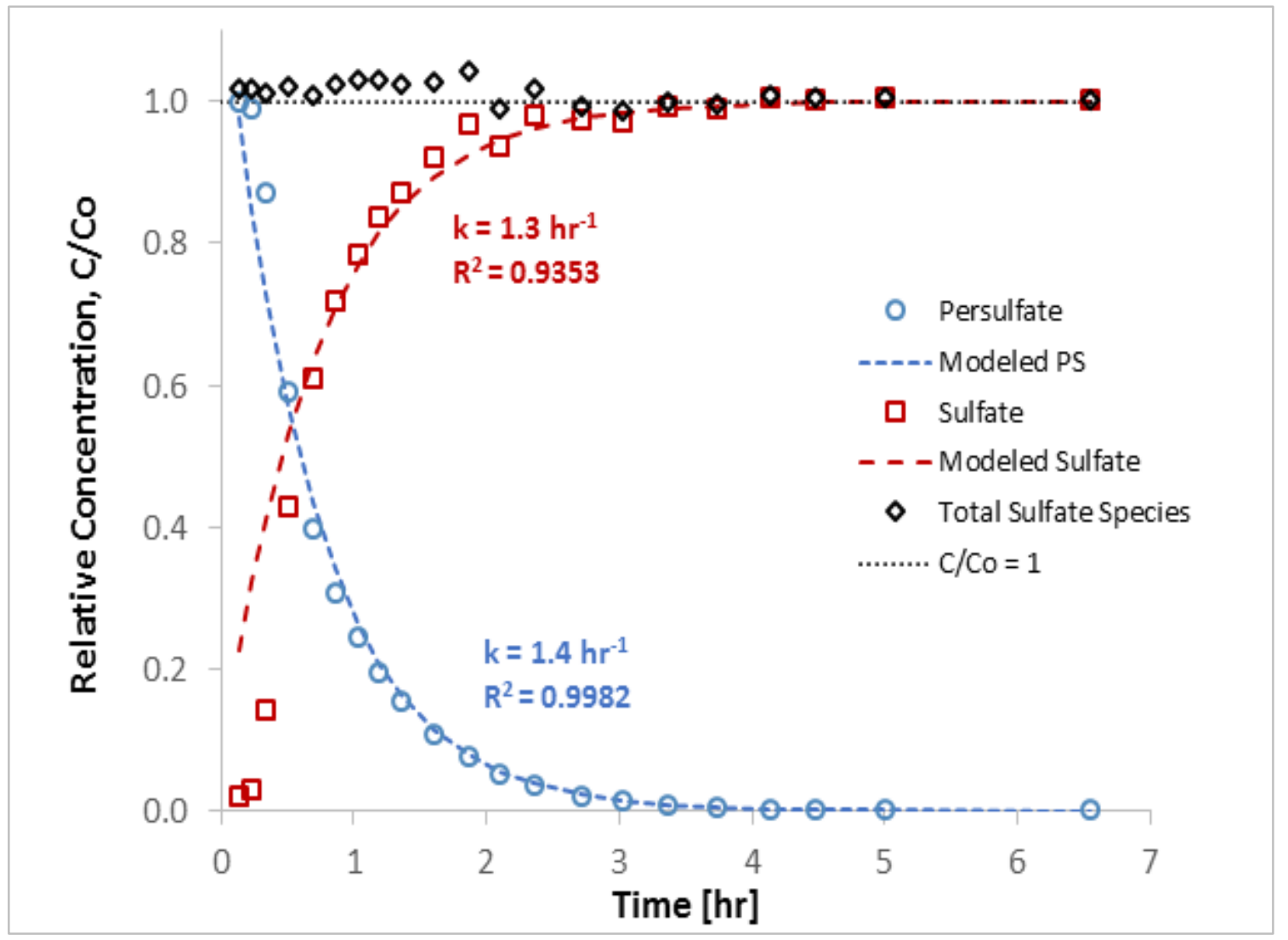

Figure 2: Relative concentration over time for persulfate and sulfate activated at $90^{\circ} \mathrm{C}$ in a batch system. Total sulfate species shown to illustrate mass balance achieved. Psuedo firstorder reaction constants of $1.4 \mathrm{hr}^{-1}$ for persulfate decomposition and $1.3 \mathrm{hr}^{-1}$ for sulfate generation determined by log-linear regression $\left(R^{2}=0.9982\right.$ and $R^{2}=0.9353$ for persulfate and sulfate, respectively).

sulfate ion in solution. As sulfate only appears in the system as persulfate decomposes, the reaction rate constants for persulfate decomposition and sulfate production should be similar. The reaction rate constant for the generation of sulfate ions in solution equaled $1.3 \mathrm{hr}^{-1}\left(\mathrm{R}^{2}=0.9353\right)$ compared to $1.4 \mathrm{hr}^{-1}\left(\mathrm{R}^{2}=0.9982\right)$ for the degradation of persulfate. The two coefficients differ by only $7.4 \%$, which agrees with this chemistry. Furthermore, total mass recovery of sulfate species in solution was between $98.7 \%$ and 
$104.3 \%$ over the duration of the experiment, with an average of $101.3 \pm 0.3 \%$. The results indicate a strong mass balance, especially considering the minimum dilutions for persulfate and sulfate analysis are 20 and 5 fold, respectively.

Batch studies were also done to test for any interaction between persulfate and the natural sandy soil and between persulfate and the glass sample vials and HPDE caps. The potential effects of the background electrolyte solution (i.e., deionized water versus $0.01 \mathrm{~N} \mathrm{CaCl}_{2}$ ) were also characterized. These batch experiments were conducted at two discrete concentrations of persulfate, $10 \mathrm{mM}(\sim 2.4 \mathrm{~g} / \mathrm{L})$ and $100 \mathrm{mM}$ ( $24 \mathrm{~g} / \mathrm{L})$. Results of these batch experiments indicate negligible interaction/interference of persulfate with the natural sand as well as the apparati (Figure 3 and the data presented in Table 3). After nine days of contact time, concentration of persulfate in all systems remained essentially constant (within $\pm 5 \%$ of initial concentration). Because of the low concentration maximum of the iodometric method, high dilution factors were necessary. For example, $100 \mathrm{mM}$ samples had to be diluted 800 fold, and $10 \mathrm{mM}$ samples were diluted 100 fold. With these large dilutions in mind, the small deviations in final persulfate concentration are to be expected. 
Table 3: Percent mass recovery of persulfate after 9 day batch experiment under a range of conditions. Standard error given for batch reactors containing Accusand.

\begin{tabular}{|l|c|c|}
\cline { 2 - 3 } \multicolumn{1}{c|}{} & \multicolumn{2}{c|}{ Percent Mass Recovery } \\
\hline Reaction Conditions & With Accusand & Without Accusand \\
\hline $10 \mathrm{mM} \mathrm{DI}$ & $102.8 \pm 0.1 \%$ & $104.9 \%$ \\
\hline $10 \mathrm{mM} \mathrm{CaCl} 2$ & $98.7 \pm 0.1 \%$ & $101.0 \%$ \\
\hline $100 \mathrm{mM} \mathrm{DI}$ & $100.1 \pm 0.5 \%$ & $100.8 \%$ \\
\hline $100 \mathrm{mM} \mathrm{CaCl} 2$ & $100.5 \pm 0.2 \%$ & $100.0 \%$ \\
\hline
\end{tabular}

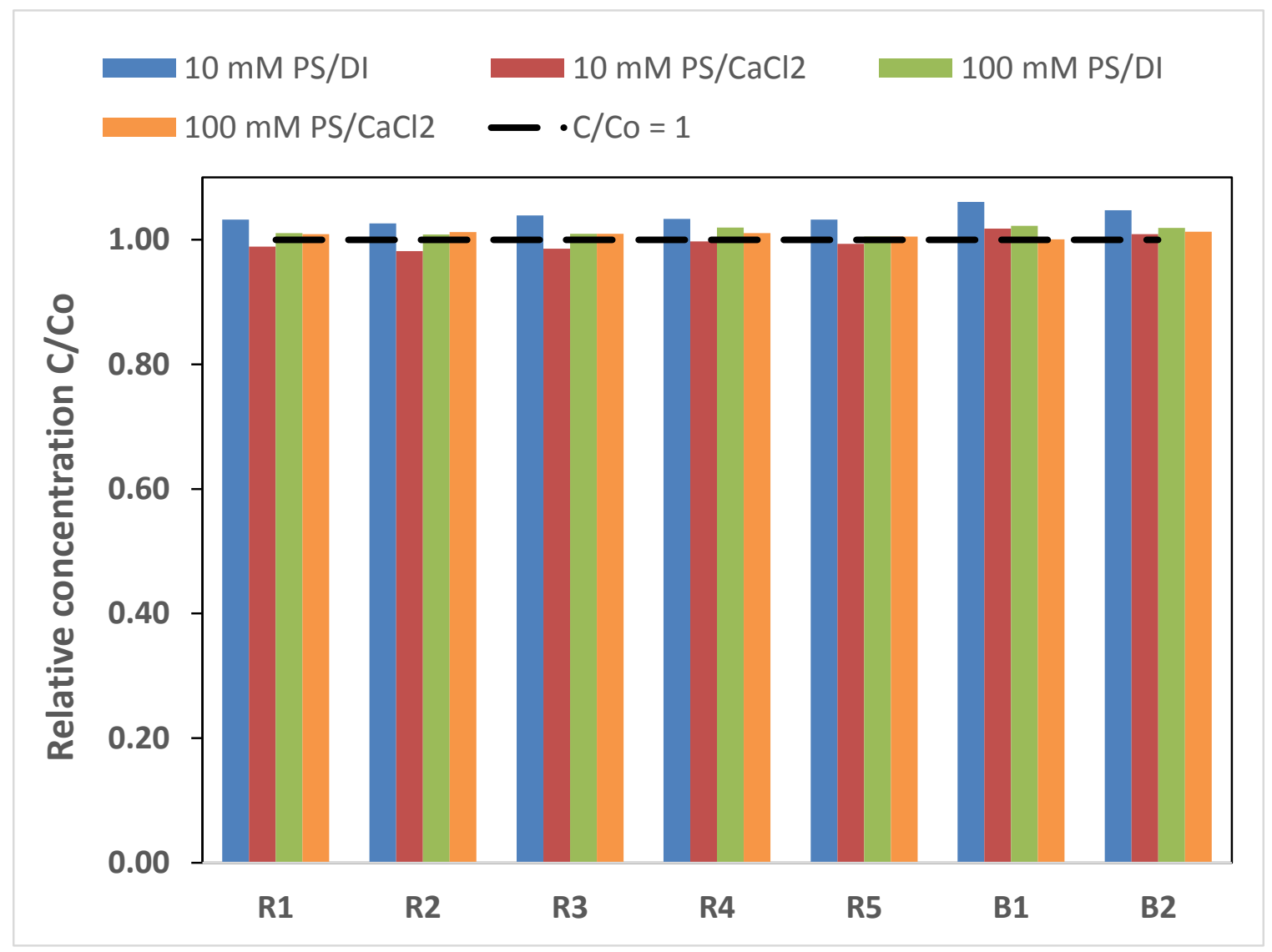

Figure 3: Persulfate concentration in batch reactors after 9 days, normalized to starting concentration $C_{o}$. Reactors R1-R5 with 1:1 $(\mathrm{m}: \mathrm{m})$ sand to persulfate and reactors B1 and B2 with only persulfate in solution. Background solutions consisted of either deionized water (DI) or $0.01 \mathrm{NCaCl}_{2}$. 


\subsection{Transport Studies}

\subsubsection{Physical Hydrodynamics}

Nonreactive tracer (NRT) experiments were conducted to characterize the overall transport behavior associated with physical hydrodynamics in the various packed soil columns as well as to determine the possible changes in column physical heterogeneity over time. Column packing A was used for all temperature transport studies (i.e., dynamic experiments characterizing the transport behavior of persulfate/activated persulfate in natural porous media), as well as a remediation study. NRTs were performed before (NRT 1A), during (NRT 2A) and after (NRT 3A) the course of experimentation in Column A.

Figure 4 shows the arrival and corresponding elution waves for all three NRT studies conducted in Column A. Arrival waves plotted against the respective inverted elution waves for each NRT experiment in Column A are shown in Figure 5. The strong reproducibility in overall transport behavior across all of these tracer studies confirms that Column A underwent no major changes in physical hydrodynamics during the course of experimentation therein.

Column B was used only for a remediation study and NRT experiments were performed pre- and post-complete dissolution/degradation of residual TCE. As with Column A, these studies characterized the overall transport behavior associated with physical hydrodynamics in the homogeneously packed soil column and confirmed no changes to those parameters over the course of experimentation (see results shown in Figure 6). A comparison of representative NRTs in Column A and Column B is shown in 
Figure 7 indicating the reproducibility in overall physical transport conditions across the two homogeneously packed soil columns.

Retardation factors and percent mass recovery for PFBA were determined from moment analysis of the NRT data measured in Columns A and B (Table 4). Retardation factors were all close to 1 and the percent mass recovery for each study was close to $100 \%$, indicating near-ideal transport behavior. The retardation factor for NRT $2 \mathrm{~A}$ is slightly high. This can also be seen in the delayed arrival of tracer for NRT 2A (see Figure 4a) and the slightly different shape of the arrival and inverted elution curves as shown in Figure $5 b$. This is likely due to an experimental error rather than a change to the physical structure of the column, given how well the elution tail trends with other studies and the comparable behavior in the first and last NRTs.

Table 4: Relevant experimental values for NRTs performed over the course of experimentation in column packings $A$ and $B$.

\begin{tabular}{|c|c|c|c|}
\hline Study & Date & $\begin{array}{c}\text { Retardation } \\
\text { Factor }\end{array}$ & $\begin{array}{c}\text { Percent } \\
\text { Recovery }\end{array}$ \\
\hline NRT 1A & January 30, 2014 & 0.955 & $100.6 \%$ \\
\hline NRT 2A & July 6, 2014 & 1.119 & $98.8 \%$ \\
\hline NRT 3A & April 12,2015 & 1.011 & $99.6 \%$ \\
\hline NRT 1B & April 26, 2015 & 0.993 & $100.2 \%$ \\
\hline & Average: & $\mathbf{1 . 0 1 9} \pm \mathbf{0 . 0 3 0}$ & $\mathbf{1 0 0 . 2} \pm \mathbf{0 . 3 \%}$ \\
\hline
\end{tabular}



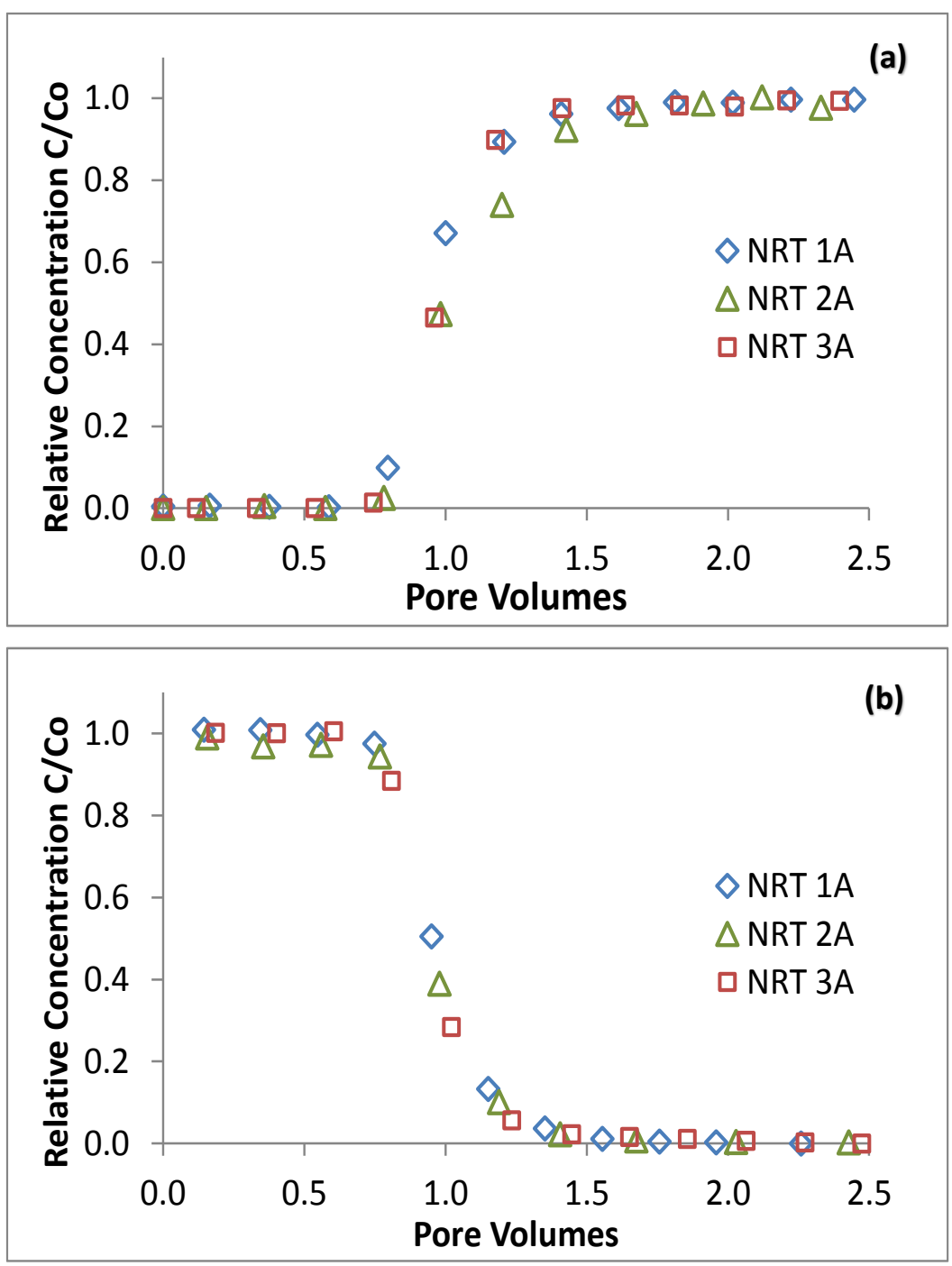

Figure 4a-b: (a) Arrival waves and (b) elution waves for three separate nonreactive tracers in column packing $A$. 

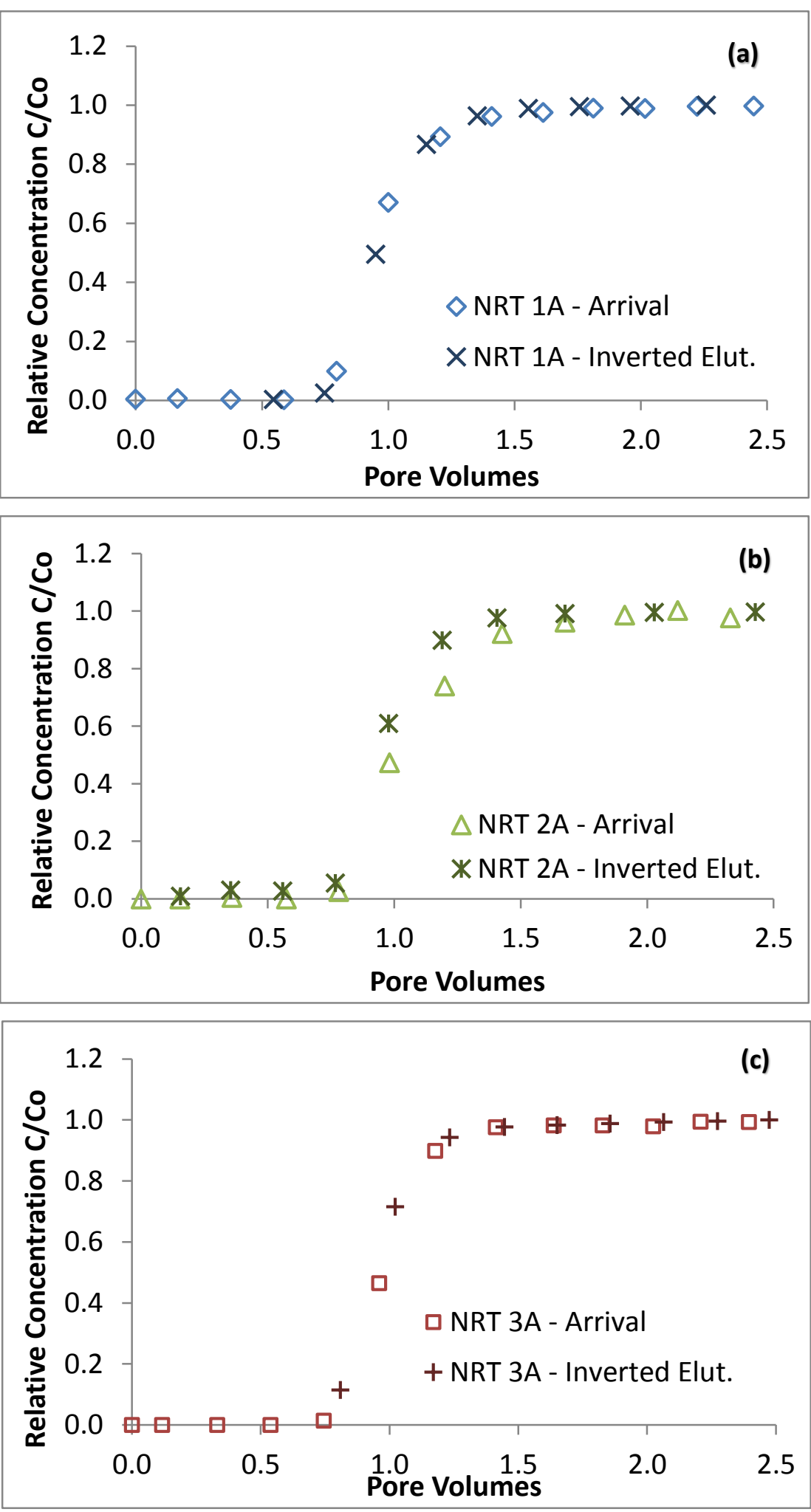

Figure 5a- c: Arrival and inverted elution waves for (a) NRT 1A, (b) NRT 2A, and (c) NRT 3A. 

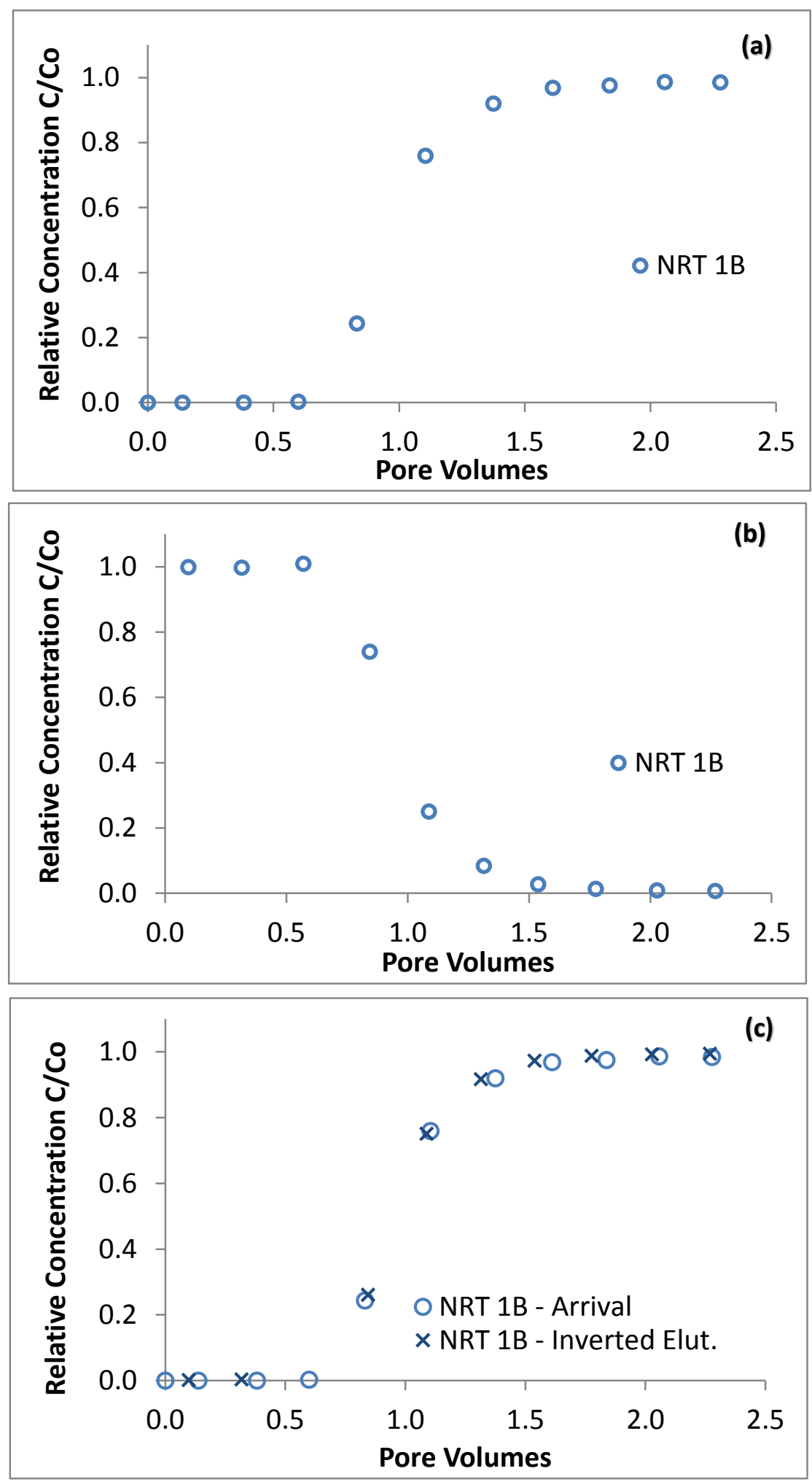

Figure 6a-c: (a) Arrival wave (b) elution wave and (c) arrival and inverted elution waves for nonreactive tracer in column packing $B$. 

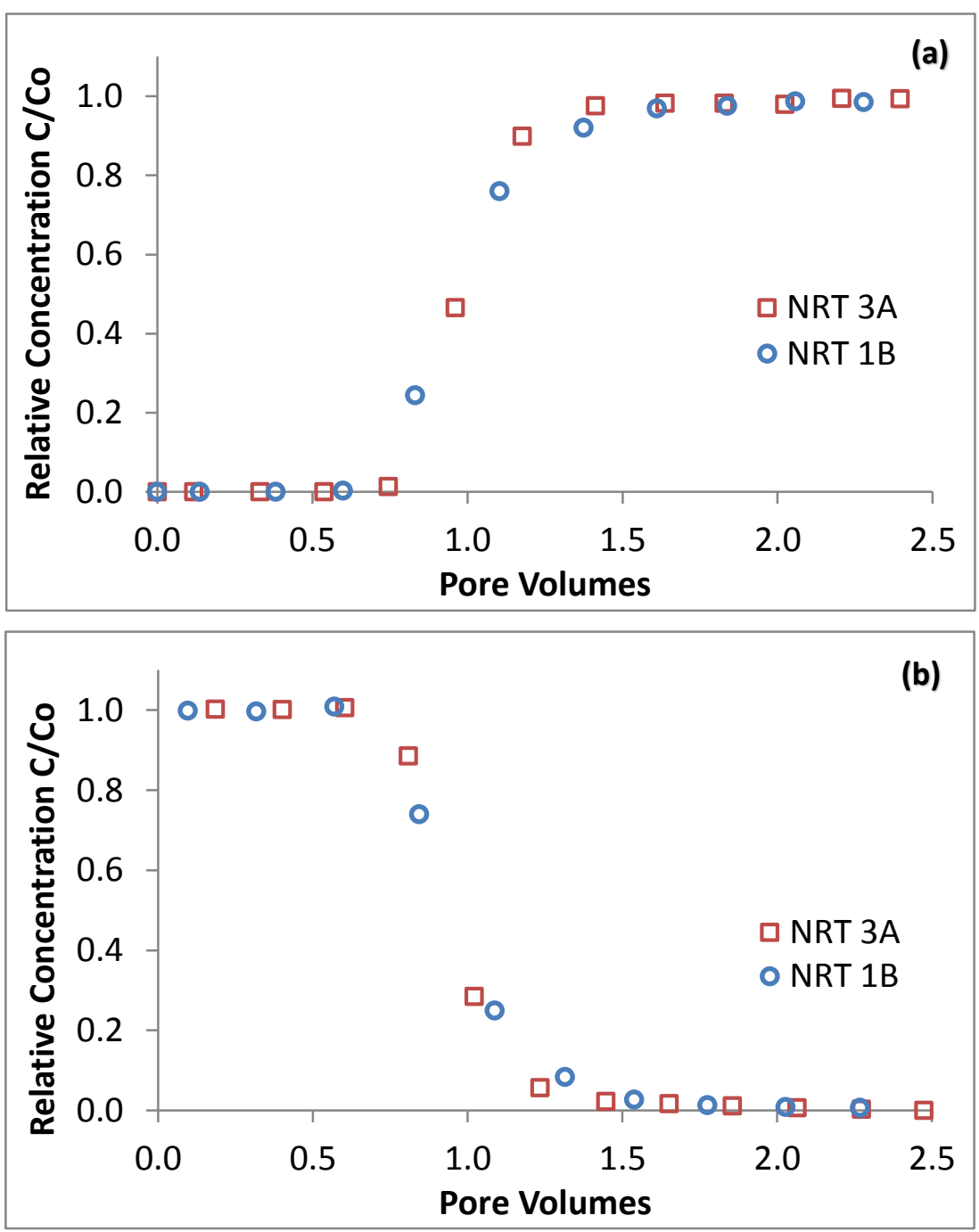

Figure 7a-b: (a) Arrival and (b) elution waves for representative NRTs in column packings A and $B$ 


\subsubsection{Temperature Effects}

The overall transport behavior of persulfate/activated persulfate was characterized for thermal activation at three temperatures: 20,60 , and $90^{\circ} \mathrm{C}$. Table 5 details some of the experimental results from this research. The degree of apparent activation achieved in each experiment has been calculated as the percent of persulfate degraded relative to initial measured persulfate concentration in solution ( $10 \mathrm{mM})$. Retardation factors and percent mass recovery were determined from moment analysis of the measured persulfate breakthrough curves. Graphics comparing representative studies for each temperature compared to a corresponding NRT in the same column can be found in Figure 8, and graphics showing reproducibility at each activation temperature are included in Figure 9.

Table 5: Relevant experimental values from thermal activation transport studies done in column $A$

\begin{tabular}{|c|c|c|c|}
\hline Study & $\begin{array}{l}\text { Degree of Apparent } \\
\text { Activation }\end{array}$ & $\begin{array}{l}\text { Retardation } \\
\text { Factor }\end{array}$ & $\begin{array}{l}\text { \% Mass recovery } \\
\text { (PS after activation) }\end{array}$ \\
\hline PS $20^{\circ} \mathrm{C}-1$ & Negligible & 0.936 & $100.7 \%$ \\
\hline PS $20^{\circ} \mathrm{C}-2$ & Negligible & 1.128 & $99.5 \%$ \\
\hline PS $60^{\circ} \mathrm{C}-1$ & $10.3 \%$ & 1.015 & $99.6 \%$ \\
\hline PS $60^{\circ} \mathrm{C}-2$ & $11.0 \%$ & 0.976 & $101.3 \%$ \\
\hline PS $60^{\circ} \mathrm{C}-3$ & $8.7 \%$ & 0.979 & $100.6 \%$ \\
\hline PS $90^{\circ} \mathrm{C}-1$ & $91.8 \%$ & 0.968 & $100.2 \%$ \\
\hline \multirow[t]{2}{*}{ PS $90^{\circ} \mathrm{C}-2$} & $90.6 \%$ & 1.024 & $101.1 \%$ \\
\hline & Average & $1.004 \pm 0.021$ & $100.4 \pm 0.3 \%$ \\
\hline
\end{tabular}

For all temperatures and all studies, the overall transport behavior of persulfate was highly similar and reproducible, indicating the transport of thermally-activated persulfate in homogeneously packed sandy material is independent of the degree of 
activation achieved for persulfate. These results suggest that in a system where persulfate is activated at the surface prior to subsurface injection, no complications for delivery of persulfate/activated persulfate to the target/source zone should occur as a result of thermal activation. The overall average retardation factor was $1.004 \pm 0.021$, and percent mass recovery was $100.4 \pm 0.3 \%$. Mass recovery was calculated relative to the effective long-term average concentration of each experiment, i.e., mass recovery of persulfate ions entering the column. Mass balance and recovery with persulfate and sulfate species is discussed further on.

The largest deviation was in the $20^{\circ} \mathrm{C}$ studies; retardation factors for all other studies were within one standard deviation of the mean. PS $20^{\circ} \mathrm{C}-2$ and NRT $2 \mathrm{~A}$ were performed in the same time frame, and both exhibit higher retardation factors, higher than the average (1.128 and 1.119, respectively). The coupled deviations in these two experiments, shown in Figure 10, indicate some experimental error consistent for both trials, most likely an incorrectly primed pump during the injection phase. This would have added dead volume to the system that could not be accounted for in moment analysis.

The potential for continued activation after the persulfate has left the heated reservoir was also examined in the elevated temperature studies. Specifically, the degree of apparent activation measured after the heated reservoir is compared to apparent activation measured at the column effluent in Table 6. The overall gains (i.e., the observed percent increase) in activation are more apparent in the lower temperature study, simply because there is a higher concentration of persulfate available in solution phase (i.e., 
leaving the temperature-controlled influent reservoir) on activation at $60^{\circ} \mathrm{C}$. However, when the overall changes in measured persulfate concentrations are compared at the two measurement points, the $90^{\circ} \mathrm{C}$ study shows a larger change, which agrees with the more rapid degradation of persulfate at that temperature.

Table 6: Activation gains observed after persulfate has left the heated reservoir in elevated temperature studies

\begin{tabular}{|c|c|c|c|c|}
\hline Study & $\begin{array}{c}\text { Percent Apparent } \\
\text { Activation, } \\
\text { Heated Reservoir }\end{array}$ & $\begin{array}{c}\text { Percent Apparent } \\
\text { Activation, } \\
\text { Column Effluent }\end{array}$ & $\begin{array}{c}\text { Percent } \\
\text { Increase }\end{array}$ & $\begin{array}{c}\text { Percent Change, } \\
\text { PS Concentration }\end{array}$ \\
\hline PS $20^{\circ} \mathrm{C}-1$ & $0.0 \%$ & $0.7 \%$ & -- & $0.7 \%$ \\
\hline PS $20^{\circ} \mathrm{C}-2$ & $0.0 \%$ & $0.3 \%$ & -- & $0.3 \%$ \\
\hline PS $60^{\circ} \mathrm{C}-1$ & $9.5 \%$ & $10.3 \%$ & $8.4 \%$ & $0.9 \%$ \\
\hline PS $60^{\circ} \mathrm{C}-2$ & $9.7 \%$ & $11.0 \%$ & $13.4 \%$ & $1.4 \%$ \\
\hline PS $60^{\circ} \mathrm{C}-3$ & $8.1 \%$ & $8.7 \%$ & $7.4 \%$ & $0.6 \%$ \\
\hline PS $90^{\circ} \mathrm{C}-1$ & $91.6 \%$ & $91.8 \%$ & $0.22 \%$ & $2.9 \%$ \\
\hline PS $90^{\circ} \mathrm{C}-2$ & $90.5 \%$ & $90.6 \%$ & $0.11 \%$ & $2.0 \%$ \\
\hline
\end{tabular}

(1) Percent difference in measured persulfate concentration post-reservoir and measured persulfate concentration at column effluent.

Mass recovery of persulfate/activated persulfate under dynamic (transport) conditions was characterized on one of the $60^{\circ} \mathrm{C}$ studies (PS $60^{\circ} \mathrm{C}-3$ ). Specifically, sulfate and persulfate ion concentrations in the effluent of the soil column were measured and compared to those initial concentrations of sulfate species in solution (see Figure 11). The total mass of sulfate species in solution (sulfate and persulfate ions) averages $101.8 \%$ of the initial measured persulfate concentration with a standard error of $0.3 \%$. This is in agreement with the sulfate-species mass balance performed on the $90^{\circ} \mathrm{C}$ batch system described previously (average $101.3 \pm 0.3 \%$ ). These results indicate that a complete mass balance was achieved across activation temperatures $\left(60^{\circ} \mathrm{C}\right.$ and $\left.90^{\circ} \mathrm{C}\right)$ as well as experimental methods (i.e., batch versus column study). 

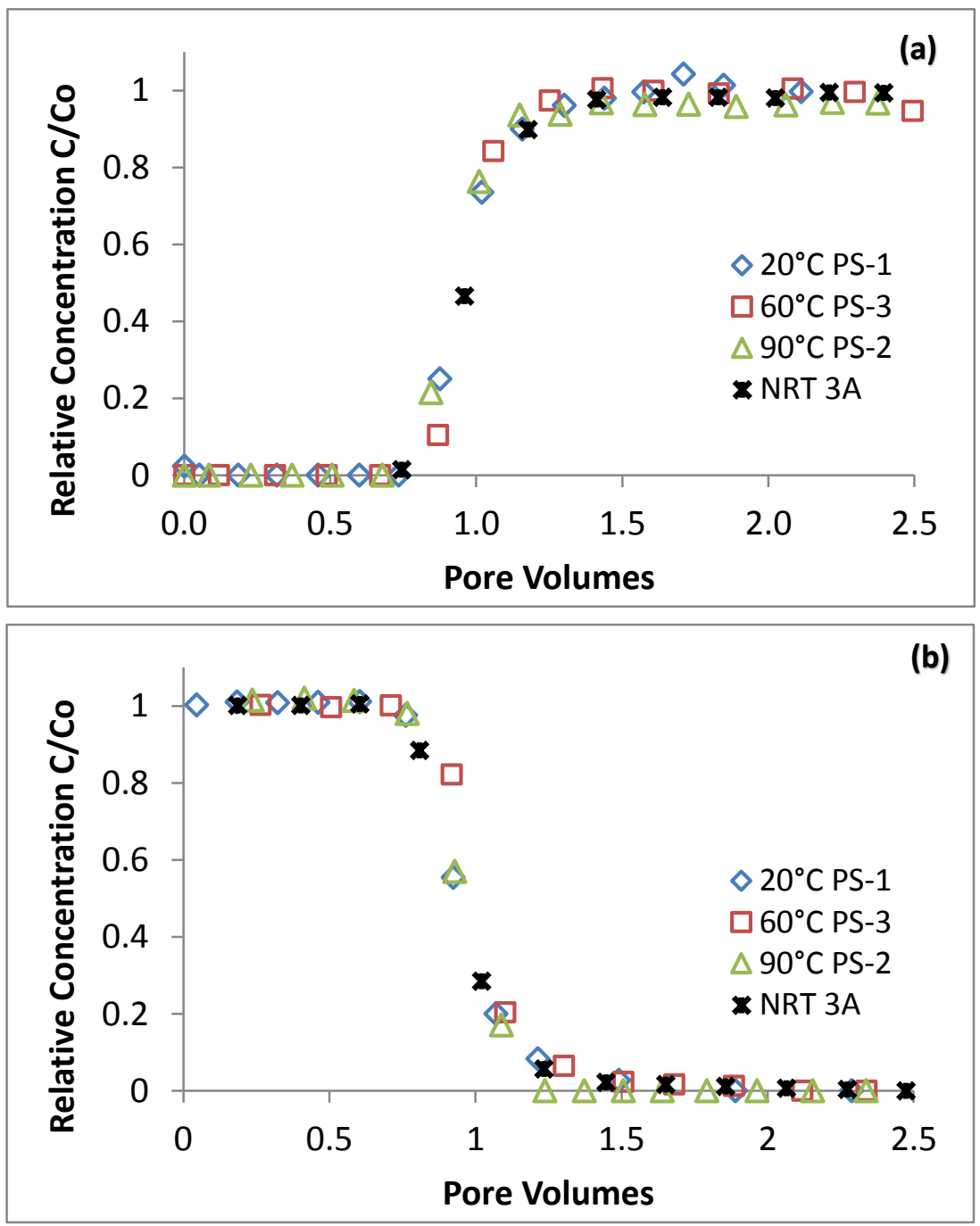

Figure 8a-b: Comparison of (a) arrival and (b) elution waves for persulfate at three different activation temperatures in column $A$. 

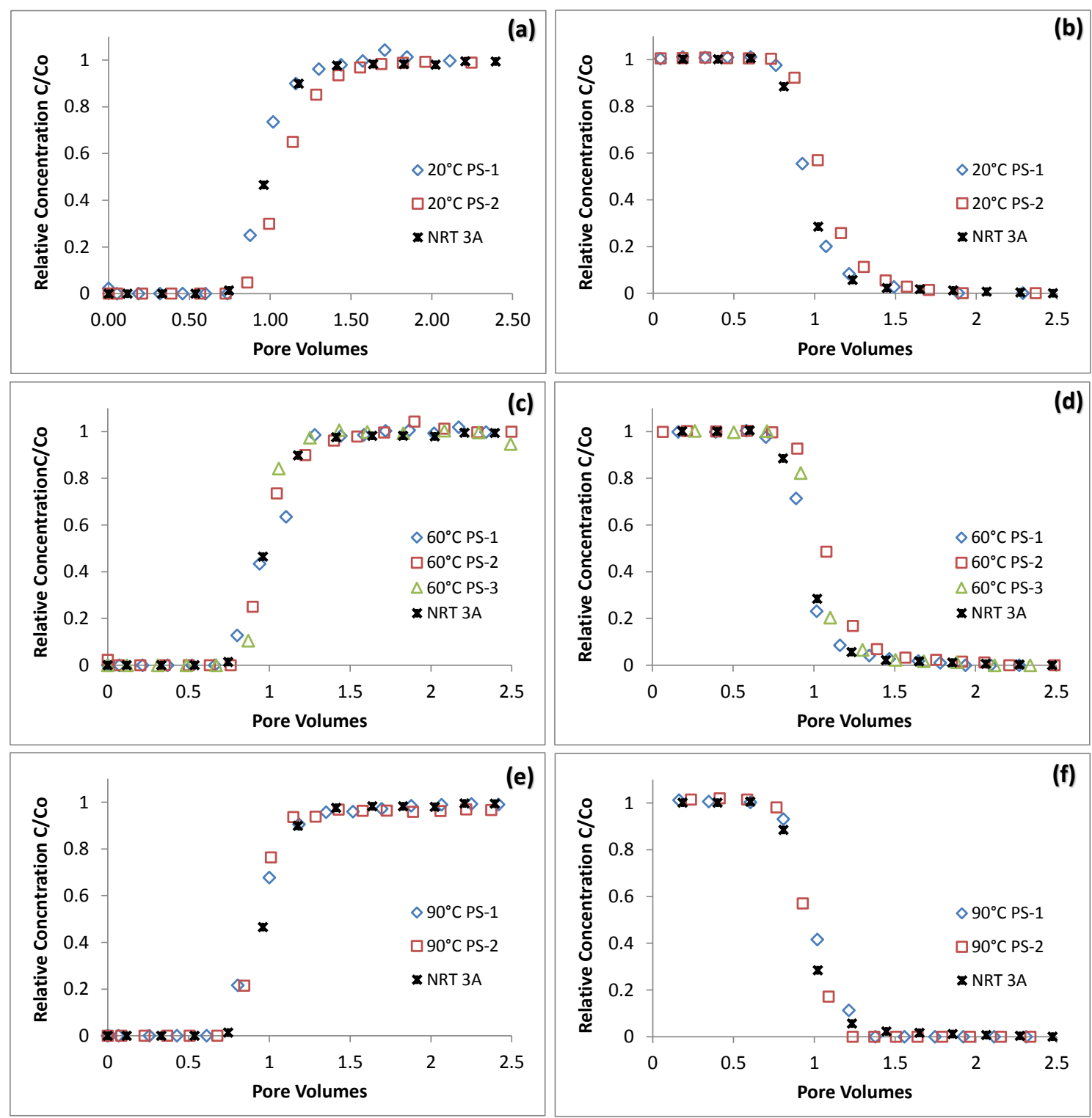

Figure 9a-f: Arrival and elution wave comparisons and reproducibility for all thermal activation studies done in column A. Arrival waves shown for $20^{\circ} \mathrm{C}, 60^{\circ} \mathrm{C}$, and $90^{\circ} \mathrm{C}$ in (a), (c) and (e) respectively. Elution waves shown studies, and elution waves shown for $20^{\circ} \mathrm{C}, 60^{\circ} \mathrm{C}$, and $90^{\circ} \mathrm{C}$ in (b), (d), and (f). 


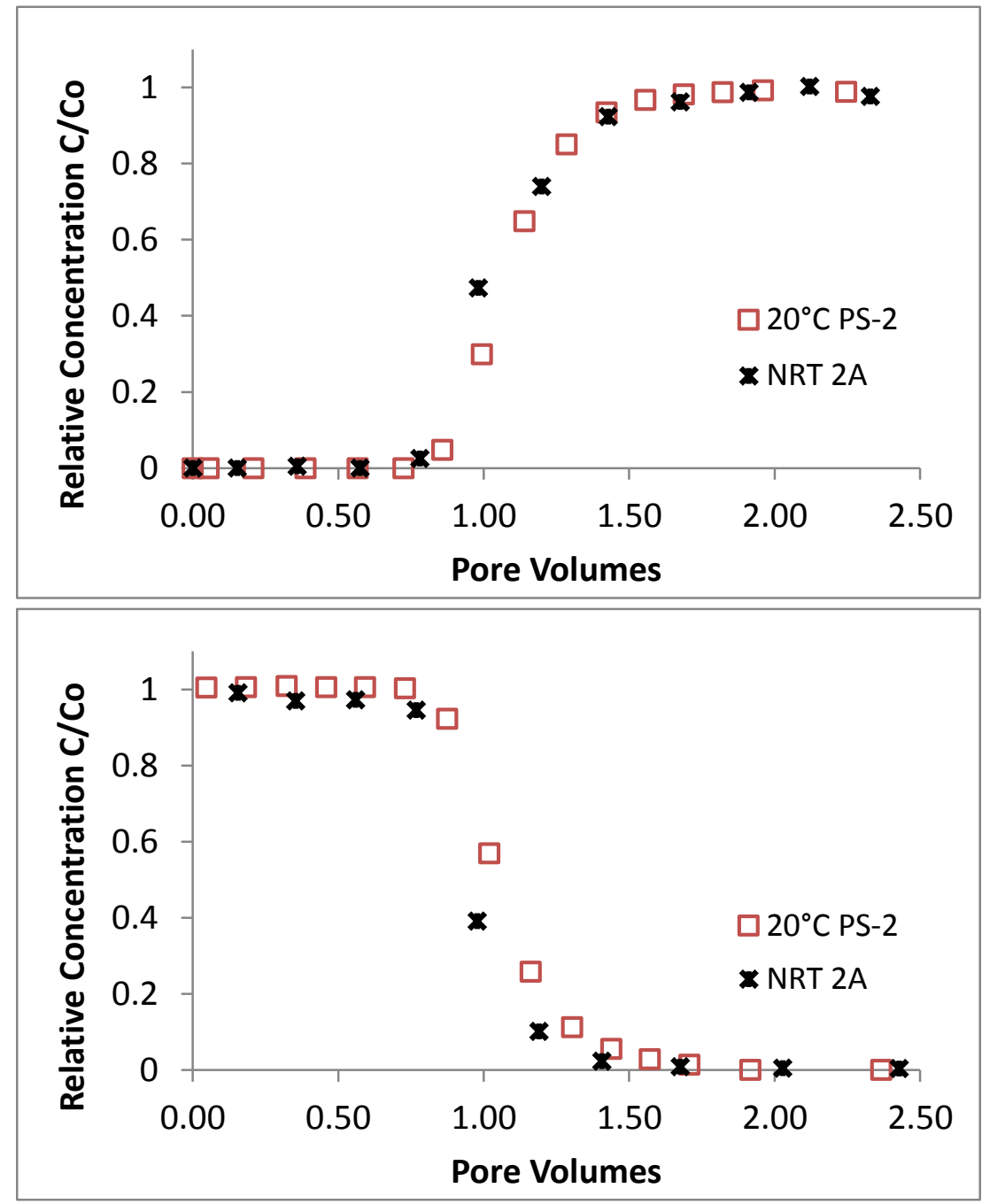

Figure 10a-b: Comparison of (a) arrival and (b) elution waves for $20^{\circ} \mathrm{C} \mathrm{PS-2}$ and NRT 2A 


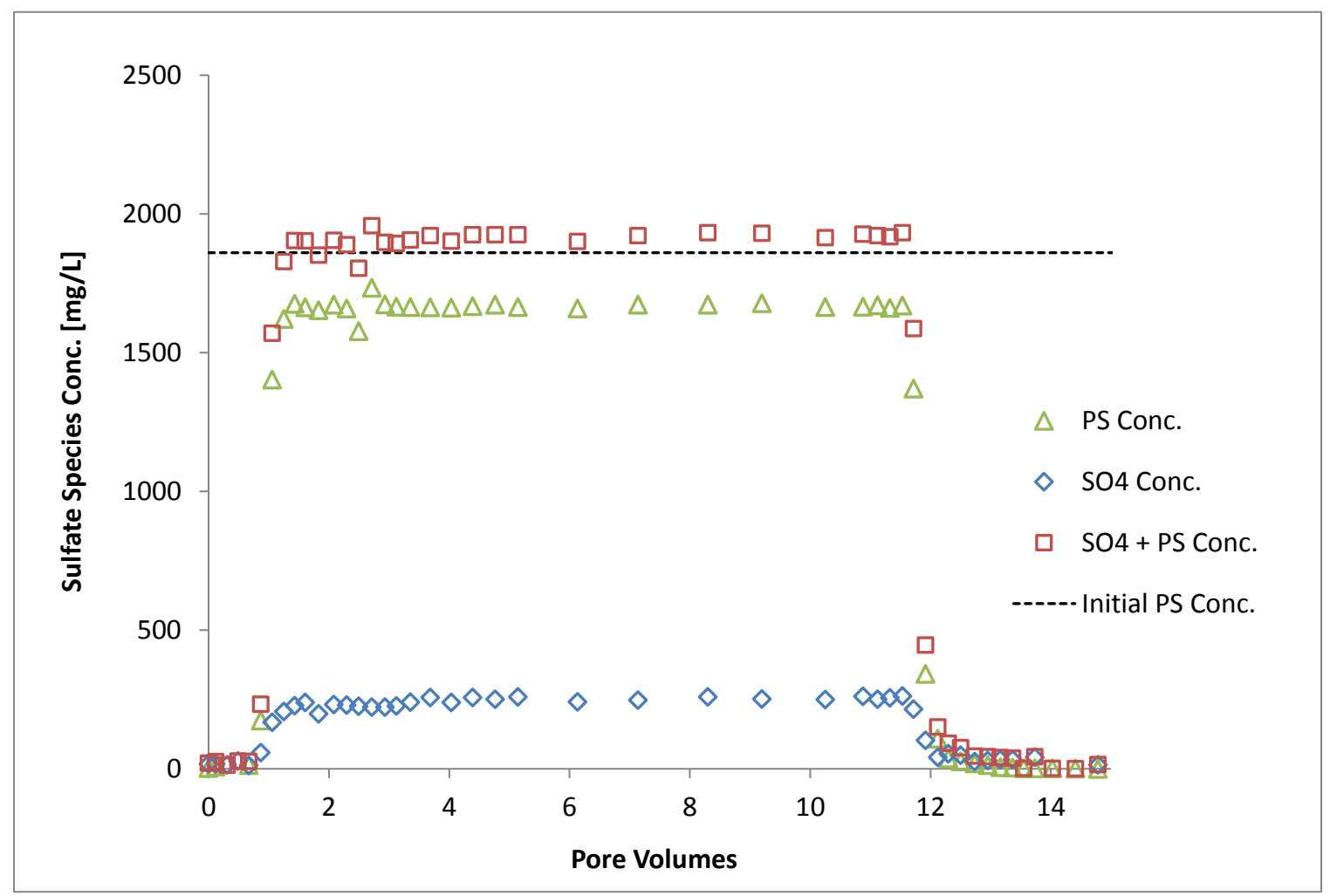

Figure 11: Transport of persulfate (PS), sulfate (SO4), and total sulfate species (PS + SO4) as measured in $\mathrm{PS} 60^{\circ} \mathrm{C}-3$, compared to initial persulfate concentration, showing a mass balance for all sulfate species. 


\subsection{Remediation Studies}

Transport experiments were conducted in homogeneously packed soil columns as a proof of concept for a thermally-activated persulfate ISCO remediation system for a dense nonaqueous phase liquid source zone. These experiments aimed to characterize the effects of heat-activated persulfate in situ chemical oxidation on residual trichloroethylene at two levels of persulfate activation. The higher degree of apparent persulfate activation was achieved by decreasing the volumetric rate of flow through the soil column (from $0.5 \mathrm{~mL} / \mathrm{min}$ in the first study to $0.2 \mathrm{~mL} / \mathrm{min}$ in the second study), while maintaining a $60^{\circ} \mathrm{C}$ temperature and fixed volume for the reservoir in each system. Lowering the volumetric flowrate through the experimental system increased the mean residence time for persulfate in the temperature-controlled, heated reservoir, leading to an overall higher degree of persulfate activation. This had the added effect of increasing the contact time between persulfate/activated persulfate and the contaminated soil core. The TCE dissolution/degradation data measured in these heat-activated persulfate ISCO experiments was compared to TCE dissolution (the control) in the absence of ISCO (i.e., traditional pump and treat of residual nonaqueous phase liquid), from data collected earlier in this research group. All dimensionless time for these experiments was scaled to the residual content of the control data to normalize for the effect of different residual saturations achieved in the discrete packed columns. Relevant properties for each system are given in Table 7 and Figure 12. 


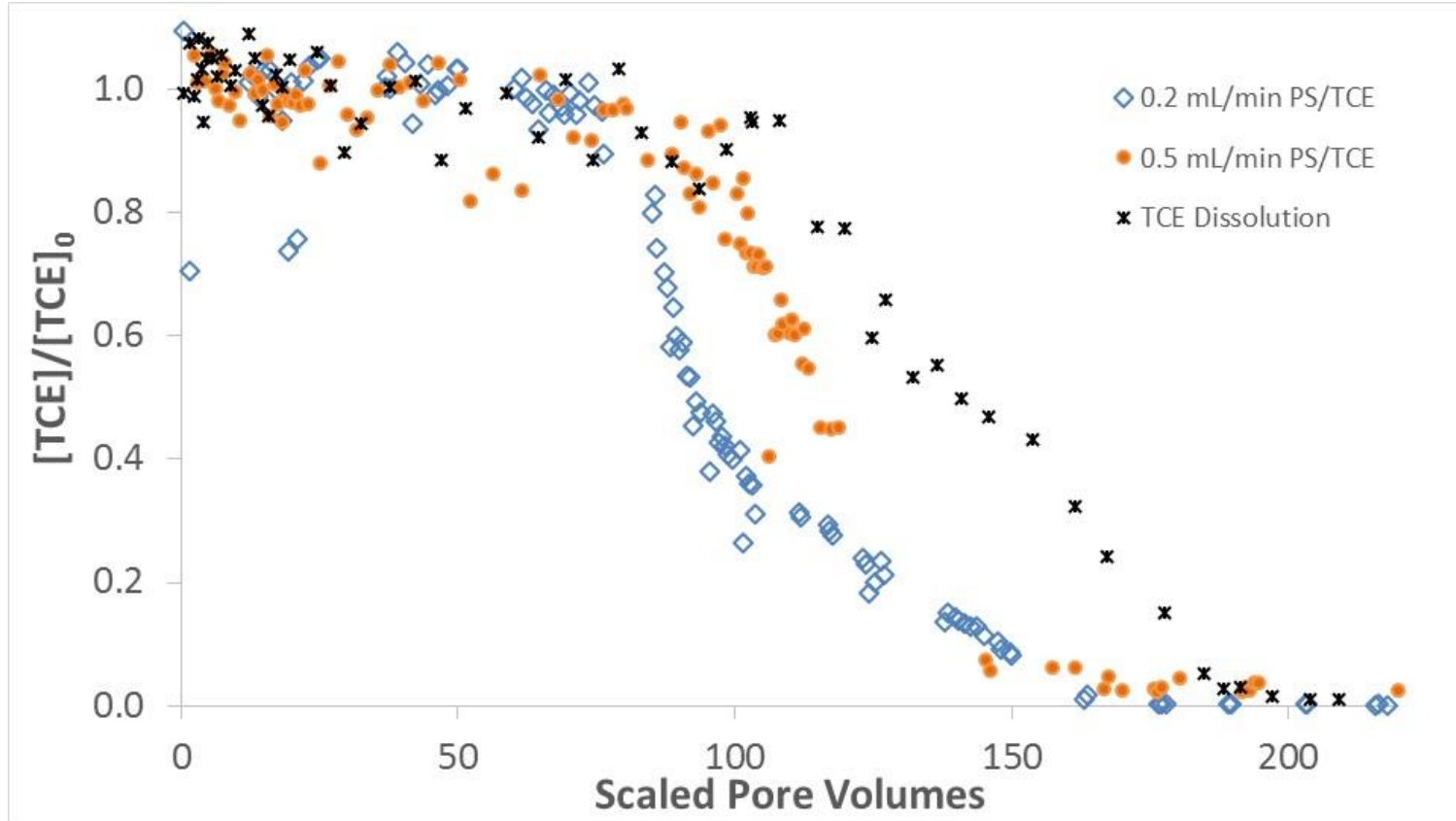

Figure 12: Relative concentration of TCE versus dimensionless time in pore volumes scaled for initial residual TCE content.

Table 7: System properties for remediation studies

\begin{tabular}{|l|c|c|c|}
\hline & $\begin{array}{c}\mathbf{0 . 2} \mathbf{~ m L / m i n} \\
\text { Activated PS Study }\end{array}$ & $\begin{array}{c}\mathbf{0 . 5} \mathbf{~ m L} / \mathbf{m i n} \\
\text { Activated PS Study }\end{array}$ & $\begin{array}{c}\text { Accusand Control } \\
\text { Study }\end{array}$ \\
\hline $\begin{array}{l}\text { TCE Residual } \\
\text { Saturation }\end{array}$ & $18.7 \%$ & $17.9 \%$ & $13.6 \%$ \\
\hline Pore Volume & $8.0 \mathrm{~mL}$ & $7.3 \mathrm{~mL}$ & $7.9 \mathrm{~mL}$ \\
\hline Porosity & $34.6 \%$ & $33.5 \%$ & $37 \%$ \\
\hline $\begin{array}{l}\text { Percent Activation, } \\
\text { measured at Reservoir }\end{array}$ & $26.8 \%$ & $9.0 \%$ & -- \\
\hline $\begin{array}{l}\text { Percent Activation, } \\
\text { measured at Effluent }\end{array}$ & $39.5 \%$ & $24.6 \%$ & -- \\
\hline
\end{tabular}


The relative concentrations of TCE measured in the column effluent from the two ISCO experiments compared to the control are shown in Figure 12. All of the results show an initial, long-term, steady-state plateau in measured TCE concentrations lasting a minimum of 75 pore volumes; it is assumed that during this phase of TCE dissolution/degradation, nonaqueous, pure phase trichloroethylene remains as residual in the porous matrix allowing for equilibrium, steady-state TCE concentrations in the column effluent. The $0.2 \mathrm{~mL} / \mathrm{min}$ study had the shortest steady-state phase, reaching $90 \%$ of TCE's saturated aqueous-phase concentration at approximately 75 pore volumes. In comparison, the $0.5 \mathrm{~mL} / \mathrm{min}$ and control experiments reached $\mathrm{C} / \mathrm{C}_{\circ}$ of $90 \%$ at 100 and 110 pore volumes, respectively. Moment analysis of the measured data was performed on the two remediation studies to quantify percent mass degradation and mass dissolution of trichloroethylene; results are shown in Table 8.

Table 8: Mass removal for remediation studies

\begin{tabular}{|l|c|c|}
\hline & $\begin{array}{c}0.2 \mathrm{~mL} / \mathrm{min}(39.5 \%) \\
\text { Activated PS Study }\end{array}$ & $\begin{array}{c}0.5 \mathrm{~mL} / \mathrm{min}(24.6 \%) \\
\text { Activated PS Study }\end{array}$ \\
\hline Mass TCE, Initial & $2200 \mathrm{mg}$ & $1900 \mathrm{mg}$ \\
\hline Mass TCE, Dissolved & $1450 \mathrm{mg}$ & $1280 \mathrm{mg}$ \\
\hline Percent Mass Dissolved & $65.7 \%$ & $68.4 \%$ \\
\hline Mass TCE, Degraded & $750 \mathrm{mg}$ & $620 \mathrm{mg}$ \\
\hline Percent Mass Degraded & $34.3 \%$ & $32.6 \%$ \\
\hline
\end{tabular}

In terms of pore volumes, the $0.2 \mathrm{~mL} / \mathrm{min}$ study saw decreases in TCE concentration $32 \%$ sooner than in the control, compared to $9 \%$ sooner in the $0.5 \mathrm{~mL} / \mathrm{min}$ study. Both remediation systems degraded approximately a third of the initial mass of TCE, but the 
shorter plateau in the $0.2 \mathrm{~mL} / \mathrm{min}$ study indicates that the larger degree of activation was more efficient at degrading the high concentrations of trichloroethylene present initially due to the nonaqueous-phase, residual fraction of the contaminant.

After the initial steady-state phase (i.e., the effluent concentration plateau), all studies exhibited pseudo first-order mass loss behavior. This exponential behavior was modeled for each experiment, using data from the end of the steady-state phase until relative concentration reached approximately 50\%. A comparison of the modeled to measured data is shown in Figure 13. Pseudo-first order rate constants equaled 0.044, 0.063 , and $0.083 \mathrm{hr}^{-1}$ for the control, $0.2 \mathrm{~mL} / \mathrm{min}$, and $0.5 \mathrm{~mL} / \mathrm{min}$ study, respectively. Rate constants associated with heat-activated persulfate treatment are $55 \%$ and $105 \%$ greater than for dissolution of residual TCE under a traditional pump and treat scenario.

The calculated rate constant for the $0.5 \mathrm{~mL} / \mathrm{min}$ study is larger than that of the 0.2 $\mathrm{mL} / \mathrm{min}$ study, despite a longer contact time and higher degree of activation. This is likely a result of faster dissolution associated with increased advective flow through the system when pumping at $0.5 \mathrm{~mL} / \mathrm{min}$ versus $0.2 \mathrm{~mL} / \mathrm{min}$. When rate constants are converted to equivalent constants in inverse pore volumes (PV), in effect scaling for differences in pore volume size and average flowrate, the rate constants are $0.011,0.042$ and $0.020 \mathrm{PV}^{-1}$ for the control, $0.2 \mathrm{~mL} / \mathrm{min}$, and $0.5 \mathrm{~mL} / \mathrm{min}$ study, respectively. It follows that under the same flow conditions, the higher level of persulfate activation in the $0.2 \mathrm{~mL} / \mathrm{min}$ study would yield a higher rate for the degradation of TCE. 

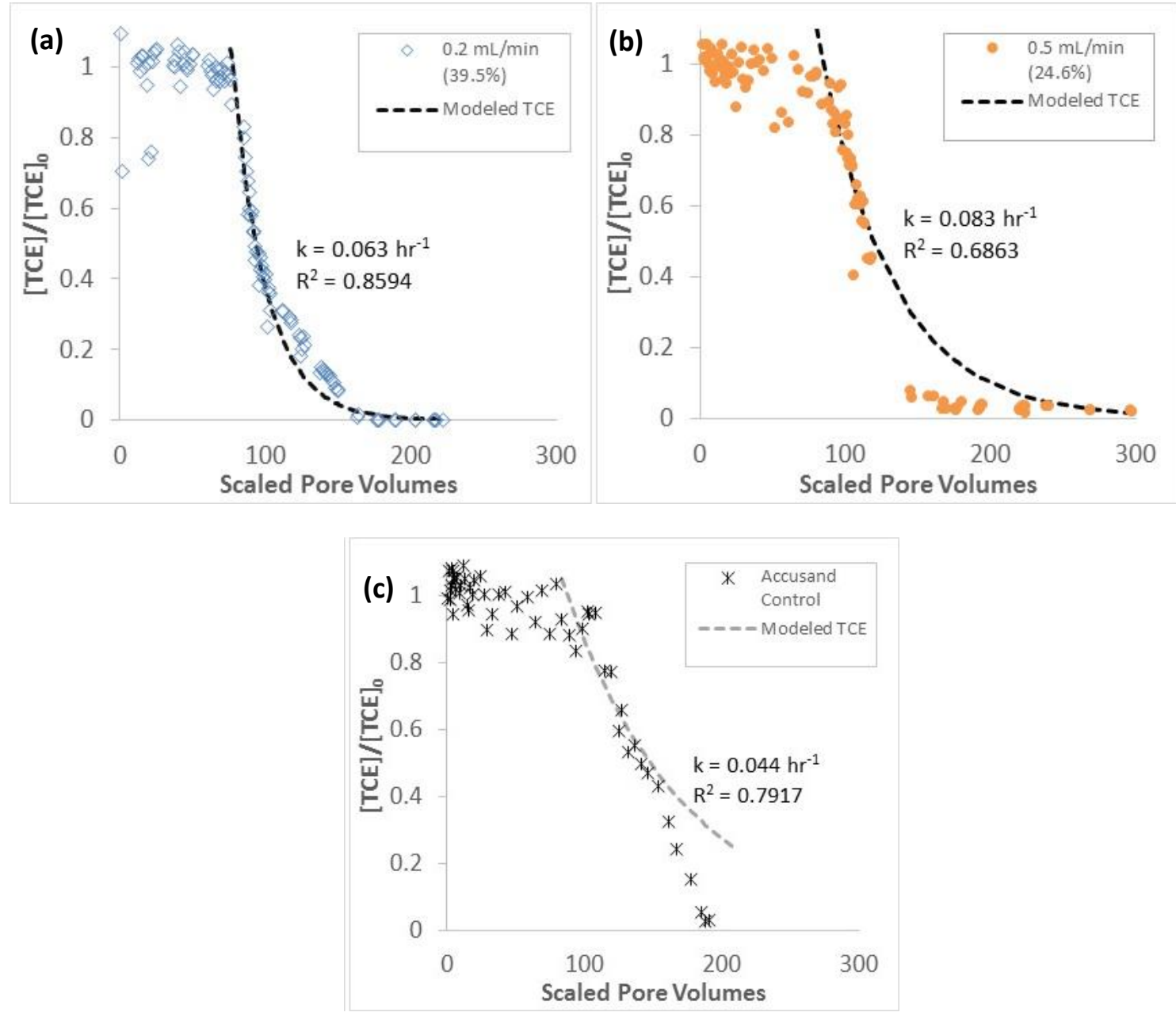

Figure 13 a-c: Modeled pseudo-first order dissolution for three TCE transport studies, (a) 0.2 $\mathrm{mL} / \mathrm{min}$ (39.5\% activated) persulfate, $\mathrm{k}=0.063 \mathrm{hr}^{-1}$ and $\mathrm{R}^{2}=0.8594$, (b) $0.5 \mathrm{~mL} / \mathrm{min}(24.6 \%$ activated) persulfate, $\mathrm{k}=0.083 \mathrm{hr}^{-1}$ and $\mathrm{R}^{2}=0.6863$, and (c) Accusand control study, $\mathrm{k}=0.044 \mathrm{hr}^{-1}$ and $R^{2}=0.7917$.

The effects of enhanced activation of persulfate upon contact with residual TCE are illustrated in Figure 14. Specifically, the concentration of persulfate and sulfate ion in solution measured at the effluent of the heated reservoir as compared to the concentrations of the same species in the column effluent indicate marked changes occur in the concentrations of sulfate species before and after contact with residual trichloroethylene. 


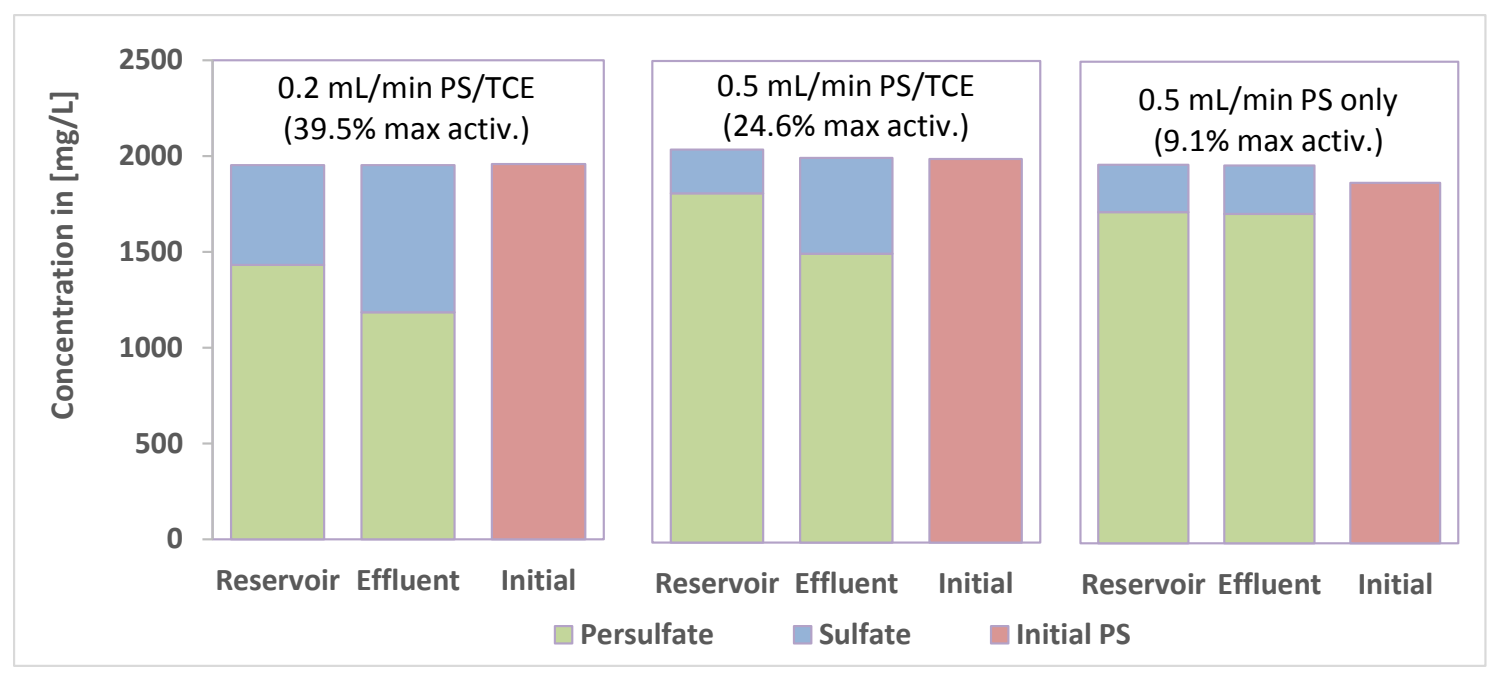

Figure 14a-c: Concentration of persulfate and sulfate as measured at the effluent of the heated reservoir ("Reservoir") and in the column effluent ("Effluent") as compared to measured concentration of initial persulfate stock concentration ("Initial PS") for remediation studies at (a) $0.2 \mathrm{~mL} / \mathrm{min}$ (39.5\% activated) persulfate (18.7\% residual TCE) and (b) $0.5 \mathrm{~mL} / \mathrm{min}$ (24.6\%. activated) persulfate (17.9\% residual TCE) and for (c) persulfate-only transport study, $60^{\circ} \mathrm{C}$ PS-3 (9.1\% activated).

It may be of interest to note that persulfate and sulfate ion concentrations measured from samples taken directly from the heated reservoir before and after the injection period during the remediation studies indicate no changes in reservoir concentration during experimentation. The distinct difference in sulfate-species concentrations pre- and post-injection into the column is seen only in the remediation studies, not the persulfate transport study where no TCE was present (see Figure 14 and Table 9). 
Table 9: Activation gains observed after persulfate has left the heated reservoir in transport and remediation studies

\begin{tabular}{|c|c|c|c|c|c|}
\hline Study & $\begin{array}{l}\text { Percent } \\
\text { Activation, } \\
\text { Heated } \\
\text { Reservoir }\end{array}$ & $\begin{array}{l}\text { Percent } \\
\text { Activation, } \\
\text { Column } \\
\text { Effluent }\end{array}$ & $\begin{array}{c}\text { TCE } \\
\text { Residual } \\
\text { Saturation }\end{array}$ & $\begin{array}{l}\text { Percent } \\
\text { Increase }\end{array}$ & $\begin{array}{c}\text { Percent Change, } \\
\text { PS } \\
\text { Concentration }^{1}\end{array}$ \\
\hline $\begin{array}{l}\text { PS Transport, } \\
20^{\circ} \mathrm{C}\end{array}$ & $0.0 \%$ & $0.5 \%$ & -- & -- & $0.5 \%$ \\
\hline $\begin{array}{l}\text { PS Transport, } \\
60^{\circ} \mathrm{C}\end{array}$ & $9.1 \%$ & $10.0 \%$ & -- & $9.9 \%$ & $1.0 \%$ \\
\hline $\begin{array}{l}\text { PS Transport, } \\
90^{\circ} \mathrm{C}\end{array}$ & $91.1 \%$ & $91.2 \%$ & -- & $0.2 \%$ & $2.5 \%$ \\
\hline $\begin{array}{l}0.5 \mathrm{~mL} / \mathrm{min} \\
\text { remediation, } \\
60^{\circ} \mathrm{C}\end{array}$ & $9.0 \%$ & $24.6 \%$ & $17.9 \%$ & $174.7 \%$ & $17.2 \%$ \\
\hline $\begin{array}{l}0.2 \mathrm{~mL} / \mathrm{min} \\
\text { remediation, } \\
60^{\circ} \mathrm{C}\end{array}$ & $26.8 \%$ & $39.5 \%$ & $18.7 \%$ & $47.2 \%$ & $17.3 \%$ \\
\hline
\end{tabular}

(1) Percent difference in measured persulfate concentration post-reservoir and measured persulfate concentration at column effluent.

This experimental evidence suggests a direct interaction between residual trichloroethylene and persulfate. The apparent increase in mass loss of persulfate ion in solution measured in these remediation studies is likely due to unactivated persulfate reacting with the high concentrations of trichloroethylene present in the system, following the persulfate reaction shown in Table 2, as previously discussed. Unactivated persulfate at ambient temperature has been used as a treatment technology on its own (e.g., [26], [68], [69], [81]). For example, one batch study reports unactivated persulfate reacting with low concentration $(60 \mathrm{mg} / \mathrm{L})$ trichloroethylene at $20^{\circ} \mathrm{C}$ with a half-life of 86.6 hours in an unbuffered aqueous system [81]. 


\section{Future Work and Conclusions}

Persulfate/activated persulfate was shown to be a viable remediation technique for residual (pure phase) trichloroethylene in this initial proof of concept work. More complete degradation of trichloroethylene is reasonably expected with optimization of this system going forward, along with a better understanding of the mechan isms involved in degradation. Future work will have several focuses: replicates, modeling, and a broadening of scope. Now that a system has been developed for the study of dynamic persulfate/activated persulfate behavior (e.g., the temperature-controlled, flow-through injection system plus delivery of persulfate/activated persulfate under steady-state flow conditions), work further characterizing this system can be done. For example, replicate work (i.e., reproducibility studies) needs to be completed on the trichloroethylene remediation studies. Experiments aimed to differentiate between the effects of contact time, flowrate, and persulfate activation on the degradation/dissolution of residual trichloroethylene in a natural sandy material should be conducted. Furthermore, following additional characterization of this one-dimensional, flow-through system, experiments replicating/comparing the overall transport behavior and application of a heat-activated persulfate ISCO system under two-dimensional flow should be completed. Ideally, these additional studies on persulfate/activated persulfate ISCO in both the oneand two-dimensional flow-through systems will also track for potential byproducts of trichloroethylene degradation, particularly chloride ion. This will allow for a mechanistic study of persulfate/activated persulfate ISCO for the remediation of TCE. Modeling work 
is also planned prior to further publication of this work, both on transport of persulfate at different activating temperatures and the persulfate/trichloroethylene system.

This future work will continue to build on the encouraging results found in this work, furthering understanding of the behavior and mechanisms of persulfate ISCO systems. The work in this study give promising indications that a heat-activated persulfate system can be effectively scaled from the laboratory to the field scale, for several reasons. Regardless of activation temperature, persulfate shows near ideal transport behavior under steady-state flow through natural porous media. As an alternative subsurface remediation technology, these results suggest that persulfate/activated persulfate may be effectively delivered to target zones for in-situ chemical oxidation and, as such, should not require advanced design techniques associated with non-ideal flow conditions on application. Both column and supporting batch work indicate that any interactions between persulfate and the natural sandy material are negligible, and a full mass balance on sulfate ion species in solution was achieved. Results also indicate persulfate/activated persulfate degraded approximately $33 \%$ of the residual mass of TCE over the course of treatment while effectively decreasing the time necessary for complete dissolution of TCE residual source zone. With increasing dependence on groundwater sources for a wide range of uses, developing effective systems for addressing subsurface contamination is vital. A variety of approaches will be needed, and this research, along with others, illustrates how promising persulfate oxidation systems are for meeting that need. 
References

[1] USGS, "Freshwater - The Water Cycle," USGS Water-Science School. [Online]. Available: http://water.usgs.gov/edu/watercyclefreshstorage.html. [Accessed: 14Jul-2015].

[2] British Geological Survey and United Nations Environment Programme. Division of Early Warning and Assessment, Groundwater and its susceptibility to degradation : a global assessment of the problem and options for management. Nairobi, Kenya: Nairobi, Kenya : UNEP, 2003.

[3] S. Siebert, J. Burke, J. M. Faures, K. Frenken, J. Hoogeveen, P. Döll, and F. T. Portmann, "Groundwater use for irrigation - a global inventory," Hydrol. Earth Syst. Sci., vol. 14, no. 10, pp. 1863-1880, Oct. 2010.

[4] NGWA, "Facts about Global Groundwater Usage," Mar-2015. [Online]. Available: http://www.ngwa.org/Fundamentals/use/Documents/global-groundwater-usefact-sheet.pdf. [Accessed: 14-Jul-2015].

[5] ATSDR (Agency for Toxic Substances and Disease Registry), "Priority List of Toxic Substances," 2013.

[6] L. A. Desimone, P. B. McMahon, and M. R. Rosen, "The quality of our nation's waters; water quality in principal aquifers of the United States, 1991-2010," 2015.

[7] R. Boulding, Practical handbook of soil, vadose zone, and ground-water contamination: assessment, prevention, and remediation. Boca Raton: Lewis Publishers, 1995.

[8] S. G. Huling and B. E. Pivetz, "In-Situ Chemical Oxidation," 2006.

[9] A. Tsitonaki, B. Petri, M. Crimi, H. MosbæK, R. L. Siegrist, and P. L. Bjerg, "In Situ Chemical Oxidation of Contaminated Soil and Groundwater Using Persulfate: A Review," Crit. Rev. Environ. Sci. Technol., vol. 40, no. 1, pp. 55-91, Jan. 2010.

[10] United States. Environmental Protection Agency. Office of Solid Waste and Emergency Response, A citizen's guide to pump and treat. Washington, D.C.: Washington, D.C. : E.P.A., Office of Solid Waste and Emergency Response, 2001. 
[11]United States. Environmental Protection Agency. Office of Solid Waste and Emergency Response, Cleaning up the nation's waste sites markets and technology trends. Washington, D.C.]: Washington, D.C. : U.S. Environmental Protection Agency, Office of Solid Waste and Emergency Response, 2004.

[12] K.-C. Huang, Z. Zhao, G. E. Hoag, A. Dahmani, and P. A. Block, "Degradation of volatile organic compounds with thermally activated persulfate oxidation," Chemosphere, vol. 61, no. 4, pp. 551-560, Oct. 2005.

[13] S. Ko, M. Crimi, B. K. Marvin, V. Holmes, and S. G. Huling, "Comparative study on oxidative treatments of NAPL containing chlorinated ethanes and ethenes using hydrogen peroxide and persulfate in soils," J. Environ. Manage., vol. 108, pp. 4248, Oct. 2012.

[14] J. Liu, X. Gong, S. Song, F. Zhang, and C. Lu, "Heat-Activated Persulfate Oxidation of Chlorinated Solvents in Sandy Soil," J. Spectrosc., vol. 2014, pp. 1-5, 2014.

[15] R. H. Waldemer, P. G. Tratnyek, R. L. Johnson, and J. T. Nurmi, "Oxidation of Chlorinated Ethenes by Heat-Activated Persulfate: Kinetics and Products," Environ. Sci. Technol., vol. 41, no. 3, pp. 1010-1015, Feb. 2007.

[16] C. Liang, C. J. Bruell, M. C. Marley, and K. L. Sperry, "Thermally Activated Persulfate Oxidation of Trichloroethylene (TCE) and 1,1,1-Trichloroethane (TCA) in Aqueous Systems and Soil Slurries," Soil Sediment Contam., vol. 12, no. 2, pp. 207-228, Mar. 2003.

[17] J. Costanza, G. Otaño, J. Callaghan, and K. D. Pennell, "PCE Oxidation by Sodium Persulfate in the Presence of Solids," Environ. Sci. Technol., vol. 44, no. 24, pp. 9445-9450, Dec. 2010.

[18] C.-F. Chen, N. T. Binh, C.-W. Chen, and C.-D. Dong, "Removal of polycyclic aromatic hydrocarbons from sediments using sodium persulfate activated by temperature and nanoscale zero-valent iron," J. Air Waste Manag. Assoc., vol. 65, no. 4, pp. 375-383, Apr. 2015.

[19] X. Liao, D. Zhao, X. Yan, and S. G. Huling, "Identification of persulfate oxidation products of polycyclic aromatic hydrocarbon during remediation of contaminated soil," J. Hazard. Mater., vol. 276, pp. 26-34, Jul. 2014. 
[20] W. R. Haag and C. C. D. Yao, "Rate constants for reaction of hydroxyl radicals with several drinking water contaminants," Environ. Sci. Technol., vol. 26, no. 5, pp. 1005-1013, May 1992.

[21] Y. Ji, C. Dong, D. Kong, and J. Lu, “New insights into atrazine degradation by cobalt catalyzed peroxymonosulfate oxidation: Kinetics, reaction products and transformation mechanisms," J. Hazard. Mater., vol. 285, pp. 491-500, Mar. 2015.

[22] A. Ghauch, A. M. Tuqan, and N. Kibbi, "Ibuprofen removal by heated persulfate in aqueous solution: A kinetics study," Chem. Eng. J., vol. 197, pp. 483-492, Jul. 2012.

[23] S. Rodriguez, A. Santos, A. Romero, and F. Vicente, "Kinetic of oxidation and mineralization of priority and emerging pollutants by activated persulfate," Chem. Eng. J., vol. 213, pp. 225-234, Dec. 2012.

[24] Y. Ji, C. Ferronato, A. Salvador, X. Yang, and J.-M. Chovelon, "Degradation of ciprofloxacin and sulfamethoxazole by ferrous-activated persulfate: Implications for remediation of groundwater contaminated by antibiotics," Sci. Total Environ., vol. 472, pp. 800-808, Feb. 2014.

[25] C. Liang and I.-L. Lee, "In situ iron activated persulfate oxidative fluid sparging treatment of TCE contamination - A proof of concept study," J. Contam. Hydrol., vol. 100, no. 3-4, pp. 91-100, Sep. 2008.

[26] C. Liang, I.-L. Lee, I.-Y. Hsu, C.-P. Liang, and Y.-L. Lin, "Persulfate oxidation of trichloroethylene with and without iron activation in porous media," Chemosphere, vol. 70, no. 3, pp. 426-435, Jan. 2008.

[27] E. R. McKenzie, R. L. Siegrist, J. E. McCray, and C. P. Higgins, "Effects of Chemical Oxidants on Perfluoroalkyl Acid Transport in One-Dimensional Porous Media Columns," Environ. Sci. Technol., vol. 49, no. 3, pp. 1681-1689, Feb. 2015.

[28] C. E. Schaefer, R. M. Towne, D. Root, and J. E. McCray, "Assessment of Chemical Oxidation for Treatment of DNAPL in Fractured Sandstone Blocks," J. Environ. Eng., vol. 138, no. 1, pp. 1-7, Jan. 2012.

[29] S. US EPA, "Ground Water Cleanup at Superfund Sites." [Online]. Available: http://www.epa.gov/superfund/health/conmedia/gwdocs/brochure.htm. [Accessed: 15-Jul-2015]. 
[30] R. L. Siegrist, Ed., Principles and practices of in situ chemical oxidation using permanganate. Columbus, Ohio: Battelle Press, 2001.

[31] United States Environmental Protection Agency, "National Primary Drinking Water Regulations." May-2009.

[32] R. Baciocchi, "Principles, Developments and Design Criteria of In Situ Chemical Oxidation," Water. Air. Soil Pollut., vol. 224, no. 12, Dec. 2013.

[33] G. P. Anipsitakis and D. D. Dionysiou, "Radical Generation by the Interaction of Transition Metals with Common Oxidants," Environ. Sci. Technol., vol. 38, no. 13, pp. 3705-3712, Jul. 2004.

[34] ITRC, "Technical and Regulatory Guidance for In Situ Chemical Oxidation of Contaminated Soil and Groundwater Second Edition," 2005.

[35] A. M. Struse, R. L. Siegrist, H. E. Dawson, and M. A. Urynowicz, "Diffusive Transport of Permanganate during In Situ Oxidation," J. Environ. Eng., vol. 128, no. 4, pp. 327-334, Apr. 2002.

[36] X. D. Li, "DNAPL mass transfer and permeability reduction during in situ chemical oxidation with permanganate," Geophys. Res. Lett., vol. 31, no. 6, 2004.

[37] Venny, S. Gan, and H. K. Ng, "Current status and prospects of Fenton oxidation for the decontamination of persistent organic pollutants (POPs) in soils," Chem. Eng. J., vol. 213, pp. 295-317, Dec. 2012.

[38] E. Lipczynska-Kochany, G. Sprah, and S. Harms, "Influence of some groundwater and surface waters constituents on the degradation of 4-chlorophenol by the Fenton reaction," Chemosphere, vol. 30, no. 1, pp. 9-20, Jan. 1995.

[39] G. Buxton, Q. Mulazzani, and A. Ross, "Critical review of rate constants for reactions of hydrated electrons, hydrogen atoms, and hydroxyl radials in aqueous solution," J Phys Chem Ref Data, vol. 24, no. 3, pp. 1055-1349, 1995.

[40] Thermoretec Consulting Corp., Mission, KS, "Technology Status Review In Situ Oxidation," 1999.

[41] H. Choi, H.-N. Lim, J. Kim, T.-M. Hwang, and J.-W. Kang, "Transport characteristics of gas phase ozone in unsaturated porous media for in-situ chemical oxidation," $J$. Contam. Hydrol., vol. 57, no. 1-2, pp. 81-98, Jul. 2002. 
[42] W. J. Braida and S. K. Ong, "Air sparging effectiveness: laboratory characterization of air-channel mass transfer zone for VOC volatilization," J. Hazard. Mater., vol. 87, no. 1-3, pp. 241-258, Oct. 2001.

[43] Ozone Solutions, "Ozone Compatible Materials." [Online]. Available: http://www.ozonesolutions.com/info/ozone-compatible-materials. [Accessed: 25Jul-2015].

[44] B.-T. Zhang, Y. Zhang, Y. Teng, and M. Fan, "Sulfate Radical and Its Application in Decontamination Technologies," Crit. Rev. Environ. Sci. Technol., vol. 45, no. 16, pp. 1756-1800, Aug. 2015.

[45] FMC, "Persulfates, Technical Information," 2001. [Online]. Available: http://www.peroxychem.com/media/90826/AOD_Brochure_Persulfate.pdf. [Accessed: 16-Jul-2015].

[46] United States Environmental Protection Agency, "Sodium in Drinking Water, Contaminant Candidate List," 3/6/2012. [Online]. Available: http://water.epa.gov/scitech/drinkingwater/dws/ccl/sodium.cfm. [Accessed: 16Jul-2015].

[47] United States Environmental Protection Agency, "Sulfate in Drinking Water, Unregulated," 06-Mar-2012. [Online]. Available: http://water.epa.gov/drink/contaminants/unregulated/sulfate.cfm. [Accessed: 16Jul-2015].

[48] R. L. Johnson, P. G. Tratnyek, and R. O. Johnson, "Persulfate Persistence under Thermal Activation Conditions," Environ. Sci. Technol., vol. 42, no. 24, pp. 93509356, Dec. 2008.

[49] D. Zhao, X. Liao, X. Yan, S. G. Huling, T. Chai, and H. Tao, "Effect and mechanism of persulfate activated by different methods for PAHs removal in soil," J. Hazard. Mater., vol. 254-255, pp. 228-235, Jun. 2013.

[50] K.-C. Huang, R. A. Couttenye, and G. E. Hoag, "Kinetics of heat-assisted persulfate oxidation of methyl tert-butyl ether (MTBE)," Chemosphere, vol. 49, no. 4, pp. 413420, Oct. 2002.

[51] V. C. Mora, J. A. Rosso, D. O. Mártire, and M. C. Gonzalez, "Phenol depletion by thermally activated peroxydisulfate at $70^{\circ} \mathrm{C}$," Chemosphere, vol. 84 , no. 9, pp. 1270-1275, Aug. 2011. 
[52] D. A. House, "Kinetics and Mechanism of Oxidations by Peroxydisulfate.," Chem. Rev., vol. 62, no. 3, pp. 185-203, Jun. 1962.

[53] L. R. Bennedsen, J. Muff, and E. G. Søgaard, "Influence of chloride and carbonates on the reactivity of activated persulfate," Chemosphere, vol. 86, no. 11, pp. 10921097, Mar. 2012.

[54] C. Liang and Y. Guo, "Mass Transfer and Chemical Oxidation of Naphthalene Particles with Zerovalent Iron Activated Persulfate," Environ. Sci. Technol., vol. 44, no. 21, pp. 8203-8208, Nov. 2010.

[55] J. Yan, L. Han, W. Gao, S. Xue, and M. Chen, "Biochar supported nanoscale zerovalent iron composite used as persulfate activator for removing trichloroethylene," Bioresour. Technol., vol. 175, pp. 269-274, Jan. 2015.

[56] S.-Y. Oh, H.-W. Kim, J.-M. Park, H.-S. Park, and C. Yoon, "Oxidation of polyvinyl alcohol by persulfate activated with heat, Fe2+, and zero-valent iron," J. Hazard. Mater., vol. 168, no. 1, pp. 346-351, Aug. 2009.

[57] M. Ahmad, A. L. Teel, and R. J. Watts, "Persulfate activation by subsurface minerals," J. Contam. Hydrol., vol. 115, no. 1-4, pp. 34-45, Jun. 2010.

[58] A. L. Teel, M. Ahmad, and R. J. Watts, "Persulfate activation by naturally occurring trace minerals," J. Hazard. Mater., vol. 196, pp. 153-159, Nov. 2011.

[59] H. Zhong, M. L. Brusseau, Y. Wang, N. Yan, L. Quig, and G. R. Johnson, "In-situ activation of persulfate by iron filings and degradation of 1,4-dioxane," Water Res., vol. 83, pp. 104-111, Oct. 2015.

[60] O. S. Furman, A. L. Teel, and R. J. Watts, "Mechanism of Base Activation of Persulfate," Environ. Sci. Technol., vol. 44, no. 16, pp. 6423-6428, Aug. 2010.

[61] JAG Consulting Group, LLC, "Case Study: Treatment of Shallow Soil Contamination Using High pH Activation of Sodium Persulfate, Industrial Site, Illinois," 2013. [Online]. Available: http://www.peroxychem.com/media/19391/FMC_Klozur_Case_Study_-_PCE_TCE-_TEX_-_IL_-_JAG.pdf. [Accessed: 25-Jul-2015]. 
[62] XDD, LLC, "Site Closure with Multi-Level Treatment Approach at a Fromer MGP Site: Central Illinois." [Online]. Available:

http://www.peroxychem.com/media/116782/klozur-aap-xdd-isco-case-studymattoon-il.pdf. [Accessed: 25-Jul-2015].

[63] T. T. Tsai, C. M. Kao, and A. Hong, "Treatment of tetrachloroethylenecontaminated groundwater by surfactant-enhanced persulfate/BOF slag oxidation-A laboratory feasibility study," J. Hazard. Mater., vol. 171, no. 1-3, pp. 571-576, Nov. 2009.

[64] X. Gu, S. Lu, L. Li, Z. Qiu, Q. Sui, K. Lin, and Q. Luo, "Oxidation of 1,1,1Trichloroethane Stimulated by Thermally Activated Persulfate," Ind. Eng. Chem. Res., vol. 50, no. 19, pp. 11029-11036, Oct. 2011.

[65] D. Deng, L. Peng, M. Guan, and Y. Kang, "Impact of activation methods on persulfate oxidation of methyl tert-butyl ether," J. Hazard. Mater., vol. 264, pp. 521-528, Jan. 2014.

[66] C. Liang, C.-F. Huang, and Y.-J. Chen, "Potential for activated persulfate degradation of BTEX contamination," Water Res., vol. 42, no. 15, pp. 4091-4100, Sep. 2008.

[67] J. Zhao, Y. Zhang, X. Quan, and S. Chen, "Enhanced oxidation of 4-chlorophenol using sulfate radicals generated from zero-valent iron and peroxydisulfate at ambient temperature," Sep. Purif. Technol., vol. 71, no. 3, pp. 302-307, Mar. 2010.

[68] K. S. Sra, N. R. Thomson, and J. F. Barker, "Persulfate injection into a gasoline source zone," J. Contam. Hydrol., vol. 150, pp. 35-44, Jul. 2013.

[69] V. Sohrabi, M. S. Ross, J. W. Martin, and J. F. Barker, "Potential for in situ chemical oxidation of acid extractable organics in oil sands process affected groundwater," Chemosphere, vol. 93, no. 11, pp. 2698-2703, Nov. 2013.

[70] F. J. Benitez, J. L. Acero, F. J. Real, G. Roldán, and E. Rodríguez, "The Effectiveness of Single Oxidants and AOPs in the Degradation of Emerging Contaminants in Waters: A Comparison Study," Ozone Sci. Eng., vol. 35, no. 4, pp. 263-272, Jul. 2013.

[71] L. Hou, H. Zhang, and X. Xue, "Ultrasound enhanced heterogeneous activation of peroxydisulfate by magnetite catalyst for the degradation of tetracycline in water," Sep. Purif. Technol., vol. 84, pp. 147-152, Jan. 2012. 
[72] A. Ghauch, G. Ayoub, and S. Naim, "Degradation of sulfamethoxazole by persulfate assisted micrometric Fe0 in aqueous solution," Chem. Eng. J., vol. 228, pp. 11681181, Jul. 2013.

[73] B. Darsinou, Z. Frontistis, M. Antonopoulou, I. Konstantinou, and D. Mantzavinos, "Sono-activated persulfate oxidation of bisphenol A: Kinetics, pathways and the controversial role of temperature," Chem. Eng. J., vol. 280, pp. 623-633, Nov. 2015.

[74] Y.-C. Lee, S.-L. Lo, P.-T. Chiueh, and D.-G. Chang, "Efficient decomposition of perfluorocarboxylic acids in aqueous solution using microwave-induced persulfate," Water Res., vol. 43, no. 11, pp. 2811-2816, Jun. 2009.

[75] Y.-C. Lee, S.-L. Lo, P.-T. Chiueh, Y.-H. Liou, and M.-L. Chen, “Microwavehydrothermal decomposition of perfluorooctanoic acid in water by iron-activated persulfate oxidation," Water Res., vol. 44, no. 3, pp. 886-892, Feb. 2010.

[76] Y.-C. Lee, S.-L. Lo, J. Kuo, and C.-P. Huang, "Promoted degradation of perfluorooctanic acid by persulfate when adding activated carbon," J. Hazard. Mater., vol. 261, pp. 463-469, Oct. 2013.

[77] Y. Deng and C. M. Ezyske, "Sulfate radical-advanced oxidation process (SR-AOP) for simultaneous removal of refractory organic contaminants and ammonia in landfill leachate," Water Res., vol. 45, no. 18, pp. 6189-6194, Nov. 2011.

[78] L. W. Pan, R. L. Siegrist, and M. Crimi, "Effects of In Situ Remediation Using Oxidants or Surfactants on Subsurface Organic Matter and Sorption of Trichloroethene," Ground Water Monit. Remediat., vol. 32, no. 2, pp. 96-105, May 2012.

[79] C. Liang and C.-W. Wang, "Assessing acute toxicity potential of persulfate ISCO treated water," Chemosphere, vol. 93, no. 11, pp. 2711-2716, Nov. 2013.

[80] C. Liang, C.-F. Huang, N. Mohanty, and R. M. Kurakalva, "A rapid spectrophotometric determination of persulfate anion in ISCO," Chemosphere, vol. 73, no. 9, pp. 1540-1543, Nov. 2008.

[81] C. Liang, Z.-S. Wang, and C. J. Bruell, "Influence of $\mathrm{pH}$ on persulfate oxidation of TCE at ambient temperatures," Chemosphere, vol. 66, no. 1, pp. 106-113, Jan. 2007. 


\section{Appendix A - Temperature Controller Design}

A temperature controller was designed to keep the heated reservoir at a steady temperature throughout experimentation. The system consists of a RKC REX-C100 proportional-integral-derivative (PID) temperature controller, 25 amp solid state relay, and K-type thermocouple. A terminal block was also used because of the number of junctions. The PID controller essentially uses the SSR to throttle the voltage being sent to the heating apparatus attached to the system, which in turn maintains a steady temperature. The auto-tuning function built into the PID optimized the relay between the PID, SSR, and heating apparatus, and was recalibrated for both $60^{\circ} \mathrm{C}$ and $90^{\circ} \mathrm{C}$. In all cases after an initial heating period, temperature stayed constant within $\pm 1^{\circ} \mathrm{C}$. A simple wall outlet was wired to the system instead of directly wiring the heating element to the controller. This allowed the same controller to be connected to any heating apparatus that requires standard $15 \mathrm{amp} / 120 \mathrm{~V}$ power supply. Over the course of this study, a Glascol heating jacket as well as a standard hot plate were both controlled with this apparatus to great success. Thermocouples were also very easy to replace as they became worn from usage. A wiring diagram of the system is include in Figure 15 


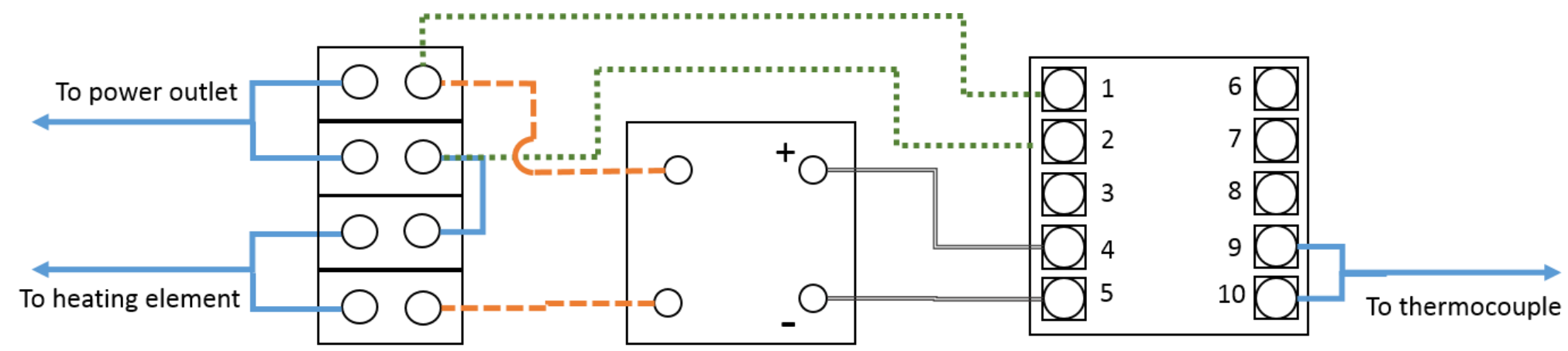

Terminal Block Solid State Relay PID Controller

옹

Power to PID

- - Control Lines, SSR to heating element

Signal Lines, PID to SSR

Lines in/out of system

Figure 15: Wiring diagram for temperature controller used in flow-through heat injection system 
Appendix B - Experimental Set-up

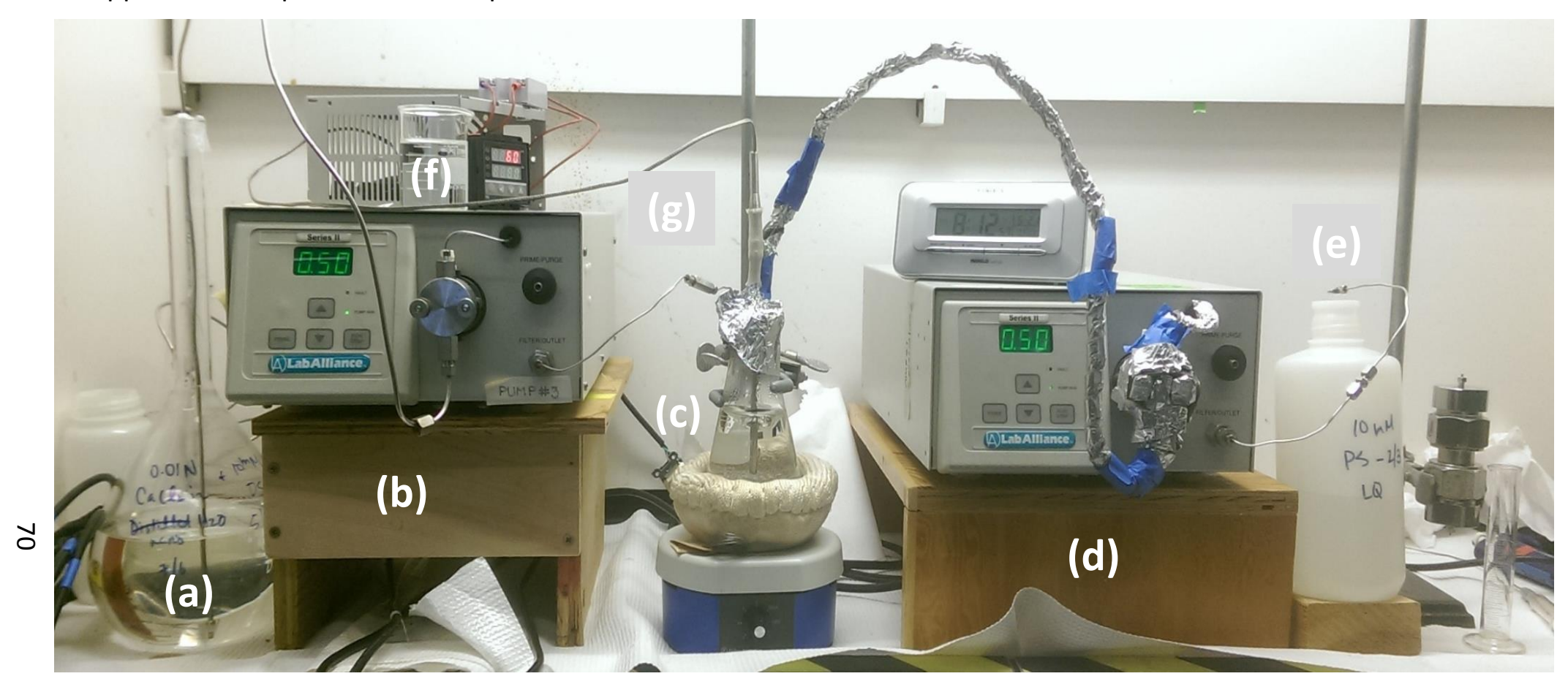

Figure 16: Experimental set-up for heat-activation, flowthrough system.

(a) Unactivated persulfate reservoir

(b) HPLC Pump \#1, delivers unactivated persulfate to heated reservoir

(c) Heated reservoir, 250-mL flask, capped with rubber stopper containing magnetic stir-bar. Placed in heating mantle, and on top of magnetic stir plate.

(d) HPLC Pump \#2, pulls activated persulfate from the reservoir, delivers persulfate to column

(e) Pump effluent/column influent tubing

(f) PID Temperature controller

(g) Thermocouple 


\section{Appendix C - Experimental Data}

\section{Table 10: Non-reactive Tracer Data - NRT 1A}

Performed for Persulfate Temperature Transport Studies

Column: A

Darcy Velocity: $0.38 \mathrm{~cm} / \mathrm{min}$

Tracer: $499.6 \mathrm{mg} / \mathrm{L}$ PFBA

Electrolyte: $0.01 \mathrm{~N} \mathrm{CaCl}_{2}$

Data results for PFBA non-reactive transport, study NRT 1A; samples 1-25

\begin{tabular}{|c|c|c|c|c|}
\hline Sample & $\begin{array}{c}\text { Pore Volume } \\
(\mathrm{mL})\end{array}$ & $\begin{array}{c}\text { UV-Vis } \\
\text { Abs }\end{array}$ & Dilution & $\mathrm{C} / \mathrm{C}_{\mathrm{o}}$ \\
\hline 1 & 0.00 & 0.016 & 3.0 & 0.004 \\
\hline 2 & 0.17 & 0.021 & 3.0 & 0.006 \\
\hline 3 & 0.38 & 0.014 & 3.0 & 0.003 \\
\hline 4 & 0.59 & 0.012 & 3.0 & 0.002 \\
\hline 5 & 0.80 & 0.254 & 3.0 & 0.099 \\
\hline 6 & 1.00 & 1.693 & 3.0 & 0.670 \\
\hline 7 & 1.21 & 2.244 & 3.0 & 0.894 \\
\hline 8 & 1.41 & 2.409 & 3.0 & 0.962 \\
\hline 9 & 1.61 & 2.444 & 3.0 & 0.976 \\
\hline 10 & 1.81 & 2.482 & 3.0 & 0.990 \\
\hline 11 & 2.02 & 2.482 & 3.0 & 0.989 \\
\hline 12 & 2.22 & 2.482 & 3.0 & 0.996 \\
\hline 13 & 2.45 & 2.495 & 3.0 & 0.997 \\
\hline 14 & 2.67 & 2.495 & 3.0 & 0.997 \\
\hline 15 & 2.97 & 2.495 & 3.0 & 0.996 \\
\hline 16 & 3.37 & 2.509 & 3.0 & 1.000 \\
\hline 17 & 3.76 & 2.523 & 3.0 & 1.005 \\
\hline 18 & 4.16 & 2.523 & 3.0 & 1.009 \\
\hline 19 & 4.55 & 2.537 & 3.0 & 1.013 \\
\hline 20 & 4.85 & 2.537 & 3.0 & 1.008 \\
\hline 21 & 5.71 & 2.523 & 3.0 & 1.007 \\
\hline 22 & 6.56 & 2.523 & 3.0 & 1.016 \\
\hline 23 & 7.44 & 2.523 & 3.0 & 1.009 \\
\hline 24 & 8.29 & 2.509 & 3.0 & 1.004 \\
\hline 25 & 8.95 & 2.523 & 3.0 & 1.008 \\
\hline
\end{tabular}


Table 10 (Continued) Non-reactive Tracer Data - NRT 1A

Data results for PFBA non-reactive transport, study NRT 1A; samples 26-54 Sample $\begin{array}{cc}\text { Pore Volume } \\ (\mathrm{mL})\end{array} \quad \begin{gathered}\text { UV-Vis } \\ \text { Abs }\end{gathered}$ Dilution $\quad \mathrm{C} / \mathrm{C}_{\mathrm{o}}$

\begin{tabular}{|c|c|c|c|c|c|}
\hline 26 & 9.83 & 2.523 & 3.0 & 1.007 & \\
\hline 27 & 10.72 & 2.523 & 3.0 & 1.010 & \\
\hline 28 & 10.93 & 2.523 & 3.0 & 1.009 & Elution \\
\hline 29 & 11.13 & 2.523 & 3.0 & 1.010 & \\
\hline 30 & 11.33 & 2.523 & 3.0 & 1.008 & \\
\hline 31 & 11.53 & 2.495 & 3.0 & 0.997 & \\
\hline 32 & 11.74 & 2.444 & 3.0 & 0.975 & \\
\hline 33 & 11.94 & 1.269 & 1.0 & 0.506 & \\
\hline 34 & 12.14 & 0.340 & 1.0 & 0.133 & \\
\hline 35 & 12.34 & 0.296 & 1.0 & 0.036 & \\
\hline 36 & 12.54 & 0.101 & 1.0 & 0.011 & \\
\hline 37 & 12.74 & 0.054 & 1.0 & 0.005 & \\
\hline 38 & 12.95 & 0.037 & 1.0 & 0.002 & \\
\hline 39 & 13.25 & 0.028 & 1.0 & 0.001 & LDL \\
\hline 40 & 13.65 & 0.020 & 1.0 & 0.000 & LDL \\
\hline 41 & 14.10 & 0.016 & 1.0 & 0.000 & LDL \\
\hline 42 & 14.57 & 0.013 & 1.0 & -0.001 & LDL \\
\hline 43 & 14.99 & 0.017 & 1.0 & 0.000 & LDL \\
\hline 44 & 15.39 & 0.014 & 1.0 & -0.001 & LDL \\
\hline 45 & 15.79 & 0.019 & 1.0 & 0.000 & LDL \\
\hline 46 & 16.10 & 0.020 & 1.0 & 0.000 & LDL \\
\hline 47 & 16.94 & 0.029 & 1.0 & 0.001 & LDL \\
\hline 48 & 17.84 & 0.027 & 1.0 & 0.001 & LDL \\
\hline 49 & 18.69 & 0.013 & 1.0 & -0.001 & LDL \\
\hline 50 & 19.55 & 0.019 & 1.0 & 0.000 & LDL \\
\hline 51 & 20.41 & 0.015 & 1.0 & -0.001 & LDL \\
\hline 52 & 21.25 & 0.015 & 1.0 & -0.001 & LDL \\
\hline 53 & 22.16 & 0.017 & 1.0 & 0.000 & LDL \\
\hline 54 & 23.11 & 0.017 & 1.0 & 0.000 & LDL \\
\hline
\end{tabular}


Table 11: Non-reactive Tracer Data - NRT 2A

Performed for Persulfate Temperature Transport Studies

Column: A

Darcy Velocity: $0.38 \mathrm{~cm} / \mathrm{min}$

Tracer: 504.4 mg/L PFBA

Electrolyte: $0.01 \mathrm{~N} \mathrm{CaCl}_{2}$

Data results for PFBA non-reactive transport, study NRT 2A; samples 1-26

\begin{tabular}{cccccc} 
Sample & $\begin{array}{c}\text { Pore } \\
\text { Volume } \\
(\mathrm{mL})\end{array}$ & $\begin{array}{c}\text { UV-Vis } \\
\text { Abs }\end{array}$ & Dilution & C/Co & \\
\hline 1 & 0.00 & 0.005 & 1.0 & 0.000 & LDL \\
2 & 0.15 & 0.001 & 1.0 & 0.000 & LDL \\
3 & 0.36 & 0.051 & 1.0 & 0.006 & \\
4 & 0.57 & 0.015 & 1.0 & 0.001 & LDL \\
5 & 0.78 & 0.226 & 1.0 & 0.027 & \\
6 & 0.98 & 0.899 & 4.0 & 0.474 & \\
7 & 1.20 & 1.364 & 4.1 & 0.740 & \\
8 & 1.43 & 1.745 & 4.0 & 0.923 & \\
9 & 1.68 & 1.827 & 4.0 & 0.962 & \\
10 & 1.91 & 1.867 & 4.0 & 0.987 & \\
11 & 2.12 & 1.893 & 4.0 & 1.002 & \\
12 & 2.33 & 1.845 & 4.0 & 0.976 & \\
13 & 2.53 & 1.854 & 4.0 & 0.981 & \\
14 & 2.74 & 1.857 & 4.0 & 0.988 & \\
15 & 3.04 & 1.887 & 4.0 & 0.989 & \\
16 & 3.44 & 1.873 & 4.0 & 0.991 & \\
17 & 3.86 & 1.891 & 4.0 & 0.987 & \\
18 & 4.33 & 1.886 & 4.0 & 0.990 & \\
19 & 4.78 & 1.873 & 4.0 & 0.978 & \\
20 & 5.18 & 1.876 & 4.0 & 0.981 & \\
21 & 5.58 & 1.863 & 4.0 & 0.983 & \\
22 & 5.88 & 1.886 & 4.0 & 0.996 & \\
23 & 6.74 & 1.886 & 4.0 & 0.998 & \\
24 & 7.64 & 1.883 & 4.1 & 1.003 & \\
25 & 8.52 & 1.876 & 4.0 & 0.992 & \\
26 & 9.45 & 1.893 & 4.0 & 1.002 & \\
& & & & & \\
& &
\end{tabular}


Table 11 (Continued): Non-reactive Tracer Data - NRT 2A

Data results for PFBA non-reactive transport, study NRT 2A; samples 27-58

\begin{tabular}{|c|c|c|c|c|c|}
\hline Sample & $\begin{array}{c}\text { Pore } \\
\text { Volume } \\
\text { (mL) }\end{array}$ & $\begin{array}{c}\text { UV-Vis } \\
\text { Abs }\end{array}$ & Dilution & $C / C_{0}$ & \\
\hline 27 & 10.39 & 1.854 & 4.1 & 0.989 & \\
\hline 28 & 11.35 & 1.928 & 4.0 & 1.017 & \\
\hline 29 & 12.34 & 1.889 & 4.0 & 0.993 & \\
\hline 30 & 13.39 & 1.905 & 4.0 & 1.008 & \\
\hline 31 & 13.60 & 1.863 & 4.1 & 0.997 & Elution \\
\hline 32 & 13.81 & 1.827 & 4.1 & 0.991 & \\
\hline 33 & 14.01 & 1.813 & 4.1 & 0.969 & \\
\hline 34 & 14.21 & 1.824 & 4.1 & 0.973 & \\
\hline 35 & 14.42 & 1.798 & 4.0 & 0.945 & \\
\hline 36 & 14.63 & 0.746 & 4.0 & 0.390 & \\
\hline 37 & 14.84 & 0.208 & 3.0 & 0.101 & \\
\hline 38 & 15.06 & 0.076 & 1.0 & 0.025 & \\
\hline 39 & 15.33 & 0.044 & 1.0 & 0.009 & \\
\hline 40 & 15.68 & 0.035 & 1.0 & 0.005 & \\
\hline 41 & 16.08 & 0.057 & 1.0 & 0.004 & \\
\hline 42 & 16.48 & 0.022 & 1.0 & 0.007 & \\
\hline 43 & 16.87 & 0.020 & 1.0 & 0.002 & \\
\hline 44 & 17.38 & 0.018 & 1.0 & 0.002 & \\
\hline 45 & 17.92 & 0.018 & 1.0 & 0.002 & LDL \\
\hline 46 & 18.34 & 0.010 & 1.0 & 0.002 & LDL \\
\hline 47 & 18.68 & 0.009 & 1.0 & 0.001 & LDL \\
\hline 48 & 19.76 & 0.008 & 1.0 & 0.001 & LDL \\
\hline 49 & 20.69 & 0.006 & 1.0 & 0.001 & LDL \\
\hline 50 & 21.78 & 0.006 & 1.0 & 0.000 & LDL \\
\hline 51 & 22.71 & 0.013 & 1.0 & 0.000 & LDL \\
\hline 52 & 23.56 & 0.007 & 1.0 & 0.001 & LDL \\
\hline 53 & 24.41 & 0.004 & 1.0 & 0.000 & LDL \\
\hline 54 & 25.35 & 0.003 & 1.0 & 0.000 & LDL \\
\hline 55 & 26.40 & 0.006 & 1.0 & 0.000 & LDL \\
\hline 56 & 27.37 & 0.004 & 1.0 & 0.000 & LDL \\
\hline 57 & 28.52 & 0.004 & 1.0 & 0.000 & LDL \\
\hline 58 & 29.64 & 0.000 & 1.0 & 0.000 & LDL \\
\hline
\end{tabular}


Table 12: Non-reactive Tracer Data - NRT 3A

Performed for Persulfate Temperature Transport Studies

Column: A

Darcy Velocity: $0.38 \mathrm{~cm} / \mathrm{min}$

Tracer: 493.9 mg/L PFBA

Electrolyte: $0.01 \mathrm{~N} \mathrm{CaCl}_{2}$

Data results for PFBA non-reactive transport, study NRT 3A; samples 1-26

\begin{tabular}{|c|c|c|c|c|c|}
\hline Sample & $\begin{array}{c}\text { Pore } \\
\text { Volume } \\
(\mathrm{mL})\end{array}$ & $\begin{array}{c}\text { UV-Vis } \\
\text { Abs }\end{array}$ & Dilution & $\mathrm{C} / \mathrm{C}_{\mathrm{o}}$ & \\
\hline 1 & -0.07 & 0.000 & 0.0 & -0.002 & $\mathrm{LDL}$ \\
\hline 2 & 0.12 & 0.000 & 0.0 & -0.002 & LDL \\
\hline 3 & 0.33 & 0.000 & 0.0 & -0.002 & LDL \\
\hline 4 & 0.54 & 0.000 & 0.0 & -0.002 & LDL \\
\hline 5 & 0.74 & 0.115 & 0.0 & 0.014 & \\
\hline 6 & 0.96 & 1.533 & 2.3 & 0.465 & \\
\hline 7 & 1.18 & 2.131 & 3.1 & 0.898 & \\
\hline 8 & 1.41 & 2.328 & 3.1 & 0.976 & \\
\hline 9 & 1.64 & 2.387 & 3.1 & 0.982 & \\
\hline 10 & 1.83 & 2.328 & 3.1 & 0.982 & \\
\hline 11 & 2.02 & 2.328 & 3.1 & 0.980 & \\
\hline 12 & 2.21 & 2.357 & 3.1 & 0.995 & \\
\hline 13 & 2.40 & 2.357 & 3.1 & 0.994 & \\
\hline 14 & 2.60 & 2.357 & 3.1 & 0.992 & \\
\hline 15 & 2.91 & 2.387 & 3.1 & 1.006 & \\
\hline 16 & 3.31 & 2.357 & 3.2 & 0.998 & \\
\hline 17 & 3.70 & 2.357 & 3.2 & 0.998 & \\
\hline 18 & 4.10 & 2.357 & 3.2 & 0.996 & \\
\hline 19 & 4.48 & 2.357 & 3.1 & 0.995 & \\
\hline 20 & 4.86 & 2.357 & 3.2 & 0.997 & \\
\hline 21 & 5.29 & 2.357 & 3.2 & 0.997 & \\
\hline 22 & 6.41 & 2.377 & 3.2 & 1.005 & \\
\hline 23 & 7.36 & 2.357 & 3.1 & 0.994 & \\
\hline 24 & 8.31 & 2.377 & 3.1 & 1.002 & \\
\hline 25 & 9.28 & 2.377 & 3.1 & 1.000 & \\
\hline 26 & 10.18 & 2.377 & 3.1 & 0.998 & \\
\hline
\end{tabular}


Table 12 (Continued): Non-reactive Tracer Data NRT 3A

Data results for PFBA no-reactive transport, study NRT 3A; samples 27-50

\begin{tabular}{cccccc} 
Sample & $\begin{array}{c}\text { Pore } \\
\text { Volume } \\
(\mathrm{mL})\end{array}$ & $\begin{array}{c}\text { UV-Vis } \\
\text { Abs }\end{array}$ & $\begin{array}{c}\text { Dilution } \\
\text { C/Co }\end{array}$ & \\
\hline 27 & 10.39 & 2.377 & 3. & 0.999 & Elution \\
28 & 10.61 & 2.377 & 3.1 & 1.002 & \\
29 & 10.83 & 2.377 & 3.1 & 1.001 & \\
30 & 11.03 & 2.377 & 3.2 & 1.005 & \\
31 & 11.24 & 2.102 & 3.1 & 0.885 & \\
32 & 11.45 & 1.119 & 1.9 & 0.284 & \\
33 & 11.66 & 0.420 & 1.0 & 0.057 & \\
34 & 11.88 & 0.176 & 1.0 & 0.022 & \\
35 & 12.08 & 0.135 & 1.0 & 0.017 & \\
36 & 12.29 & 0.100 & 1.0 & 0.012 & \\
37 & 12.49 & 0.064 & 1.0 & 0.007 & \\
38 & 12.70 & 0.040 & 1.0 & 0.003 & \\
39 & 12.90 & 0.028 & 1.0 & 0.002 & LDL \\
40 & 13.18 & 0.012 & 1.0 & -0.001 & LDL \\
41 & 13.57 & 0.007 & 1.0 & -0.001 & LDL \\
42 & 14.03 & 0.007 & 1.0 & -0.001 & LDL \\
43 & 14.52 & 0.008 & 1.0 & -0.001 & LDL \\
44 & 14.12 & 0.001 & 1.0 & -0.002 & LDL \\
45 & 15.39 & 0.001 & 1.0 & -0.002 & LDL \\
46 & 16.37 & 0.001 & 1.0 & -0.002 & LDL \\
47 & 17.41 & 0.001 & 1.0 & -0.002 & LDL \\
48 & 18.48 & 0.002 & 1.0 & -0.002 & LDL \\
49 & 19.44 & 0.001 & 1.0 & -0.002 & LDL \\
50 & 20.33 & 0.002 & 1.0 & -0.002 & LDL
\end{tabular}


Table 13: Non-reactive Tracer Data - NRT 1B

Performed for Persulfate/TCE Remediation Studies

Column: A

Darcy Velocity: $0.39 \mathrm{~cm} / \mathrm{min}$

Tracer: 504.9 mg/L PFBA

Electrolyte: $0.01 \mathrm{~N} \mathrm{CaCl}_{2}$

Data results for PFBA non-reactive transport, study NRT 1B; samples 1-26

\begin{tabular}{|c|c|c|c|c|c|}
\hline Sample & $\begin{array}{c}\text { Pore } \\
\text { Volume } \\
\text { (mL) }\end{array}$ & $\begin{array}{c}\text { UV-Vis } \\
\text { Abs }\end{array}$ & Dilution & $\mathrm{C} / \mathrm{C}_{\mathrm{o}}$ & \\
\hline 1 & 0.00 & 0.004 & 1.0 & 0.000 & $\mathrm{LDL}$ \\
\hline 2 & 0.14 & 0.004 & 1.0 & 0.000 & LDL \\
\hline 3 & 0.38 & 0.001 & 1.0 & 0.000 & LDL \\
\hline 4 & 0.60 & 0.028 & 1.0 & 0.003 & \\
\hline 5 & 0.83 & 1.854 & 1.0 & 0.244 & \\
\hline 6 & 1.10 & 1.889 & 3.0 & 0.760 & \\
\hline 7 & 1.38 & 2.301 & 3.0 & 0.920 & \\
\hline 8 & 1.61 & 2.420 & 3.0 & 0.968 & \\
\hline 9 & 1.84 & 2.444 & 3.0 & 0.976 & \\
\hline 10 & 2.06 & 2.468 & 3.0 & 0.986 & \\
\hline 11 & 2.28 & 2.468 & 3.0 & 0.985 & \\
\hline 12 & 2.51 & 2.509 & 3.0 & 1.003 & \\
\hline 13 & 2.76 & 2.509 & 3.0 & 1.002 & \\
\hline 14 & 3.01 & 2.509 & 3.0 & 1.001 & \\
\hline 15 & 3.35 & 2.509 & 3.0 & 1.002 & \\
\hline 16 & 3.83 & 2.523 & 3.0 & 1.007 & \\
\hline 17 & 4.43 & 2.495 & 3.0 & 0.999 & \\
\hline 18 & 5.00 & 2.482 & 3.0 & 1.004 & \\
\hline 19 & 5.50 & 2.523 & 3.0 & 1.011 & \\
\hline 20 & 6.01 & 2.495 & 3.0 & 1.000 & \\
\hline 21 & 7.18 & 2.523 & 3.0 & 1.005 & \\
\hline 22 & 8.18 & 2.523 & 3.0 & 1.007 & \\
\hline 23 & 9.19 & 2.523 & 3.0 & 1.007 & \\
\hline 24 & 10.27 & 2.509 & 3.0 & 1.003 & \\
\hline 25 & 11.19 & 2.509 & 3.0 & 1.001 & \\
\hline 26 & 12.05 & 2.495 & 3.0 & 1.001 & \\
\hline
\end{tabular}


Table 13 (Continued): Non-reactive Tracer Data - NRT 1B

Data results for PFBA non-reactive transport, study NRT 1B; samples 27-54

\begin{tabular}{|c|c|c|c|c|c|}
\hline Sample & $\begin{array}{c}\text { Pore } \\
\text { Volume } \\
\text { (mL) }\end{array}$ & $\begin{array}{c}\text { UV-Vis } \\
\text { Abs }\end{array}$ & Dilution & $\mathrm{C} / \mathrm{C}_{\mathrm{o}}$ & \\
\hline 27 & 12.73 & 2.523 & 3.0 & 1.007 & \\
\hline 28 & 13.00 & 2.509 & 3.0 & 1.003 & Elution \\
\hline 29 & 13.21 & 2.495 & 3.0 & 0.998 & \\
\hline 30 & 13.43 & 2.495 & 3.0 & 0.996 & \\
\hline 31 & 13.69 & 2.523 & 3.0 & 1.008 & \\
\hline 32 & 13.96 & 1.857 & 3.0 & 0.739 & \\
\hline 33 & 14.20 & 1.896 & 1.0 & 0.249 & \\
\hline 34 & 14.43 & 0.653 & 1.0 & 0.083 & \\
\hline 35 & 14.65 & 0.229 & 1.0 & 0.026 & \\
\hline 36 & 14.89 & 0.109 & 1.0 & 0.012 & \\
\hline 37 & 15.14 & 0.069 & 1.0 & 0.008 & \\
\hline 38 & 15.38 & 0.054 & 1.0 & 0.006 & \\
\hline 39 & 15.62 & 0.051 & 1.0 & 0.006 & \\
\hline 40 & 15.91 & 0.042 & 1.0 & 0.004 & \\
\hline 41 & 16.29 & 0.036 & 1.0 & 0.004 & \\
\hline 42 & 16.71 & 0.029 & 1.0 & 0.003 & \\
\hline 43 & 17.17 & 0.026 & 1.0 & 0.003 & \\
\hline 44 & 17.63 & 0.024 & 1.0 & 0.002 & \\
\hline 45 & 18.14 & 0.025 & 1.0 & 0.003 & \\
\hline 46 & 18.70 & 0.022 & 1.0 & 0.002 & \\
\hline 47 & 19.82 & 0.013 & 1.0 & 0.001 & LDL \\
\hline 48 & 21.50 & 0.015 & 1.0 & 0.001 & LDL \\
\hline 49 & 22.24 & 0.015 & 1.0 & 0.001 & LDL \\
\hline 50 & 23.92 & 0.014 & 1.0 & 0.001 & LDL \\
\hline 51 & 24.97 & 0.013 & 1.0 & 0.001 & LDL \\
\hline 52 & 26.00 & 0.010 & 1.0 & 0.001 & LDL \\
\hline 53 & 27.31 & 0.007 & 1.0 & 0.000 & LDL \\
\hline 54 & 28.49 & 0.002 & 1.0 & 0.000 & LDL \\
\hline
\end{tabular}


Table 14: Persulfate Transport Data, $20^{\circ} \mathrm{C}$ Activation, Study: $20^{\circ} \mathrm{C}$ PS-1

Performed for Heat-activated Persulfate Transport Study

Column: A

Darcy Velocity: $0.38 \mathrm{~cm} / \mathrm{min}$

Concentration, $\mathrm{C}_{\mathrm{o}}: 2427.0 \mathrm{mg} / \mathrm{L} \mathrm{Na}_{2} \mathrm{~S}_{2} \mathrm{O}_{8}$

Electrolyte: $0.01 \mathrm{~N} \mathrm{CaCl}_{2}$

Data results for activated PS transport, $20^{\circ} \mathrm{C}$ PS-1; samples 1-29

\begin{tabular}{|c|c|c|c|c|c|}
\hline Sample & $\begin{array}{c}\text { Pore } \\
\text { Volume } \\
(\mathrm{mL})\end{array}$ & $\begin{array}{c}\text { UV-Vis } \\
\text { Abs (avg.) }\end{array}$ & Dilution & $C / C_{0}$ & \\
\hline 1 & -0.08 & 0.076 & 20.0 & 0.023 & \\
\hline 2 & 0.05 & 0.007 & 19.8 & 0.003 & LDL \\
\hline 3 & 0.18 & 0.002 & 19.9 & 0.001 & LDL \\
\hline 4 & 0.32 & 0.001 & 19.9 & 0.001 & LDL \\
\hline 5 & 0.46 & 0.002 & 61.9 & 0.005 & LDL \\
\hline 6 & 0.60 & 0.002 & 62.2 & 0.004 & LDL \\
\hline 7 & 0.73 & 0.012 & 61.6 & 0.014 & LDL \\
\hline 8 & 0.88 & 0.274 & 62.2 & 0.250 & \\
\hline 9 & 1.02 & 0.479 & 102.7 & 0.735 & \\
\hline 10 & 1.16 & 0.586 & 102.0 & 0.899 & \\
\hline 11 & 1.30 & 0.620 & 103.0 & 0.961 & \\
\hline 12 & 1.44 & 0.630 & 103.1 & 0.979 & \\
\hline 13 & 1.57 & 0.637 & 103.8 & 0.996 & \\
\hline 14 & 1.71 & 0.672 & 102.9 & 1.043 & \\
\hline 15 & 1.85 & 0.651 & 103.2 & 1.013 & \\
\hline 16 & 2.11 & 0.641 & 103.2 & 0.997 & \\
\hline 17 & 2.52 & 0.651 & 101.9 & 1.000 & \\
\hline 18 & 2.92 & 0.647 & 102.6 & 1.001 & \\
\hline 19 & 3.33 & 0.646 & 102.9 & 1.001 & \\
\hline 20 & 3.74 & 0.644 & 103.8 & 1.008 & \\
\hline 21 & 4.72 & 0.651 & 103.0 & 1.011 & \\
\hline 22 & 5.57 & 0.647 & 103.3 & 1.006 & \\
\hline 23 & 6.46 & 0.648 & 102.9 & 1.004 & \\
\hline 24 & 7.37 & 0.646 & 103.3 & 1.006 & \\
\hline 25 & 8.28 & 0.644 & 103.0 & 1.001 & \\
\hline 26 & 9.17 & 0.648 & 102.8 & 1.004 & \\
\hline 27 & 10.05 & 0.652 & 102.6 & 1.009 & \\
\hline 28 & 10.92 & 0.643 & 103.7 & 1.005 & \\
\hline \multirow[t]{2}{*}{29} & 11.77 & 0.655 & 103.2 & 1.019 & \\
\hline & & & 79 & & \\
\hline
\end{tabular}


Table 14 (Continued): Persulfate Transport Data, $20^{\circ} \mathrm{C}$ Activation, Study: $20^{\circ} \mathrm{C} \mathrm{PS}-1$

Data results for activated PS transport, $20^{\circ} \mathrm{C}$ PS-1; samples 30-55

\begin{tabular}{cccccc} 
Sample & $\begin{array}{c}\text { Pore } \\
\text { Volume } \\
(\mathrm{mL})\end{array}$ & $\begin{array}{c}\text { UV-Vis } \\
\text { Abs (avg.) }\end{array}$ & Dilution & C/Co & \\
\hline 30 & 12.63 & 0.656 & 103.5 & 1.023 & \\
31 & 12.83 & 0.634 & 103.8 & 0.992 & Elution \\
32 & 12.96 & 0.646 & 103.1 & 1.003 & \\
33 & 13.10 & 0.652 & 102.8 & 1.011 & \\
34 & 13.24 & 0.649 & 103.1 & 1.009 & \\
35 & 13.38 & 0.651 & 102.8 & 1.009 & \\
36 & 13.52 & 0.651 & 103.0 & 1.011 & \\
37 & 13.68 & 0.628 & 103.3 & 0.976 & \\
38 & 13.84 & 0.365 & 102.5 & 0.555 & \\
39 & 13.99 & 0.127 & 104.7 & 0.200 & \\
40 & 14.13 & 0.281 & 20.2 & 0.083 & \\
41 & 14.41 & 0.091 & 19.8 & 0.027 & \\
42 & 14.81 & 0.018 & 19.8 & 0.006 & LDL \\
43 & 15.21 & 0.008 & 19.8 & 0.003 & LDL \\
44 & 15.60 & 0.005 & 20.3 & 0.002 & LDL \\
45 & 16.01 & 0.002 & 19.9 & 0.001 & LDL \\
46 & 16.42 & 0.001 & 19.8 & 0.001 & LDL \\
47 & 17.40 & 0.001 & 19.8 & 0.001 & LDL \\
48 & 18.27 & -0.001 & 19.8 & 0.001 & LDL \\
49 & 19.13 & -0.001 & 6.7 & 0.000 & LDL \\
50 & 20.03 & -0.001 & 19.9 & 0.001 & LDL \\
51 & 20.88 & 0.000 & 19.8 & 0.001 & LDL \\
52 & 21.75 & -0.001 & 19.8 & 0.001 & LDL \\
53 & 22.61 & -0.002 & 19.9 & 0.000 & LDL \\
54 & 23.45 & 0.000 & 20.0 & 0.001 & LDL \\
55 & 24.38 & -0.001 & 19.9 & 0.001 & LDL
\end{tabular}


Table 15: Persulfate Transport Data, $20^{\circ} \mathrm{C}$ Activation, Study: $20^{\circ} \mathrm{C}$ PS-2

Performed for Heat-activated Persulfate Transport Study

Column: A

Darcy Velocity: $0.38 \mathrm{~cm} / \mathrm{min}$

Concentration, $\mathrm{C}_{\mathrm{o}}: 2410.6 \mathrm{mg} / \mathrm{L} \mathrm{Na}_{2} \mathrm{~S}_{2} \mathrm{O}_{8}$

Electrolyte: $0.01 \mathrm{~N} \mathrm{CaCl}_{2}$

Data results for activated PS transport, $20^{\circ} \mathrm{C}$ PS-2; samples 1-30

\begin{tabular}{|c|c|c|c|c|c|}
\hline Sample & $\begin{array}{c}\text { Pore } \\
\text { Volume } \\
(\mathrm{mL})\end{array}$ & $\begin{array}{c}\text { UV-Vis } \\
\text { Abs (avg.) }\end{array}$ & Dilution & $\mathrm{C} / \mathrm{C}_{\mathrm{o}}$ & \\
\hline 1 & 0.00 & 0.000 & 20.3 & -0.001 & LDL \\
\hline 2 & 0.05 & 0.001 & 20.1 & 0.000 & LDL \\
\hline 3 & 0.21 & 0.001 & 20.3 & 0.000 & LDL \\
\hline 4 & 0.39 & 0.001 & 20.3 & 0.000 & LDL \\
\hline 5 & 0.57 & 0.001 & 20.2 & 0.000 & LDL \\
\hline 6 & 0.72 & 0.002 & 20.2 & 0.000 & LDL \\
\hline 7 & 0.86 & 0.161 & 20.1 & 0.048 & \\
\hline 8 & 0.99 & 0.200 & 100.9 & 0.299 & \\
\hline 9 & 1.14 & 0.427 & 102.5 & 0.649 & \\
\hline 10 & 1.28 & 0.559 & 101.7 & 0.851 & \\
\hline 11 & 1.42 & 0.616 & 101.0 & 0.934 & \\
\hline 12 & 1.56 & 0.629 & 102.3 & 0.968 & \\
\hline 13 & 1.69 & 0.639 & 102.2 & 0.982 & \\
\hline 14 & 1.82 & 0.636 & 103.2 & 0.987 & \\
\hline 15 & 1.96 & 0.643 & 102.7 & 0.992 & \\
\hline 16 & 2.25 & 0.636 & 103.4 & 0.989 & \\
\hline 17 & 2.63 & 0.650 & 101.8 & 0.995 & \\
\hline 18 & 3.00 & 0.645 & 102.4 & 0.993 & \\
\hline 19 & 3.38 & 0.646 & 102.1 & 0.992 & \\
\hline 20 & 3.76 & 0.636 & 104.1 & 0.996 & \\
\hline 21 & 4.19 & 0.645 & 102.7 & 0.996 & \\
\hline 22 & 4.63 & 0.643 & 103.2 & 0.997 & \\
\hline 23 & 4.95 & 0.643 & 102.9 & 0.996 & \\
\hline 24 & 5.85 & 0.637 & 104.0 & 0.996 & \\
\hline 25 & 6.75 & 0.645 & 103.1 & 1.000 & \\
\hline 26 & 7.64 & 0.639 & 103.7 & 0.997 & \\
\hline 27 & 8.57 & 0.648 & 102.3 & 0.997 & \\
\hline 28 & 9.46 & 0.650 & 102.2 & 0.999 & \\
\hline 29 & 10.30 & 0.650 & 102.2 & 0.999 & \\
\hline \multirow[t]{2}{*}{30} & 11.16 & 0.645 & 102.7 & 0.996 & \\
\hline & & & 81 & & \\
\hline
\end{tabular}


Table 15 (Continued): Persulfate Transport Data, $20^{\circ} \mathrm{C}$ Activation, Study: $20^{\circ} \mathrm{C}$ PS-2

Data results for activated PS transport, $20^{\circ} \mathrm{C}$ PS-2; samples $31-57$

\begin{tabular}{|c|c|c|c|c|c|}
\hline Sample & $\begin{array}{c}\text { Pore } \\
\text { Volume } \\
\text { (mL) }\end{array}$ & $\begin{array}{c}\text { UV-Vis } \\
\text { Abs (avg.) }\end{array}$ & Dilution & $\mathrm{C} / \mathrm{C}_{\mathrm{o}}$ & \\
\hline 31 & 11.35 & 0.644 & 102.2 & 0.989 & Elution \\
\hline 32 & 11.49 & 0.658 & 101.4 & 1.005 & \\
\hline 33 & 11.62 & 0.657 & 101.8 & 1.006 & \\
\hline 34 & 11.76 & 0.658 & 101.8 & 1.008 & \\
\hline 35 & 11.90 & 0.651 & 102.7 & 1.005 & \\
\hline 36 & 12.03 & 0.661 & 101.1 & 1.005 & \\
\hline 37 & 12.17 & 0.658 & 101.3 & 1.003 & \\
\hline 38 & 12.31 & 0.603 & 101.9 & 0.922 & \\
\hline 39 & 12.46 & 0.377 & 102.6 & 0.569 & \\
\hline 40 & 12.60 & 0.845 & 20.2 & 0.258 & \\
\hline 41 & 12.74 & 0.379 & 20.2 & 0.113 & \\
\hline 42 & 12.88 & 0.184 & 20.2 & 0.055 & \\
\hline 43 & 13.01 & 0.094 & 20.2 & 0.028 & \\
\hline 44 & 13.14 & 0.048 & 20.1 & 0.014 & \\
\hline 45 & 13.35 & 0.015 & 20.1 & 0.004 & LDL \\
\hline 46 & 13.80 & 0.014 & 20.2 & 0.003 & LDL \\
\hline 47 & 14.32 & 0.004 & 20.2 & 0.001 & LDL \\
\hline 48 & 14.72 & 0.003 & 20.2 & 0.000 & LDL \\
\hline 49 & 15.11 & 0.002 & 20.2 & 0.000 & LDL \\
\hline 50 & 15.40 & 0.001 & 20.2 & 0.000 & LDL \\
\hline 51 & 16.39 & 0.000 & 20.2 & -0.001 & LDL \\
\hline 52 & 17.42 & 0.000 & 20.1 & -0.001 & LDL \\
\hline 53 & 18.26 & 0.000 & 20.1 & -0.001 & LDL \\
\hline 54 & 19.09 & 0.000 & 20.1 & -0.001 & LDL \\
\hline 55 & 19.97 & -0.001 & 20.3 & -0.001 & LDL \\
\hline 56 & 20.96 & 0.000 & 20.4 & -0.001 & LDL \\
\hline 57 & 21.85 & -0.001 & 20.4 & -0.001 & LDL \\
\hline
\end{tabular}


Table 16: Persulfate Transport Data, $60^{\circ} \mathrm{C}$ Activation, Study: $60^{\circ} \mathrm{C} \mathrm{PS-1}$

Performed for Heat-activated Persulfate Transport Study

Column: A

Darcy Velocity: $0.38 \mathrm{~cm} / \mathrm{min}$

Concentration, $\mathrm{C}_{\mathrm{o}}: 2357.6 \mathrm{mg} / \mathrm{L} \mathrm{Na}_{2} \mathrm{~S}_{2} \mathrm{O}_{8}$

Electrolyte: $0.01 \mathrm{~N} \mathrm{CaCl}_{2}$

Data results for activated PS transport, $60^{\circ} \mathrm{C}$ PS-1; samples E-1 - 19

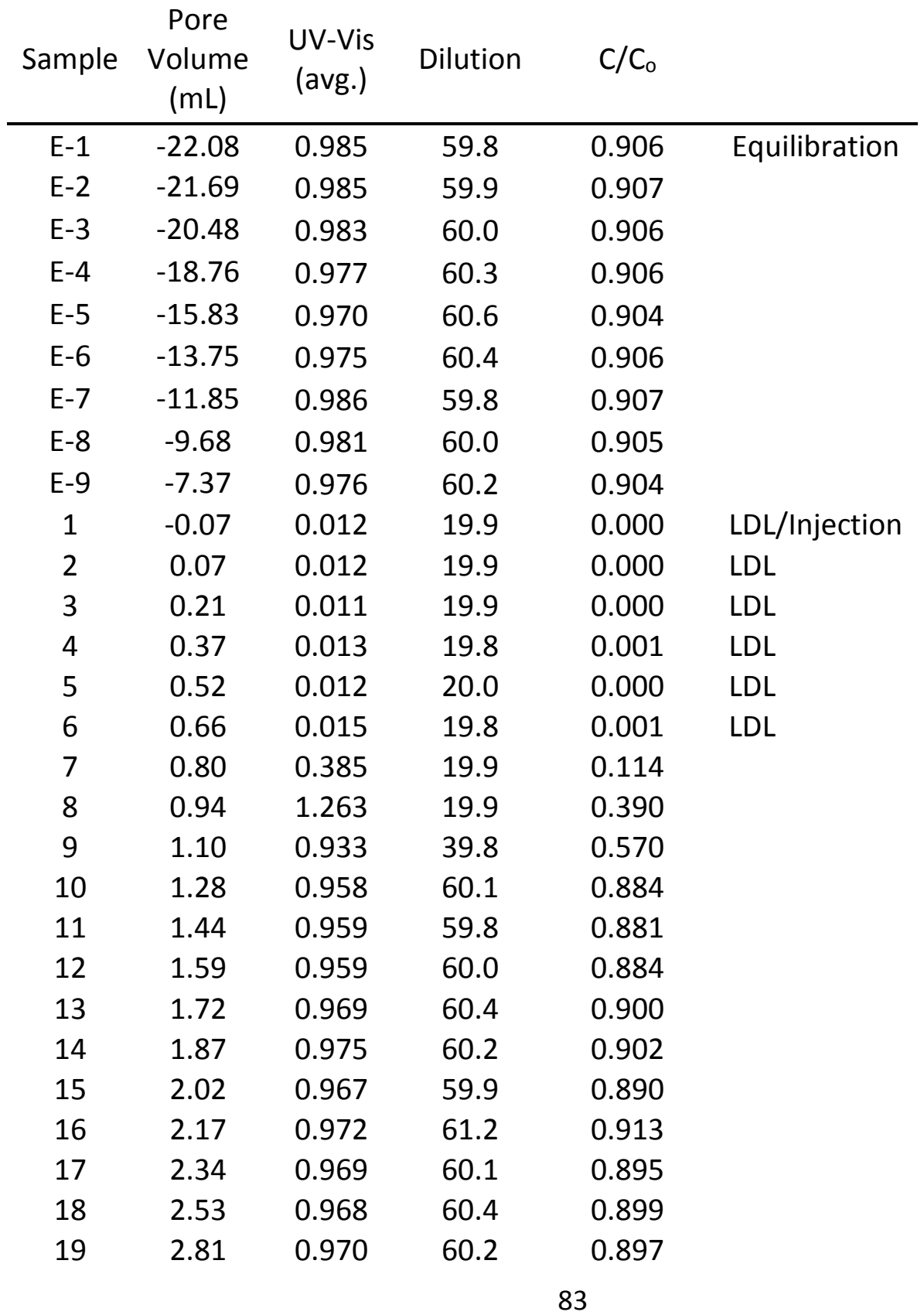


Table 16 (Continued): Persulfate Transport Data, $60^{\circ} \mathrm{C}$ Activation, Study: $60^{\circ} \mathrm{C}$ PS-1

Data results for activated PS transport, $60^{\circ} \mathrm{C}$ PS-1; samples $20-53$

\begin{tabular}{|c|c|c|c|c|c|}
\hline Sample & $\begin{array}{c}\text { Pore } \\
\text { Volume } \\
\text { (mL) }\end{array}$ & $\begin{array}{l}\text { UV-Vis } \\
\text { (avg.) }\end{array}$ & Dilution & $\mathrm{C} / \mathrm{C}_{\mathrm{o}}$ & \\
\hline 20 & 3.19 & 0.969 & 60.3 & 0.897 & \\
\hline 21 & 3.59 & 0.968 & 60.4 & 0.898 & \\
\hline 22 & 3.99 & 0.964 & 60.2 & 0.892 & \\
\hline 23 & 4.40 & 0.964 & 60.6 & 0.897 & \\
\hline 24 & 4.83 & 0.964 & 60.6 & 0.898 & \\
\hline 25 & 5.79 & 0.968 & 60.3 & 0.896 & \\
\hline 26 & 6.71 & 0.970 & 60.1 & 0.895 & \\
\hline 27 & 8.03 & 0.969 & 60.0 & 0.894 & \\
\hline 28 & 9.26 & 0.969 & 59.8 & 0.891 & \\
\hline 29 & 10.57 & 0.974 & 60.0 & 0.897 & \\
\hline 30 & 12.93 & 0.961 & 60.4 & 0.892 & \\
\hline 31 & 14.40 & 0.959 & 61.0 & 0.899 & \\
\hline 32 & 14.63 & 0.947 & 61.5 & 0.895 & Elution \\
\hline 33 & 14.85 & 0.961 & 60.7 & 0.896 & \\
\hline 34 & 15.08 & 0.966 & 60.4 & 0.896 & \\
\hline 35 & 15.27 & 0.976 & 60.0 & 0.901 & \\
\hline 36 & 15.39 & 1.407 & 40.0 & 0.875 & \\
\hline 37 & 15.58 & 1.044 & 39.8 & 0.641 & \\
\hline 38 & 15.70 & 0.688 & 19.9 & 0.207 & \\
\hline 39 & 15.85 & 0.261 & 20.0 & 0.077 & \\
\hline 40 & 16.03 & 0.133 & 19.9 & 0.038 & \\
\hline 41 & 16.15 & 0.089 & 20.0 & 0.024 & \\
\hline 42 & 16.33 & 0.063 & 19.9 & 0.016 & \\
\hline 43 & 16.47 & 0.040 & 19.9 & 0.009 & \\
\hline 44 & 16.62 & 0.028 & 20.4 & 0.005 & LDL \\
\hline 45 & 16.78 & 0.024 & 19.9 & 0.004 & LDL \\
\hline 46 & 16.96 & 0.022 & 20.0 & 0.003 & LDL \\
\hline 47 & 17.30 & 0.018 & 19.8 & 0.002 & LDL \\
\hline 48 & 17.77 & 0.016 & 19.9 & 0.002 & LDL \\
\hline 49 & 18.25 & 0.017 & 20.0 & 0.002 & LDL \\
\hline 50 & 18.65 & 0.017 & 19.9 & 0.002 & LDL \\
\hline 51 & 19.00 & 0.015 & 20.0 & 0.001 & LDL \\
\hline 52 & 19.56 & 0.016 & 20.0 & 0.002 & LDL \\
\hline 53 & 20.02 & 0.015 & 20.0 & 0.001 & LDL \\
\hline
\end{tabular}


Table 16 (Continued): Persulfate Transport Data, $60^{\circ} \mathrm{C}$ Activation, Study: $60^{\circ} \mathrm{C}$ PS-1

Data results for activated PS transport, $60^{\circ} \mathrm{C}$ PS-1; samples $54-57$

\begin{tabular}{cccccc} 
Sample & $\begin{array}{c}\text { Pore } \\
\text { Volume } \\
(\mathrm{mL})\end{array}$ & $\begin{array}{c}\text { UV-Vis } \\
\text { (avg.) }\end{array}$ & Dilution & $\mathrm{C} / \mathrm{C}_{\mathrm{o}}$ & \\
\hline 54 & 20.37 & 0.014 & 20.1 & 0.001 & $\mathrm{LDL}$ \\
55 & 21.23 & 0.013 & 19.8 & 0.001 & $\mathrm{LDL}$ \\
56 & 22.08 & 0.013 & 20.0 & 0.001 & $\mathrm{LDL}$ \\
57 & 23.07 & 0.013 & 19.9 & 0.001 & $\mathrm{LDL}$
\end{tabular}


Table 17: Persulfate Transport Data, $60^{\circ} \mathrm{C}$ Activation, Study: $60^{\circ} \mathrm{C} \mathrm{PS-2}$

Performed for Heat-activated Persulfate Transport Study

Column: A

Darcy Velocity: $0.38 \mathrm{~cm} / \mathrm{min}$

Concentration, $\mathrm{C}_{\mathrm{o}}: 2330.9 \mathrm{mg} / \mathrm{L} \mathrm{Na}_{2} \mathrm{~S}_{2} \mathrm{O}_{8}$

Electrolyte: $0.01 \mathrm{~N} \mathrm{CaCl}_{2}$

Data results for activated PS transport, $60^{\circ} \mathrm{C}$ PS-2; samples E-1 - 12

\begin{tabular}{|c|c|c|c|c|c|}
\hline Sample & $\begin{array}{c}\text { Pore } \\
\text { Volume } \\
\text { (mL) }\end{array}$ & $\begin{array}{c}\text { UV- } \\
\text { Vis } \\
\text { (avg.) }\end{array}$ & Dilution & $\mathrm{C} / \mathrm{Co}$ & \\
\hline E-1 & -27.10 & 0.979 & 60.6 & 0.910 & Equilibration \\
\hline$E-2$ & -25.32 & 0.885 & 67.2 & 0.909 & \\
\hline$E-3$ & -23.25 & 0.982 & 60.3 & 0.908 & \\
\hline$E-4$ & -21.31 & 0.970 & 61.1 & 0.908 & \\
\hline$E-5$ & -20.66 & 0.995 & 59.5 & 0.908 & \\
\hline$E-6$ & -18.02 & 0.974 & 60.7 & 0.907 & \\
\hline$E-7$ & -14.29 & 0.971 & 60.8 & 0.904 & \\
\hline$E-8$ & -10.65 & 0.975 & 60.6 & 0.906 & \\
\hline E-9 & -8.62 & 0.960 & 61.5 & 0.904 & \\
\hline$E-10$ & -6.78 & 0.964 & 61.2 & 0.903 & \\
\hline $\mathrm{E}-11$ & -5.37 & 0.967 & 61.0 & 0.903 & \\
\hline $\mathrm{E}-12$ & -3.71 & 0.966 & 60.8 & 0.901 & \\
\hline$E-13$ & -1.76 & 0.968 & 60.7 & 0.900 & \\
\hline$E-14$ & -0.23 & 0.970 & 60.7 & 0.902 & \\
\hline$E-15$ & 0.15 & 0.965 & 60.8 & 0.900 & \\
\hline 1 & -0.07 & 0.012 & 20.2 & 0.000 & LDL \\
\hline 2 & 0.07 & 0.012 & 20.2 & 0.000 & LDL \\
\hline 3 & 0.20 & 0.013 & 20.0 & 0.000 & LDL \\
\hline 4 & 0.35 & 0.013 & 20.2 & 0.000 & LDL \\
\hline 5 & 0.50 & 0.011 & 20.2 & 0.000 & LDL \\
\hline 6 & 0.63 & 0.013 & 20.1 & 0.000 & LDL \\
\hline 7 & 0.76 & 0.057 & 19.9 & 0.014 & \\
\hline 8 & 0.90 & 0.462 & 40.2 & 0.273 & \\
\hline 9 & 1.05 & 1.150 & 40.5 & 0.718 & \\
\hline 10 & 1.22 & 0.922 & 60.1 & 0.849 & \\
\hline 11 & 1.40 & 0.946 & 60.5 & 0.876 & \\
\hline 12 & 1.54 & 0.951 & 60.4 & 0.880 & \\
\hline
\end{tabular}


Table 17 (Continued): Persulfate Transport Data, $60^{\circ} \mathrm{C}$ Activation, Study: $60^{\circ} \mathrm{C}$ PS-2

Data results for activated PS transport, $60^{\circ} \mathrm{C}$ PS-2; samples $13-46$

\begin{tabular}{|c|c|c|c|c|c|}
\hline Sample & $\begin{array}{c}\text { Pore } \\
\text { Volume } \\
(\mathrm{mL})\end{array}$ & $\begin{array}{c}\text { UV- } \\
\text { Vis } \\
\text { (avg.) }\end{array}$ & Dilution & $\mathrm{C} / \mathrm{Co}$ & \\
\hline 13 & 1.71 & 0.945 & 60.7 & 0.878 & \\
\hline 14 & 1.90 & 0.949 & 60.6 & 0.881 & \\
\hline 15 & 2.08 & 0.954 & 60.5 & 0.884 & \\
\hline 16 & 2.29 & 0.965 & 60.0 & 0.887 & \\
\hline 17 & 2.50 & 0.970 & 59.8 & 0.890 & \\
\hline 18 & 2.72 & 0.961 & 60.4 & 0.889 & \\
\hline 19 & 3.06 & 0.960 & 60.4 & 0.888 & \\
\hline 20 & 3.46 & 0.967 & 60.2 & 0.893 & \\
\hline 21 & 3.85 & 0.954 & 61.0 & 0.891 & \\
\hline 22 & 4.25 & 0.966 & 60.2 & 0.891 & \\
\hline 23 & 4.66 & 0.966 & 60.2 & 0.892 & \\
\hline 24 & 5.08 & 0.959 & 60.5 & 0.888 & \\
\hline 25 & 5.50 & 0.961 & 60.4 & 0.890 & \\
\hline 26 & 6.51 & 0.955 & 60.9 & 0.891 & \\
\hline 27 & 7.59 & 0.957 & 60.7 & 0.889 & \\
\hline 28 & 8.45 & 0.968 & 59.9 & 0.889 & \\
\hline 29 & 9.44 & 0.963 & 60.2 & 0.889 & \\
\hline 30 & 10.39 & 0.956 & 60.6 & 0.889 & \\
\hline 31 & 10.57 & 0.960 & 60.4 & 0.082 & Elution \\
\hline 32 & 10.71 & 0.959 & 60.5 & 0.889 & \\
\hline 33 & 10.86 & 0.957 & 60.8 & 0.892 & \\
\hline 34 & 11.04 & 0.971 & 59.8 & 0.890 & \\
\hline 35 & 11.23 & 0.964 & 60.4 & 0.892 & \\
\hline 36 & 11.39 & 0.955 & 60.6 & 0.888 & \\
\hline 37 & 11.54 & 1.043 & 51.5 & 0.826 & \\
\hline 38 & 11.72 & 1.395 & 20.0 & 0.433 & \\
\hline 39 & 11.89 & 0.507 & 20.0 & 0.150 & \\
\hline 40 & 12.04 & 0.211 & 20.0 & 0.061 & \\
\hline 41 & 12.21 & 0.105 & 20.0 & 0.029 & \\
\hline 42 & 12.40 & 0.077 & 20.0 & 0.020 & \\
\hline 43 & 12.56 & 0.056 & 19.9 & 0.014 & \\
\hline 44 & 12.70 & 0.046 & 20.0 & 0.011 & \\
\hline 45 & 12.86 & 0.035 & 20.0 & 0.007 & LDL \\
\hline 46 & 13.14 & 0.024 & 19.9 & 0.004 & LDL \\
\hline
\end{tabular}


Table 17 (Continued): Persulfate Transport Data, $60^{\circ} \mathrm{C}$ Activation, Study: $60^{\circ} \mathrm{C}$ PS-2

Data results for activated PS transport, $60^{\circ} \mathrm{C}$ PS-2; samples 47-57

\begin{tabular}{cccccl} 
Pore & $\begin{array}{c}\text { Polume } \\
\text { Vam1ple }\end{array}$ & $\begin{array}{c}\text { UV-Vis } \\
\text { (mL) }\end{array}$ & $\begin{array}{cccc}\text { (avg.) } \\
\text { Dilution }\end{array}$ & C/Co & \\
\hline 47 & 13.55 & 0.021 & 20.1 & 0.003 & LDL \\
48 & 14.00 & 0.017 & 20.0 & 0.002 & LDL \\
49 & 14.43 & 0.018 & 20.1 & 0.002 & LDL \\
50 & 14.85 & 0.017 & 20.0 & 0.002 & LDL \\
51 & 16.05 & 0.017 & 20.0 & 0.002 & LDL \\
52 & 17.01 & 0.017 & 19.8 & 0.002 & LDL \\
53 & 17.92 & 0.017 & 20.0 & 0.002 & LDL \\
54 & 18.97 & 0.017 & 19.9 & 0.002 & LDL \\
55 & 19.87 & 0.016 & 20.0 & 0.001 & LDL \\
56 & 20.74 & 0.015 & 20.1 & 0.001 & LDL \\
57 & 21.81 & 0.014 & 19.9 & 0.001 & LDL
\end{tabular}


Table 18: Persulfate Transport Data, $60^{\circ} \mathrm{C}$ Activation, Study: $60^{\circ} \mathrm{C} \mathrm{PS-3}$

Performed for Heat-activated Persulfate Transport Study, Sulfate Species Mass Balance Column: A

Darcy Velocity: $0.38 \mathrm{~cm} / \mathrm{min}$

Concentration, $\mathrm{C}_{\mathrm{o}}: 2320.4 \mathrm{mg} / \mathrm{L} \mathrm{Na}_{2} \mathrm{~S}_{2} \mathrm{O}_{8}$

Electrolyte: $0.01 \mathrm{~N} \mathrm{CaCl}_{2}$

Data results for activated PS transport, $60^{\circ} \mathrm{C}$ PS-3; samples E-1 - 16

\begin{tabular}{|c|c|c|c|c|c|c|}
\hline Sample & $\begin{array}{l}\text { Pore Volume } \\
\qquad(\mathrm{mL})\end{array}$ & $\begin{array}{c}\text { UV-Vis } \\
\text { (avg., PS) }\end{array}$ & $\begin{array}{l}\text { Dilution } \\
\text { (PS) }\end{array}$ & $\mathrm{C} / \mathrm{C}_{\mathrm{o}}(\mathrm{PS})$ & $\begin{array}{l}\mathrm{C} / \mathrm{C}_{0} \\
(\mathrm{SO} 4)\end{array}$ & \\
\hline$E-1$ & -18.98 & 0.980 & 0.0 & 0.925 & & Equilibr. \\
\hline$E-2$ & -17.78 & 0.956 & 0.0 & 0.902 & & \\
\hline$E-3$ & -16.10 & 0.963 & 0.0 & 0.919 & & \\
\hline$E-4$ & -14.70 & 0.970 & 0.0 & 0.919 & & \\
\hline$E-5$ & -12.62 & 0.962 & 0.0 & 0.919 & & \\
\hline$E-6$ & -11.41 & 0.969 & 0.0 & 0.921 & & \\
\hline$E-7$ & -9.90 & 0.963 & 0.0 & 0.919 & & \\
\hline$E-8$ & -7.63 & 0.962 & 0.0 & 0.918 & 0.126 & \\
\hline$E-9$ & -6.47 & 0.957 & 0.0 & 0.908 & 0.120 & \\
\hline$E-10$ & -4.15 & 0.969 & 0.0 & 0.916 & 0.139 & \\
\hline E-11 & -2.54 & 0.968 & 0.0 & 0.918 & 0.136 & \\
\hline $\mathrm{E}-12$ & -0.73 & 0.966 & 0.0 & 0.922 & 0.135 & \\
\hline E-13 & -0.29 & 0.978 & 0.0 & 0.927 & 0.141 & \\
\hline 1 & 0.00 & 0.017 & 20.0 & 0.003 & 0.010 & LDL/Inj. \\
\hline 2 & 0.12 & 0.026 & 20.0 & 0.006 & 0.010 & LDL \\
\hline 3 & 0.31 & 0.011 & 20.0 & 0.001 & 0.008 & LDL \\
\hline 4 & 0.49 & 0.011 & 20.0 & 0.001 & 0.016 & LDL \\
\hline 5 & 0.67 & 0.020 & 60.6 & 0.011 & 0.007 & LDL \\
\hline 6 & 0.87 & 0.110 & 60.5 & 0.096 & 0.032 & \\
\hline 7 & 1.06 & 0.821 & 59.7 & 0.769 & 0.090 & \\
\hline 8 & 1.25 & 0.934 & 60.3 & 0.889 & 0.110 & \\
\hline 9 & 1.43 & 0.969 & 60.0 & 0.919 & 0.122 & \\
\hline 10 & 1.61 & 1.010 & 57.0 & 0.912 & 0.128 & \\
\hline 11 & 1.83 & 0.954 & 60.1 & 0.906 & 0.106 & \\
\hline 12 & 2.08 & 0.962 & 60.3 & 0.917 & 0.124 & \\
\hline 13 & 2.30 & 0.962 & 59.8 & 0.909 & 0.123 & \\
\hline 14 & 2.49 & 0.913 & 60.0 & 0.865 & 0.121 & \\
\hline 15 & 2.71 & 0.955 & 63.1 & 0.951 & 0.119 & \\
\hline 16 & 2.93 & 0.967 & 60.1 & 0.918 & 0.119 & \\
\hline
\end{tabular}


Table 18 (Continued): Persulfate Transport Data, $60^{\circ} \mathrm{C}$ Activation, Study: $60^{\circ} \mathrm{C}$ PS-3

Data results for activated PS transport, $60^{\circ} \mathrm{C}$ PS-3; samples $17-53$

\begin{tabular}{|c|c|c|c|c|c|c|}
\hline Sample & $\begin{array}{l}\text { Pore Volume } \\
(\mathrm{mL})\end{array}$ & $\begin{array}{c}\text { UV-Vis Abs } \\
\text { (avg.) }\end{array}$ & Dilution & $\mathrm{C} / \mathrm{C}_{\mathrm{o}}(\mathrm{PS})$ & $\begin{array}{l}\mathrm{C} / \mathrm{C}_{\mathrm{o}} \\
(\mathrm{SO} 4)\end{array}$ & \\
\hline 17 & 3.12 & 0.966 & 59.8 & 0.913 & 0.122 & \\
\hline 18 & 3.35 & 0.961 & 60.1 & 0.913 & 0.129 & \\
\hline 19 & 3.68 & 0.962 & 60.0 & 0.912 & 0.138 & \\
\hline 20 & 4.03 & 0.955 & 60.5 & 0.911 & 0.128 & \\
\hline 21 & 4.39 & 0.961 & 60.2 & 0.914 & 0.138 & \\
\hline 22 & 4.76 & 0.965 & 60.1 & 0.917 & 0.134 & \\
\hline 23 & 5.14 & 0.962 & 60.0 & 0.912 & 0.139 & \\
\hline 24 & 6.13 & 0.955 & 60.3 & 0.909 & 0.129 & \\
\hline 25 & 7.14 & 0.951 & 61.1 & 0.917 & 0.133 & \\
\hline 26 & 8.30 & 0.963 & 60.3 & 0.917 & 0.139 & \\
\hline 27 & 9.20 & 0.972 & 59.9 & 0.920 & 0.135 & \\
\hline 28 & 10.25 & 0.965 & 59.8 & 0.912 & 0.134 & \\
\hline 29 & 10.60 & 0.959 & 60.3 & 0.141 & 0.140 & Elution \\
\hline 30 & 10.88 & 0.944 & 61.5 & 0.420 & 0.134 & \\
\hline 31 & 11.12 & 0.953 & 60.5 & 0.662 & 0.137 & \\
\hline 32 & 11.33 & 0.960 & 60.3 & 0.915 & 0.140 & \\
\hline 33 & 11.53 & 1.177 & 40.1 & 0.751 & 0.115 & \\
\hline 34 & 11.72 & 0.310 & 39.9 & 0.186 & 0.055 & \\
\hline 35 & 11.92 & 0.201 & 19.9 & 0.060 & 0.023 & \\
\hline 36 & 12.12 & 0.076 & 19.9 & 0.021 & 0.029 & \\
\hline 37 & 12.30 & 0.058 & 20.0 & 0.016 & 0.026 & \\
\hline 38 & 12.50 & 0.047 & 20.1 & 0.012 & 0.014 & \\
\hline 39 & 12.74 & 0.035 & 20.0 & 0.008 & 0.016 & LDL \\
\hline 40 & 12.95 & 0.023 & 20.0 & 0.005 & 0.018 & LDL \\
\hline 41 & 13.16 & 0.021 & 20.0 & 0.004 & 0.018 & LDL \\
\hline 42 & 13.36 & 0.015 & 20.0 & 0.002 & & LDL \\
\hline 43 & 13.55 & 0.016 & 19.9 & 0.002 & 0.022 & LDL \\
\hline 44 & 13.74 & 0.016 & 19.9 & 0.002 & & LDL \\
\hline 45 & 14.02 & 0.014 & 19.9 & 0.002 & & LDL \\
\hline 46 & 14.41 & 0.013 & 20.0 & 0.002 & 0.008 & LDL \\
\hline 47 & 14.78 & 0.013 & 19.9 & 0.002 & & LDL \\
\hline 48 & 15.15 & 0.012 & 20.1 & 0.001 & & LDL \\
\hline 49 & 15.97 & 0.012 & 20.0 & 0.001 & 0.016 & LDL \\
\hline 50 & 16.78 & 0.014 & 20.0 & 0.002 & & LDL \\
\hline 51 & 17.62 & 0.013 & 20.0 & 0.002 & & LDL \\
\hline 52 & 18.47 & 0.012 & 19.9 & 0.001 & 0.010 & LDL \\
\hline 53 & 19.41 & 0.012 & 19.9 & 0.001 & & LDL \\
\hline
\end{tabular}


Table 19: Persulfate Transport Data, $60^{\circ} \mathrm{C}$ Activation, Study: $90^{\circ} \mathrm{C} \mathrm{PS-1}$

Performed for Heat-activated Persulfate Transport Study

Column: A

Darcy Velocity: $0.38 \mathrm{~cm} / \mathrm{min}$

Concentration, $\mathrm{C}_{0}: 2479.9 \mathrm{mg} / \mathrm{L} \mathrm{Na}_{2} \mathrm{~S}_{2} \mathrm{O}_{8}$

Electrolyte: $0.01 \mathrm{~N} \mathrm{CaCl}_{2}$

Data results for activated PS transport, $90^{\circ} \mathrm{C}$ PS-1; samples E-2 - 18

\begin{tabular}{|c|c|c|c|c|c|}
\hline Sample & $\begin{array}{c}\text { Pore } \\
\text { Volume } \\
\text { (mL) }\end{array}$ & $\begin{array}{c}\text { UV-Vis Abs } \\
\text { (avg.) }\end{array}$ & Dilution & $\mathrm{C} / \mathrm{C}_{\mathrm{o}}$ & \\
\hline$E-2$ & -14.24 & 0.299 & 19.9 & 0.085 & \\
\hline$E-3$ & -12.60 & 0.297 & 19.9 & 0.084 & \\
\hline$E-4$ & -10.69 & 0.295 & 21.2 & 0.089 & \\
\hline$E-5$ & -8.44 & 0.294 & 19.9 & 0.084 & \\
\hline E-6 & -6.99 & 0.296 & 19.9 & 0.084 & \\
\hline$E-7$ & -5.69 & 0.299 & 19.8 & 0.084 & \\
\hline$E-8$ & -4.16 & 0.305 & 19.8 & 0.086 & \\
\hline E-9 & -2.65 & 0.295 & 19.9 & 0.084 & \\
\hline E-10 & -0.81 & 0.295 & 19.9 & 0.084 & \\
\hline 1 & -0.71 & 0.012 & 19.8 & 0.000 & LDL \\
\hline 2 & -0.52 & 0.010 & 20.2 & 0.000 & LDL \\
\hline 3 & -0.33 & 0.011 & 19.9 & 0.000 & LDL \\
\hline 4 & -0.14 & 0.014 & 20.0 & 0.001 & $\mathrm{LDL}$ \\
\hline 5 & 0.07 & 0.010 & 20.0 & 0.000 & $\mathrm{LDL}$ \\
\hline 6 & 0.26 & 0.010 & 19.9 & 0.000 & $\mathrm{LDL}$ \\
\hline 7 & 0.43 & 0.011 & 19.9 & 0.000 & LDL \\
\hline 8 & 0.61 & 0.013 & 20.0 & 0.001 & $\mathrm{LDL}$ \\
\hline 9 & 0.80 & 0.070 & 19.9 & 0.018 & \\
\hline 10 & 1.00 & 0.196 & 19.9 & 0.056 & \\
\hline 11 & 1.18 & 0.258 & 19.9 & 0.074 & \\
\hline 12 & 1.35 & 0.272 & 19.9 & 0.078 & \\
\hline 13 & 1.52 & 0.279 & 19.8 & 0.079 & \\
\hline 14 & 1.69 & 0.282 & 19.9 & 0.080 & \\
\hline 15 & 1.88 & 0.285 & 19.9 & 0.081 & \\
\hline 16 & 2.07 & 0.286 & 19.9 & 0.081 & \\
\hline 17 & 2.25 & 0.288 & 19.9 & 0.081 & \\
\hline \multirow[t]{2}{*}{18} & 2.42 & 0.287 & 19.9 & 0.081 & \\
\hline & & & 91 & & \\
\hline
\end{tabular}


Table 19 (Continued): Persulfate Transport Data, $90^{\circ} \mathrm{C}$ Activation, Study: $90^{\circ} \mathrm{C}$ PS-1

Data results for activated PS transport, $90^{\circ} \mathrm{C}$ PS-1; samples $19-52$

\begin{tabular}{|c|c|c|c|c|c|}
\hline Sample & $\begin{array}{c}\text { Pore } \\
\text { Volume } \\
\text { (mL) }\end{array}$ & $\begin{array}{c}\text { UV-Vis Abs } \\
\text { (avg.) }\end{array}$ & Dilution & $\mathrm{C} / \mathrm{C}_{0}$ & \\
\hline 19 & 2.58 & 0.290 & 19.9 & 0.082 & \\
\hline 20 & 2.76 & 0.290 & 19.8 & 0.082 & \\
\hline 21 & 2.95 & 0.288 & 20.0 & 0.082 & \\
\hline 22 & 3.23 & 0.288 & 19.9 & 0.082 & \\
\hline 23 & 3.64 & 0.289 & 19.9 & 0.082 & \\
\hline 24 & 4.05 & 0.289 & 19.9 & 0.082 & \\
\hline 25 & 4.49 & 0.291 & 19.9 & 0.082 & \\
\hline 26 & 4.93 & 0.289 & 20.0 & 0.082 & \\
\hline 27 & 5.35 & 0.290 & 19.9 & 0.082 & \\
\hline 28 & 5.68 & 0.292 & 19.9 & 0.082 & \\
\hline 29 & 6.57 & 0.288 & 19.9 & 0.081 & \\
\hline 30 & 7.54 & 0.291 & 19.9 & 0.082 & \\
\hline 31 & 8.44 & 0.291 & 19.9 & 0.082 & \\
\hline 32 & 9.39 & 0.290 & 19.8 & 0.082 & \\
\hline 33 & 10.37 & 0.291 & 19.8 & 0.082 & \\
\hline 34 & 12.25 & 0.288 & 19.9 & 0.082 & \\
\hline 35 & 14.43 & 0.289 & 19.8 & 0.082 & \\
\hline 36 & 17.13 & 0.292 & 19.9 & 0.083 & \\
\hline 37 & 17.32 & 0.290 & 19.9 & 0.082 & \\
\hline 38 & 17.54 & 0.291 & 19.9 & 0.082 & \\
\hline 39 & 17.78 & 0.291 & 19.9 & 0.082 & \\
\hline 40 & 18.00 & 0.292 & 19.8 & 0.082 & \\
\hline 41 & 18.19 & 0.295 & 19.7 & 0.083 & \\
\hline 42 & 18.38 & 0.292 & 19.8 & 0.082 & \\
\hline 43 & 18.63 & 0.290 & 19.9 & 0.082 & \\
\hline 44 & 18.84 & 0.265 & 19.9 & 0.076 & \\
\hline 45 & 19.05 & 0.124 & 19.9 & 0.034 & \\
\hline 46 & 19.24 & 0.042 & 19.9 & 0.009 & \\
\hline 47 & 19.41 & 0.024 & 20.0 & 0.004 & LDL \\
\hline 48 & 19.59 & 0.020 & 19.9 & 0.003 & LDL \\
\hline 49 & 19.78 & 0.016 & 20.0 & 0.001 & LDL \\
\hline 50 & 19.95 & 0.014 & 20.0 & 0.001 & LDL \\
\hline 51 & 20.14 & 0.015 & 20.0 & 0.001 & LDL \\
\hline 52 & 20.34 & 0.014 & 20.0 & 0.001 & LDL \\
\hline
\end{tabular}


Table 19 (Continued): Persulfate Transport Data, $90^{\circ} \mathrm{C}$ Activation, Study: $90^{\circ} \mathrm{C}$ PS-1

Data results for activated PS transport, $90^{\circ} \mathrm{C}$ PS-1; samples 53-62

\begin{tabular}{cccccc} 
Sample & $\begin{array}{c}\text { Pore } \\
\text { Volume } \\
(\mathrm{mL})\end{array}$ & $\begin{array}{c}\text { UV-Vis Abs } \\
\text { (avg.) }\end{array}$ & Dilution & $\mathrm{C} / \mathrm{C}_{\mathrm{o}}$ & \\
\hline 53 & 20.66 & 0.012 & 19.9 & 0.000 & $\mathrm{LDL}$ \\
54 & 21.08 & 0.012 & 20.0 & 0.000 & $\mathrm{LDL}$ \\
55 & 21.45 & 0.011 & 19.9 & 0.000 & $\mathrm{LDL}$ \\
56 & 21.85 & 0.012 & 19.8 & 0.000 & $\mathrm{LDL}$ \\
57 & 22.27 & 0.011 & 20.0 & 0.000 & $\mathrm{LDL}$ \\
58 & 23.30 & 0.011 & 19.9 & 0.000 & $\mathrm{LDL}$ \\
59 & 24.23 & 0.011 & 19.0 & 0.000 & $\mathrm{LDL}$ \\
60 & 25.37 & 0.011 & 19.8 & 0.000 & $\mathrm{LDL}$ \\
61 & 26.83 & 0.011 & 19.9 & 0.000 & $\mathrm{LDL}$ \\
62 & 28.19 & 0.012 & 19.9 & 0.000 & LDL
\end{tabular}


Table 20: Persulfate Transport Data, $90^{\circ} \mathrm{C}$ Activation, Study: $90^{\circ} \mathrm{C}$ PS-2

Performed for Heat-activated Persulfate Transport Study

Column: A

Darcy Velocity: $0.38 \mathrm{~cm} / \mathrm{min}$

Concentration, $\mathrm{C}_{\mathrm{o}}: 2407.4 \mathrm{mg} / \mathrm{L} \mathrm{Na}_{2} \mathrm{~S}_{2} \mathrm{O}_{8}$

Electrolyte: $0.01 \mathrm{~N} \mathrm{CaCl}_{2}$

Data results for activated PS transport, $90^{\circ} \mathrm{C}$ PS-1; samples E-1 - 14

\begin{tabular}{|c|c|c|c|c|c|}
\hline Sample & $\begin{array}{c}\text { Pore } \\
\text { Volume }(\mathrm{mL})\end{array}$ & $\begin{array}{c}\text { UV-Vis Abs } \\
\text { (avg.) }\end{array}$ & Dilution & $\mathrm{C} / \mathrm{C}_{0}$ & \\
\hline$E-1$ & -17.98 & 0.315 & 19.7 & 0.089 & Equilibrium \\
\hline$E-2$ & -15.00 & 0.333 & 20.0 & 0.095 & \\
\hline$E-3$ & -12.41 & 0.333 & 19.9 & 0.095 & \\
\hline$E-4$ & -10.89 & 0.334 & 19.9 & 0.095 & \\
\hline$E-5$ & -9.94 & 0.334 & 19.9 & 0.095 & \\
\hline$E-6$ & -8.86 & 0.335 & 19.9 & 0.095 & \\
\hline$E-7$ & -7.48 & 0.337 & 19.8 & 0.096 & \\
\hline$E-8$ & -6.37 & 0.335 & 19.9 & 0.096 & \\
\hline$E-9$ & -4.87 & 0.335 & 19.9 & 0.095 & \\
\hline E-10 & -3.48 & 0.336 & 19.9 & 0.096 & \\
\hline E-11 & -2.61 & 0.334 & 19.9 & 0.095 & \\
\hline E-12 & -1.48 & 0.338 & 19.8 & 0.096 & \\
\hline E-13 & -0.16 & 0.332 & 19.9 & 0.095 & \\
\hline 1 & -0.07 & 0.015 & 20.0 & 0.001 & LDL/Injection \\
\hline 2 & 0.08 & 0.017 & 19.9 & 0.002 & LDL \\
\hline 3 & 0.23 & 0.017 & 19.9 & 0.002 & LDL \\
\hline 4 & 0.37 & 0.018 & 19.9 & 0.002 & LDL \\
\hline 5 & 0.51 & 0.013 & 19.9 & 0.000 & LDL \\
\hline 6 & 0.68 & 0.017 & 20.0 & 0.002 & LDL \\
\hline 7 & 0.85 & 0.078 & 19.9 & 0.020 & \\
\hline 8 & 1.01 & 0.171 & 20.0 & 0.071 & \\
\hline 9 & 1.15 & 0.307 & 19.9 & 0.088 & \\
\hline 10 & 1.29 & 0.315 & 19.9 & 0.088 & \\
\hline 11 & 1.43 & 0.318 & 19.9 & 0.091 & \\
\hline 12 & 1.58 & 0.315 & 20.0 & 0.090 & \\
\hline 13 & 1.73 & 0.316 & 19.9 & 0.090 & \\
\hline \multirow[t]{2}{*}{14} & 1.89 & 0.315 & 19.9 & 0.090 & \\
\hline & & & 94 & & \\
\hline
\end{tabular}


Table 20 (Continued): Persulfate Transport Data, $90^{\circ} \mathrm{C}$ Activation, Study: $90^{\circ} \mathrm{C}$ PS-2

Data results for activated PS transport, $90^{\circ} \mathrm{C}$ PS-1; samples $15-49$

\begin{tabular}{|c|c|c|c|c|c|}
\hline Sample & $\begin{array}{c}\text { Pore } \\
\text { Volume (mL) }\end{array}$ & $\begin{array}{c}\text { UV-Vis Abs } \\
\text { (avg.) }\end{array}$ & Dilution & $\mathrm{C} / \mathrm{C}_{0}$ & \\
\hline 15 & 2.06 & 0.317 & 19.8 & 0.090 & \\
\hline 16 & 2.22 & 0.316 & 20.1 & 0.091 & \\
\hline 17 & 2.37 & 0.316 & 20.0 & 0.090 & \\
\hline 18 & 2.52 & 0.318 & 20.0 & 0.091 & \\
\hline 19 & 2.68 & 0.323 & 19.9 & 0.092 & \\
\hline 20 & 2.85 & 0.321 & 19.9 & 0.092 & \\
\hline 21 & 3.19 & 0.325 & 19.8 & 0.093 & \\
\hline 22 & 3.68 & 0.324 & 19.9 & 0.092 & \\
\hline 23 & 4.09 & 0.324 & 19.9 & 0.092 & \\
\hline 24 & 4.52 & 0.328 & 19.9 & 0.093 & \\
\hline 25 & 5.04 & 0.327 & 19.9 & 0.093 & \\
\hline 26 & 6.13 & 0.329 & 19.9 & 0.094 & \\
\hline 27 & 7.23 & 0.328 & 19.9 & 0.094 & \\
\hline 28 & 8.19 & 0.330 & 20.0 & 0.094 & \\
\hline 29 & 9.41 & 0.330 & 20.0 & 0.095 & \\
\hline 30 & 10.62 & 0.328 & 20.0 & 0.094 & \\
\hline 31 & 11.50 & 0.327 & 20.1 & 0.094 & \\
\hline 32 & 11.76 & 0.330 & 19.8 & 0.095 & Elution \\
\hline 33 & 12.00 & 0.333 & 19.9 & 0.095 & \\
\hline 34 & 12.18 & 0.333 & 20.0 & 0.095 & \\
\hline 35 & 12.35 & 0.332 & 19.9 & 0.092 & \\
\hline 36 & 12.53 & 0.321 & 20.0 & 0.053 & \\
\hline 37 & 12.70 & 0.191 & 20.0 & 0.016 & \\
\hline 38 & 12.86 & 0.065 & 19.9 & 0.006 & \\
\hline 39 & 13.01 & 0.030 & 20.0 & 0.004 & LDL \\
\hline 40 & 13.14 & 0.023 & 20.0 & 0.003 & LDL \\
\hline 41 & 13.27 & 0.020 & 20.0 & 0.003 & LDL \\
\hline 42 & 13.41 & 0.020 & 19.9 & 0.002 & LDL \\
\hline 43 & 13.56 & 0.019 & 20.0 & 0.002 & LDL \\
\hline 44 & 13.73 & 0.017 & 20.1 & 0.001 & LDL \\
\hline 45 & 13.92 & 0.015 & 20.0 & 0.001 & LDL \\
\hline 46 & 14.11 & 0.015 & 20.0 & 0.000 & LDL \\
\hline 47 & 14.27 & 0.013 & 19.9 & 0.001 & LDL \\
\hline 48 & 14.46 & 0.014 & 19.9 & 0.001 & LDL \\
\hline 49 & 14.76 & 0.016 & 19.9 & 0.001 & LDL \\
\hline
\end{tabular}


Table 20 (Continued): Persulfate Transport Data, $90^{\circ} \mathrm{C}$ Activation, Study: $90^{\circ} \mathrm{C}$ PS-2

Data results for activated PS transport, $90^{\circ} \mathrm{C}$ PS-1; samples 50-59

\begin{tabular}{cccccc} 
Sample & $\begin{array}{c}\text { Pore } \\
\text { Volume }(\mathrm{mL})\end{array}$ & $\begin{array}{c}\text { UV-Vis Abs } \\
\text { (avg.) }\end{array}$ & Dilution & C/Co & \\
\hline 50 & 15.17 & 0.015 & 19.7 & 0.001 & LDL \\
51 & 15.54 & 0.015 & 19.9 & 0.001 & LDL \\
52 & 15.97 & 0.014 & 21.1 & 0.001 & LDL \\
53 & 16.49 & 0.014 & 19.9 & 0.001 & LDL \\
54 & 17.60 & 0.014 & 20.0 & 0.001 & LDL \\
55 & 19.30 & 0.014 & 19.9 & 0.001 & LDL \\
56 & 20.42 & 0.015 & 19.9 & 0.001 & LDL \\
57 & 21.41 & 0.015 & 19.9 & 0.001 & LDL \\
58 & 22.41 & 0.014 & 20.0 & 0.001 & LDL \\
59 & 23.35 & 0.015 & 19.9 & 0.000 & LDL
\end{tabular}




\section{Table 21: $0.5 \mathrm{~mL} / \mathrm{min}$ Remediation Data, $60^{\circ} \mathrm{C}$ Activation}

Performed for Heat-activated Persulfate Remediation of Residual, Proof of Concept

\section{Column: A}

Darcy Velocity: $0.38 \mathrm{~cm} / \mathrm{min}$

Concentrations, $\mathrm{C}_{0}: 2427.4 \mathrm{mg} / \mathrm{L} \mathrm{Na} 2 \mathrm{~S}_{2} \mathrm{O}_{8}, 1259 \mathrm{mg} / \mathrm{L} \mathrm{TCE}$

Electrolyte: $0.01 \mathrm{~N} \mathrm{CaCl}_{2}$

Data results for $0.5 \mathrm{~mL} / \mathrm{min}$ Remediation Data, $60^{\circ} \mathrm{C}$ Activation; samples 1-16

\begin{tabular}{|c|c|c|c|c|c|c|c|c|c|c|c|}
\hline Sample & $\begin{array}{l}\text { Pore } \\
\text { Volume } \\
(\mathrm{mL})\end{array}$ & $\begin{array}{c}\text { UV-Vis } \\
\text { Abs (avg.) } \\
\text { TCE }\end{array}$ & $\begin{array}{c}\text { TCE C/Co } \\
(\mathrm{UV})\end{array}$ & $\begin{array}{c}\text { GC-FID } \\
\text { Area, TCE }\end{array}$ & $\begin{array}{l}\text { TCE C/C } \\
\text { (GC-FID) }\end{array}$ & $\begin{array}{c}\text { UV-Vis } \\
\text { Abs (avg.) } \\
\text { PS }\end{array}$ & $\begin{array}{c}\text { Dilution } \\
\text { PS }\end{array}$ & $\mathrm{PS} C / \mathrm{C}_{0}$ & $\begin{array}{c}\text { UV-Vis } \\
\text { Abs (avg.) } \\
\text { SO4 }\end{array}$ & $\begin{array}{l}\text { Dilution } \\
\text { sO4 }\end{array}$ & $\mathrm{SO} 4 \mathrm{C} / \mathrm{C}_{\mathrm{o}}$ \\
\hline 1 & -9.31 & & & 370396.80 & 1.03 & & & & & & \\
\hline 2 & -8.68 & & & & & & & & & & \\
\hline 3 & -8.01 & & & & & & & & & & \\
\hline 4 & -7.33 & & & 430522.40 & 1.19 & & & & & & \\
\hline 5 & -1.50 & & & & & & & & & & \\
\hline 6 & -0.77 & & & & & & & & & & \\
\hline 7 & 0.19 & 1.186 & 1.11 & & & & & & & & \\
\hline 8 & 0.72 & & & 401073.10 & 1.11 & 0.043 & 20.4 & 0.007 & & & \\
\hline 9 & 1.13 & & & & & 0.475 & 40.6 & 0.552 & 0.147 & 11.5 & 0.189 \\
\hline 10 & 1.41 & & & & & 0.402 & 62.2 & 0.708 & 0.352 & 9.6 & 0.286 \\
\hline 12 & 1.72 & & & & & 0.417 & 62.0 & 0.734 & 0.060 & 10.1 & 0.331 \\
\hline 13 & 2.25 & 1.532 & 1.00 & 468548.70 & 1.29 & 0.440 & 62.3 & 0.781 & 0.398 & 8.6 & 0.283 \\
\hline 14 & 3.16 & 1.592 & 1.06 & & & & & & & & \\
\hline 15 & 4.01 & 1.543 & 1.01 & & & 0.443 & 61.7 & 0.779 & 0.334 & 9.3 & 0.268 \\
\hline 16 & 4.88 & 1.551 & 1.02 & & & 0.463 & 59.5 & 0.788 & 0.671 & 5.8 & 0.294 \\
\hline
\end{tabular}


Table 21 (Continued): $0.5 \mathrm{~mL} / \mathrm{min}$ Remediation Data, $60^{\circ} \mathrm{C}$ Activation

Data results for $0.5 \mathrm{~mL} / \mathrm{min}$ Remediation Data, $60^{\circ} \mathrm{C}$ Activation; samples $17-36$

\begin{tabular}{|c|c|c|c|c|c|c|c|c|c|c|c|}
\hline Sample & $\begin{array}{c}\text { Pore } \\
\text { Volume } \\
(\mathrm{mL})\end{array}$ & $\begin{array}{c}\text { UV-Vis } \\
\text { Abs (avg.) } \\
\text { TCE }\end{array}$ & $\begin{array}{c}\text { TCE C/C } \\
\text { (UV) }\end{array}$ & $\begin{array}{c}\text { GC-FID } \\
\text { Area, TCE }\end{array}$ & $\begin{array}{l}\text { TCE C/Co } \\
\text { (GC-FID) }\end{array}$ & $\begin{array}{c}\text { UV-Vis } \\
\text { Abs (avg.) } \\
\text { PS }\end{array}$ & $\begin{array}{c}\text { Dilution } \\
\text { PS }\end{array}$ & $\mathrm{PS} C / \mathrm{C}_{\mathrm{o}}$ & $\begin{array}{c}\text { UV-Vis } \\
\text { Abs (avg.) } \\
\text { SO4 }\end{array}$ & $\begin{array}{l}\text { Dilution } \\
\text { SO4 }\end{array}$ & $\mathrm{SO} 4 \mathrm{C} / \mathrm{C}_{\mathrm{o}}$ \\
\hline 17 & 5.85 & 1.546 & 1.01 & & & 0.441 & 61.7 & 0.775 & 0.375 & 9.0 & 0.281 \\
\hline 18 & 6.59 & & & & & & & & & & \\
\hline 19 & 7.28 & 1.593 & 1.06 & & & 0.443 & 61.8 & 0.781 & 0.580 & 7.0 & 0.312 \\
\hline 20 & 8.18 & 1.532 & 1.00 & & & & 62.5 & & & & \\
\hline 21 & 9.04 & 1.508 & 0.98 & & & 0.444 & 61.7 & 0.780 & 0.511 & 6.9 & 0.278 \\
\hline 22 & 9.86 & 1.560 & 1.03 & & & & & & & & \\
\hline 23 & 10.50 & 1.576 & 1.04 & & & & & & & & \\
\hline 24 & 11.52 & 1.561 & 1.03 & 331315.70 & 0.92 & 0.461 & 59.8 & 0.787 & & & \\
\hline 25 & 12.92 & 1.526 & 1.00 & & & & & & & & \\
\hline 26 & 13.81 & 1.473 & 0.95 & & & & & & & & \\
\hline 27 & 16.44 & 1.533 & 1.00 & 378864.20 & 1.05 & 0.403 & 62.2 & 0.711 & 0.907 & 7.1 & 0.234 \\
\hline 28 & 17.52 & 1.524 & 0.99 & & & & & & & & \\
\hline 29 & 18.27 & 1.546 & 1.02 & & & & & & & & \\
\hline 30 & 19.24 & 1.527 & 1.00 & & & 0.409 & 62.0 & 0.720 & & & \\
\hline 31 & 20.34 & 1.532 & 1.00 & 401196.70 & 1.11 & & & & & & \\
\hline 32 & 21.21 & 1.483 & 0.96 & & & & & & & & \\
\hline 33 & 22.20 & 1.540 & 1.01 & & & 0.382 & 62.1 & 0.670 & & & \\
\hline 34 & 23.05 & 1.503 & 0.98 & & & & & & & & \\
\hline 35 & 23.88 & 1.471 & 0.95 & & & & & & & & \\
\hline 36 & 24.74 & 1.521 & 0.99 & & & 0.382 & 62.4 & 0.674 & & & \\
\hline
\end{tabular}


Table 21 (Continued): $0.5 \mathrm{~mL} / \mathrm{min}$ Remediation Data, $60^{\circ} \mathrm{C}$ Activation

Data results for $0.5 \mathrm{~mL} / \mathrm{min}$ Remediation Data, $60^{\circ} \mathrm{C}$ Activation; samples $37-56$

\begin{tabular}{|c|c|c|c|c|c|c|c|c|c|c|c|}
\hline Sample & $\begin{array}{c}\text { Pore } \\
\text { Volume } \\
(\mathrm{mL})\end{array}$ & $\begin{array}{c}\text { UV-Vis } \\
\text { Abs (avg.) } \\
\text { TCE }\end{array}$ & $\begin{array}{c}\text { TCE C/C } \\
\text { (UV) }\end{array}$ & $\begin{array}{c}\text { GC-FID } \\
\text { Area, TCE }\end{array}$ & $\begin{array}{l}\text { TCE C/C } \\
\text { (GC-FID) }\end{array}$ & $\begin{array}{c}\text { UV-Vis } \\
\text { Abs (avg.) } \\
\text { PS }\end{array}$ & $\begin{array}{c}\text { Dilution } \\
\text { PS }\end{array}$ & $\mathrm{PS} \mathrm{C} / \mathrm{C}_{\mathrm{o}}$ & $\begin{array}{c}\text { UV-Vis } \\
\text { Abs (avg.) } \\
\text { SO4 }\end{array}$ & $\begin{array}{c}\text { Dilution } \\
\text { SO4 }\end{array}$ & $\mathrm{SO} 4 \mathrm{C} / \mathrm{C}_{0}$ \\
\hline 37 & 25.60 & 1.510 & 0.98 & & & & & & & & \\
\hline 38 & 26.50 & 1.508 & 0.98 & & & & & & & & \\
\hline 39 & 27.40 & 1.521 & 0.99 & & & & & & & & \\
\hline 40 & 28.44 & 1.502 & 0.97 & & & & & & & & \\
\hline 41 & 29.40 & 1.563 & 1.03 & & & 0.832 & 62.5 & 0.758 & 0.626 & 10.0 & 0.238 \\
\hline 42 & 30.28 & 1.505 & 0.98 & & & & & & & & \\
\hline 43 & 33.09 & 1.397 & 0.88 & & & & & & & & \\
\hline 44 & 35.38 & 1.537 & 1.01 & & & & & & & & \\
\hline 45 & 37.56 & 1.581 & 1.05 & & & & & & & & \\
\hline 46 & 39.57 & 1.484 & 0.96 & & & & & & & & \\
\hline 47 & 41.77 & 1.458 & 0.94 & & & & & & & & \\
\hline 48 & 44.28 & 1.480 & 0.96 & & & & & & & & \\
\hline 49 & 46.65 & 1.530 & 1.00 & & & & & & & & \\
\hline 50 & 49.51 & 1.574 & 1.04 & & & & & & & & \\
\hline 51 & 51.73 & 1.534 & 1.00 & & & 0.777 & 62.3 & 0.704 & 0.788 & 8.0 & 0.232 \\
\hline 52 & 54.18 & 1.542 & 1.01 & & & & & & & & \\
\hline 53 & 57.72 & 1.509 & 0.98 & & & & & & & & \\
\hline 54 & 61.33 & 1.577 & 1.04 & & & & & & & & \\
\hline 55 & 65.01 & & & & & & & & & & \\
\hline 56 & 68.75 & 1.331 & 0.82 & & & & & & & & \\
\hline
\end{tabular}


Table 21 (Continued): $0.5 \mathrm{~mL} / \mathrm{min}$ Remediation Data, $60^{\circ} \mathrm{C}$ Activation

Data results for $0.5 \mathrm{~mL} / \mathrm{min}$ Remediation Data, $60^{\circ} \mathrm{C}$ Activation; samples $57-76$

\begin{tabular}{|c|c|c|c|c|c|c|c|c|c|c|c|}
\hline Sample & $\begin{array}{c}\text { Pore } \\
\text { Volume } \\
(\mathrm{mL})\end{array}$ & $\begin{array}{c}\text { UV-Vis } \\
\text { Abs (avg.) } \\
\text { TCE }\end{array}$ & $\begin{array}{c}\text { TCE C/C } \\
\text { (UV) }\end{array}$ & $\begin{array}{c}\text { GC-FID } \\
\text { Area, TCE }\end{array}$ & $\begin{array}{l}\text { TCE C/C } \\
\text { (GC-FID) }\end{array}$ & $\begin{array}{c}\text { UV-Vis } \\
\text { Abs (avg.) } \\
\text { PS }\end{array}$ & $\begin{array}{l}\text { Dilution } \\
\text { PS }\end{array}$ & $\mathrm{PS} \mathrm{C} / \mathrm{C}_{0}$ & $\begin{array}{c}\text { UV-Vis } \\
\text { Abs (avg.) } \\
\text { SO4 }\end{array}$ & $\begin{array}{c}\text { Dilution } \\
\text { SO4 }\end{array}$ & $\mathrm{SO} 4 \mathrm{C} / \mathrm{C}_{\mathrm{o}}$ \\
\hline 57 & 74.19 & 1.380 & 0.86 & & & & & & & & \\
\hline 58 & 80.95 & 1.349 & 0.84 & & & & & & & & \\
\hline 59 & 85.29 & 1.556 & 1.02 & & & & & & & & \\
\hline 60 & 89.76 & 1.512 & 0.98 & & & & & & & & \\
\hline 61 & 93.36 & 1.443 & 0.92 & & & 0.841 & 62.2 & 0.763 & 0.627 & 9.9 & 0.236 \\
\hline 62 & 97.59 & 1.439 & 0.92 & & & & & & & & \\
\hline 63 & 100.49 & 1.493 & 0.97 & & & & & & & & \\
\hline 64 & 102.73 & 1.493 & 0.97 & & & & & & & & \\
\hline 65 & 105.07 & 1.503 & 0.98 & & & & & & & & \\
\hline 66 & 105.91 & 1.496 & 0.97 & & & 0.833 & 62.6 & 0.760 & 0.545 & 10.1 & 0.214 \\
\hline 67 & 110.98 & 1.404 & 0.89 & & & & & & & & \\
\hline 68 & 115.87 & & & & & & & & & & \\
\hline 69 & 116.61 & 1.416 & 0.90 & & & & & & & & \\
\hline 70 & 118.80 & & & 340886.90 & 0.95 & & & & & & \\
\hline 71 & 119.69 & 1.390 & 0.87 & & & 0.851 & 62.5 & 0.775 & 0.571 & 9.9 & 0.218 \\
\hline 72 & 122.49 & & & 309734.60 & 0.86 & & & & & & \\
\hline 73 & 123.31 & 1.319 & 0.81 & & & & & & & & \\
\hline 74 & 125.36 & & & 335331.40 & 0.93 & & & & & & \\
\hline 75 & 126.29 & 1.364 & 0.85 & & & & & & & & \\
\hline 76 & 128.32 & & & 338774.80 & 0.94 & & & & & & \\
\hline
\end{tabular}


Table 21 (Continued): $0.5 \mathrm{~mL} / \mathrm{min}$ Remediation Data, $60^{\circ} \mathrm{C}$ Activation

Data results for $0.5 \mathrm{~mL} / \mathrm{min}$ Remediation Data, $60^{\circ} \mathrm{C}$ Activation; samples 77-96

\begin{tabular}{|c|c|c|c|c|c|c|c|c|c|c|c|}
\hline Sample & $\begin{array}{r}\text { Pore } \\
\text { Volume } \\
(\mathrm{mL})\end{array}$ & $\begin{array}{r}\text { UV-Vis } \\
\text { Abs (avg.) } \\
\text { TCE }\end{array}$ & $\begin{array}{r}\text { TCE C/C } 0 \\
\text { (UV) }\end{array}$ & $\begin{array}{r}\text { GC-FID } \\
\text { Area, TCE }\end{array}$ & $\begin{array}{l}\text { TCE C/Co } \\
\text { (GC-FID) }\end{array}$ & $\begin{array}{r}\text { UV-Vis } \\
\text { Abs (avg.) } \\
\text { PS }\end{array}$ & $\begin{array}{r}\text { Dilution } \\
\text { PS }\end{array}$ & $\mathrm{PS} C / \mathrm{C}_{0}$ & $\begin{array}{r}\text { UV-Vis } \\
\text { Abs (avg.) } \\
\text { SO4 }\end{array}$ & $\begin{array}{r}\text { Dilution } \\
\text { SO4 }\end{array}$ & $\mathrm{SO} 4 \mathrm{C} / \mathrm{C}_{\mathrm{o}}$ \\
\hline 77 & 129.30 & 1.261 & 0.76 & & & 0.822 & 62.7 & 0.751 & 0.481 & 10.0 & 0.191 \\
\hline 78 & 132.11 & & & 297839.30 & 0.83 & & & & & & \\
\hline 79 & 132.90 & 1.254 & 0.75 & & & & & & & & \\
\hline 80 & 133.46 & & & 307290.70 & 0.86 & & & & & & \\
\hline 81 & 134.19 & 1.238 & 0.73 & & & & & & & & \\
\hline 82 & 134.75 & & & 285746.50 & 0.80 & & & & & & \\
\hline 83 & 135.41 & 1.217 & 0.72 & 268783.60 & 0.75 & 0.412 & 62.3 & 0.729 & 0.978 & 7.1 & 0.252 \\
\hline 84 & 136.21 & 1.214 & 0.71 & & & & & & & & \\
\hline 85 & 136.72 & & & 254453.60 & 0.71 & & & & & & \\
\hline 86 & 137.36 & 1.241 & 0.74 & 259547.90 & 0.73 & & & & & & \\
\hline 87 & 138.22 & 1.211 & 0.71 & & & & & & & & \\
\hline 88 & 138.86 & & & 254000.70 & 0.71 & & & & & & \\
\hline 89 & 139.58 & 1.211 & 0.71 & 27116.80 & 0.10 & 0.802 & 62.4 & 0.728 & 0.625 & 10.9 & 0.259 \\
\hline 90 & 141.08 & 1.168 & 0.67 & 188156.50 & 0.53 & & & & & & \\
\hline 91 & 141.85 & 1.095 & 0.61 & & & & & & & & \\
\hline 92 & 142.44 & & & 234486.90 & 0.66 & & & & & & \\
\hline 93 & 143.14 & 1.135 & 0.64 & 211390.00 & 0.60 & & & & & & \\
\hline 94 & 144.69 & 1.095 & 0.61 & & & & & & & & \\
\hline 95 & 145.17 & & & 222418.10 & 0.63 & & & & & & \\
\hline 96 & 145.81 & 1.074 & 0.59 & 218928.90 & 0.62 & 0.823 & 62.4 & 0.748 & 0.563 & 10.4 & 0.226 \\
\hline
\end{tabular}


Table 21 (Continued): $0.5 \mathrm{~mL} / \mathrm{min}$ Remediation Data, $60^{\circ} \mathrm{C}$ Activation

Data results for $0.5 \mathrm{~mL} / \mathrm{min}$ Remediation Data, $60^{\circ} \mathrm{C}$ Activation; samples $97-116$

\begin{tabular}{|c|c|c|c|c|c|c|c|c|c|c|c|}
\hline Sample & $\begin{array}{c}\text { Pore } \\
\text { Volume } \\
(\mathrm{mL}) \\
\end{array}$ & $\begin{array}{c}\text { UV-Vis } \\
\text { Abs (avg.) } \\
\text { TCE } \\
\end{array}$ & $\begin{array}{c}\text { TCE C/C } \\
\text { (UV) }\end{array}$ & $\begin{array}{c}\text { GC-FID } \\
\text { Area, TCE }\end{array}$ & $\begin{array}{l}\text { TCE C/Co } \\
\text { (GC-FID) }\end{array}$ & $\begin{array}{c}\text { UV-Vis } \\
\text { Abs (avg.) } \\
\text { PS } \\
\end{array}$ & $\begin{array}{l}\text { Dilution } \\
\text { PS }\end{array}$ & $\mathrm{PS} C / \mathrm{C}_{0}$ & $\begin{array}{c}\text { UV-Vis } \\
\text { Abs (avg.) } \\
\text { SO4 } \\
\end{array}$ & $\begin{array}{l}\text { Dilution } \\
\text { SO4 }\end{array}$ & $\mathrm{SO} 4 \mathrm{C} / \mathrm{C}_{0}$ \\
\hline 97 & 147.56 & 1.041 & 0.56 & & & & & & & & \\
\hline 98 & 148.19 & & & 216692.30 & 0.61 & & & & & & \\
\hline 99 & 149.00 & 1.019 & 0.54 & 197062.60 & 0.56 & 0.833 & 62.5 & 0.759 & 0.545 & 10.0 & 0.213 \\
\hline 100 & 151.91 & 0.990 & 0.51 & 136192.30 & 0.39 & & & & & & \\
\hline 101 & 154.52 & 0.974 & 0.50 & 138790.80 & 0.40 & & & & & & \\
\hline 102 & 156.34 & & & 157817.50 & 0.45 & & & & & & \\
\hline 103 & 190.65 & & & & & & & & & & \\
\hline 104 & 191.24 & 0.517 & 0.07 & 19411.30 & 0.08 & 0.853 & 62.6 & 0.778 & 0.604 & 9.9 & 0.229 \\
\hline 105 & 192.36 & 0.496 & 0.05 & 16027.80 & 0.07 & & & & & & \\
\hline 106 & 207.15 & & & 13599.60 & 0.06 & & & & & & \\
\hline 107 & 212.43 & & & 13033.40 & 0.06 & & & & & & \\
\hline 108 & 219.24 & 0.467 & 0.01 & 10406.00 & 0.04 & & & & & & \\
\hline 109 & 223.79 & 0.461 & 0.00 & 11406.70 & 0.05 & 0.865 & 63.0 & 0.794 & 0.532 & 9.9 & 0.206 \\
\hline 110 & 231.20 & 0.467 & 0.01 & 10532.20 & 0.04 & & & & & & \\
\hline 111 & 232.04 & 0.465 & 0.01 & 8783.50 & 0.04 & & & & & & \\
\hline 112 & 232.92 & 0.468 & 0.01 & 11040.80 & 0.05 & & & & & & \\
\hline 113 & 237.22 & & & 11001.70 & 0.04 & & & & & & \\
\hline 114 & 252.15 & 0.467 & 0.01 & 8669.80 & 0.04 & & & & & & \\
\hline 115 & 252.97 & 0.475 & 0.02 & 8940.00 & 0.04 & & & & & & \\
\hline 116 & 253.96 & 0.470 & 0.01 & 8949.30 & 0.04 & & & & & & \\
\hline
\end{tabular}


Table 21 (Continued): $0.5 \mathrm{~mL} / \mathrm{min}$ Remediation Data, $60^{\circ} \mathrm{C}$ Activation

Data results for $0.5 \mathrm{~mL} / \mathrm{min}$ Remediation Data, $60^{\circ} \mathrm{C}$ Activation; samples $117-132$

\begin{tabular}{|c|c|c|c|c|c|c|c|c|c|c|c|}
\hline Sample & $\begin{array}{c}\text { Pore } \\
\text { Volume } \\
(\mathrm{mL})\end{array}$ & $\begin{array}{c}\text { UV-Vis } \\
\text { Abs (avg.) } \\
\text { TCE }\end{array}$ & $\begin{array}{c}\text { TCE C/Co } \\
\text { (UV) }\end{array}$ & $\begin{array}{c}\text { GC-FID } \\
\text { Area, TCE }\end{array}$ & $\begin{array}{l}\text { TCE C/C }{ }_{\circ} \\
\text { (GC-FID) }\end{array}$ & $\begin{array}{c}\text { UV-Vis } \\
\text { Abs (avg.) } \\
\text { PS }\end{array}$ & $\begin{array}{l}\text { Dilution } \\
\text { PS }\end{array}$ & $\mathrm{PS} \mathrm{C} / \mathrm{C}_{\mathrm{o}}$ & $\begin{array}{c}\text { UV-Vis } \\
\text { Abs (avg.) } \\
\text { SO4 }\end{array}$ & $\begin{array}{c}\text { Dilution } \\
\text { SO4 }\end{array}$ & $\mathrm{SO} 4 \mathrm{C} / \mathrm{C}_{\mathrm{o}}$ \\
\hline 117 & 256.27 & & & 9091.10 & 0.04 & & & & & & \\
\hline 118 & 289.31 & 0.474 & 0.02 & 7412.50 & 0.03 & & & & & & \\
\hline 119 & 290.25 & 0.468 & 0.01 & 7574.80 & 0.03 & & & & & & \\
\hline 120 & 291.18 & 0.473 & 0.02 & 7180.50 & 0.03 & 0.856 & 62.4 & 0.779 & 0.624 & 9.9 & 0.236 \\
\hline 121 & 294.15 & & & 8104.70 & 0.03 & & & & & & \\
\hline 122 & 294.76 & & & 2710.00 & 0.01 & & & & & & \\
\hline 123 & 313.88 & & & 8271.00 & 0.03 & & & & & & \\
\hline 124 & 315.54 & & & 8280.89 & 0.03 & & & & & & \\
\hline 125 & 353.40 & & & 5434.95 & 0.02 & & & & & & \\
\hline 126 & 354.06 & & & 5459.99 & 0.02 & & & & & & \\
\hline 127 & 389.62 & & & 5473.51 & 0.02 & & & & & & \\
\hline 129 & 390.56 & & & 3899.43 & 0.02 & & & & & & \\
\hline 130 & 400.99 & & & 4152.09 & 0.02 & & & & & & \\
\hline 131 & 401.71 & 0.470 & 0.01 & 4541.10 & 0.02 & 0.854 & 62.4 & 0.777 & 0.530 & 10.9 & 0.226 \\
\hline 132 & 403.24 & & & 4767.55 & 0.02 & & & & & & \\
\hline
\end{tabular}




\section{Table 22: $0.2 \mathrm{~mL} / \mathrm{min}$ Remediation Data, $60^{\circ} \mathrm{C}$ Activation}

Performed for Heat-activated Persulfate Remediation of Residual, Proof of Concept

\section{Column: A}

Darcy Velocity: $0.15 \mathrm{~cm} / \mathrm{min}$

Concentrations, $\mathrm{C}_{0}: 2469.3 \mathrm{mg} / \mathrm{L} \mathrm{Na} 2 \mathrm{~S}_{2} \mathrm{O}_{8}, 1127 \mathrm{mg} / \mathrm{L} \mathrm{TCE}$

Electrolyte: $0.01 \mathrm{~N} \mathrm{CaCl}_{2}$

Data results for $0.2 \mathrm{~mL} / \mathrm{min}$ Remediation Data, $60^{\circ} \mathrm{C}$ Activation; samples 1-15

\begin{tabular}{|c|c|c|c|c|c|c|c|c|c|c|c|}
\hline Sample & $\begin{array}{c}\text { Pore } \\
\text { Volume } \\
\text { (mL) }\end{array}$ & $\begin{array}{c}\text { UV-Vis } \\
\text { Abs (avg.) } \\
\text { TCE }\end{array}$ & $\begin{array}{c}\text { TCE C/Co } \\
\text { (UV) }\end{array}$ & $\begin{array}{c}\text { GC-FID } \\
\text { Area, TCE }\end{array}$ & $\begin{array}{l}\text { TCE C/C。 } \\
\text { (GC-FID) }\end{array}$ & $\begin{array}{c}\text { UV-Vis } \\
\text { Abs (avg.) } \\
\text { PS }\end{array}$ & $\begin{array}{l}\text { Dilution } \\
\text { PS }\end{array}$ & $\mathrm{PS} C / \mathrm{C}_{0}$ & $\begin{array}{c}\text { UV-Vis } \\
\text { Abs (avg.) } \\
\text { SO4 }\end{array}$ & $\begin{array}{c}\text { Dilution } \\
\text { SO4 }\end{array}$ & $\mathrm{SO} 4 \mathrm{C} / \mathrm{C}_{\mathrm{o}}$ \\
\hline 1 & -9.00 & 1.085 & 1.00 & 4986804.20 & 1.09 & & & & & & \\
\hline 2 & -8.41 & 1.134 & 1.04 & 5014374.60 & 1.09 & & & & & & \\
\hline t옹 & -7.21 & 1.270 & 1.16 & 5160150.30 & 1.12 & & & & & & \\
\hline 4 & -6.01 & 1.276 & 1.17 & 5043743.10 & 1.10 & & & & & & \\
\hline 5 & -4.76 & 1.245 & 1.14 & 4999481.50 & 1.09 & & & & & & \\
\hline 6 & -3.50 & 1.286 & 1.17 & 4799184.00 & 1.05 & & & & & & \\
\hline 7 & -2.21 & 1.280 & 1.17 & 4596609.20 & 1.00 & & & & & & \\
\hline 8 & -0.75 & 1.258 & 1.15 & 4387494.20 & 0.96 & & & & & & \\
\hline 9 & -0.29 & & & 3996191.60 & 0.88 & & & & & & \\
\hline 10 & 0.26 & 1.288 & 1.18 & 4797878.60 & 1.05 & 0.018 & 19.7 & 0.001 & 0.001 & 28.0 & 0.058 \\
\hline 11 & 0.81 & 1.303 & 1.19 & 4584135.50 & 1.00 & 0.227 & 39.3 & 0.123 & 0.052 & 13.0 & 0.052 \\
\hline 12 & 1.22 & & & & & 0.970 & 39.8 & 0.574 & 0.842 & 10.0 & 0.333 \\
\hline 13 & 1.46 & & & & & 1.020 & 39.4 & 0.599 & 0.873 & 10.1 & 0.346 \\
\hline 14 & 1.71 & & & & & 1.028 & 39.1 & 0.598 & 0.912 & 10.0 & 0.359 \\
\hline 15 & 2.15 & 1.608 & 1.06 & 1548284.00 & 0.35 & 1.029 & 39.4 & 0.604 & 1.041 & 10.0 & 0.407 \\
\hline
\end{tabular}


Table 22 (Continued): $0.2 \mathrm{~mL} / \mathrm{min}$ Remediation Data, $60^{\circ} \mathrm{C}$ Activation

Data results for $0.2 \mathrm{~mL} / \mathrm{min}$ Remediation Data, $60^{\circ} \mathrm{C}$ Activation; samples $16-35$

\begin{tabular}{|c|c|c|c|c|c|c|c|c|c|c|c|}
\hline Sample & $\begin{array}{c}\text { Pore } \\
\text { Volume } \\
\text { (mL) }\end{array}$ & $\begin{array}{c}\text { UV-Vis } \\
\text { Abs (avg.) } \\
\text { TCE }\end{array}$ & $\begin{array}{c}\text { TCE C/C } \\
\text { (UV) }\end{array}$ & $\begin{array}{c}\text { GC-FID } \\
\text { Area, TCE }\end{array}$ & $\begin{array}{l}\text { TCE C/C } \\
\text { (GC-FID) }\end{array}$ & $\begin{array}{c}\text { UV-Vis } \\
\text { Abs (avg.) } \\
\text { PS }\end{array}$ & $\begin{array}{l}\text { Dilution } \\
\text { PS }\end{array}$ & $\mathrm{PS} \mathrm{C} / \mathrm{C}_{0}$ & $\begin{array}{c}\text { UV-Vis } \\
\text { Abs (avg.) } \\
\text { SO4 }\end{array}$ & $\begin{array}{l}\text { Dilution } \\
\text { SO4 }\end{array}$ & $\mathrm{SO} 4 \mathrm{C} / \mathrm{C}_{0}$ \\
\hline 16 & 16.76 & 1.611 & 1.06 & 4410717.80 & 0.96 & 1.033 & 39.6 & 0.610 & 1.016 & 10.0 & 0.398 \\
\hline 17 & 17.46 & 1.611 & 1.06 & 4507571.10 & 0.98 & & & & & & \\
\hline 18 & 18.96 & 1.607 & 1.06 & 4214450.70 & 0.92 & & & & & & \\
\hline 19 & 20.38 & 1.588 & 1.04 & 4668265.50 & 1.02 & 1.013 & 39.4 & 0.594 & 0.775 & 13.1 & 0.403 \\
\hline 20 & 22.14 & 1.594 & 1.05 & 4653399.70 & 1.02 & & & & & & \\
\hline 21 & 23.56 & 1.599 & 1.05 & 4346928.00 & 0.95 & & & & & & \\
\hline 22 & 25.15 & 1.575 & 1.03 & 3981579.00 & 0.87 & 1.031 & 39.6 & 0.608 & 1.005 & 10.1 & 0.395 \\
\hline 23 & 26.73 & 1.583 & 1.04 & 1970226.70 & 0.44 & & & & & & \\
\hline 24 & 27.44 & 1.610 & 1.06 & 4398824.90 & 0.96 & & & & & & \\
\hline 25 & 28.90 & 1.600 & 1.05 & 2085157.60 & 0.47 & & & & & & \\
\hline 26 & 30.42 & 1.621 & 1.07 & 4386213.10 & 0.96 & 1.068 & 38.4 & 0.611 & 0.668 & 15.3 & 0.410 \\
\hline 27 & 31.95 & 1.619 & 1.07 & 4625493.50 & 1.01 & & & & & & \\
\hline 28 & 33.76 & 1.634 & 1.08 & 4646483.80 & 1.01 & & & & & & \\
\hline 29 & 34.48 & 1.627 & 1.07 & 4705225.40 & 1.03 & 1.064 & 39.1 & 0.620 & 0.953 & 10.1 & 0.375 \\
\hline 30 & 50.54 & 1.568 & 1.02 & 4518251.30 & 0.99 & 1.033 & 39.8 & 0.613 & 1.197 & 10.1 & 0.467 \\
\hline 31 & 51.26 & 1.597 & 1.05 & 4541567.50 & 0.99 & & & & & & \\
\hline 32 & 51.94 & 1.614 & 1.06 & 4297044.20 & 0.94 & & & & & & \\
\hline 33 & 53.89 & 1.612 & 1.06 & 4860216.30 & 1.06 & & & & & & \\
\hline 34 & 55.71 & 1.607 & 1.06 & 4725661.70 & 1.03 & 1.028 & 39.5 & 0.604 & 0.844 & 11.1 & 0.370 \\
\hline 35 & 57.43 & 1.593 & 1.04 & 3861692.50 & 0.85 & & & & & & \\
\hline
\end{tabular}


Table 22 (Continued): $0.2 \mathrm{~mL} / \mathrm{min}$ Remediation Data, $60^{\circ} \mathrm{C}$ Activation

Data results for $0.2 \mathrm{~mL} / \mathrm{min}$ Remediation Data, $60^{\circ} \mathrm{C}$ Activation; samples $36-55$

\begin{tabular}{|c|c|c|c|c|c|c|c|c|c|c|c|}
\hline Sample & $\begin{array}{c}\text { Pore } \\
\text { Volume } \\
\text { (mL) }\end{array}$ & $\begin{array}{c}\text { UV-Vis } \\
\text { Abs (avg.) } \\
\text { TCE }\end{array}$ & $\begin{array}{c}\text { TCE C/Co } \\
\text { (UV) }\end{array}$ & $\begin{array}{c}\text { GC-FID } \\
\text { Area, TCE }\end{array}$ & $\begin{array}{l}\text { TCE C/Co } \\
\text { (GC-FID) }\end{array}$ & $\begin{array}{c}\text { UV-Vis } \\
\text { Abs (avg.) } \\
\text { PS }\end{array}$ & $\begin{array}{l}\text { Dilution } \\
\text { PS }\end{array}$ & $\mathrm{PS} \mathrm{C} / \mathrm{C}_{\mathrm{o}}$ & $\begin{array}{c}\text { UV-Vis } \\
\text { Abs (avg.) } \\
\text { SO4 }\end{array}$ & $\begin{array}{l}\text { Dilution } \\
\text { SO4 }\end{array}$ & $\mathrm{SO} 4 \mathrm{C} / \mathrm{C}_{\mathrm{o}}$ \\
\hline 36 & 59.48 & 1.590 & 1.04 & 4466385.90 & 0.98 & & & & & & \\
\hline 37 & 61.42 & 1.592 & 1.04 & 4760999.20 & 1.04 & 1.039 & 39.8 & 0.617 & 0.865 & 11.2 & 0.380 \\
\hline 38 & 63.29 & 1.556 & 1.01 & 4455591.30 & 0.97 & & & & & & \\
\hline 39 & 64.01 & 1.598 & 1.05 & 4336308.20 & 0.95 & & & & & & \\
\hline 40 & 66.16 & 1.566 & 1.02 & 4553757.80 & 0.99 & 1.050 & 39.5 & 0.617 & 0.875 & 11.2 & 0.386 \\
\hline 41 & 68.28 & 1.594 & 1.05 & 4693638.30 & 1.02 & & & & & & \\
\hline 42 & 68.93 & 1.592 & 1.04 & 4689361.60 & 1.02 & 1.056 & 39.4 & 0.619 & 0.757 & 12.5 & 0.377 \\
\hline 43 & 82.77 & 1.575 & 1.03 & 4470175.50 & 0.98 & 1.035 & 39.1 & 0.603 & 0.353 & 25.7 & 0.388 \\
\hline 44 & 84.47 & 1.584 & 1.04 & 4593173.10 & 1.00 & & & & & & \\
\hline 45 & 85.87 & 1.579 & 1.03 & 4299743.20 & 0.94 & & & & & & \\
\hline 46 & 87.34 & 1.583 & 1.04 & 4200562.80 & 0.92 & 1.057 & 39.2 & 0.617 & 0.762 & 12.5 & 0.379 \\
\hline 47 & 88.58 & 1.558 & 1.01 & 3920691.10 & 0.86 & & & & & & \\
\hline 48 & 90.81 & 1.534 & 0.99 & 4612756.20 & 1.01 & & & & & & \\
\hline 49 & 91.57 & 1.563 & 1.02 & 4139845.40 & 0.91 & & & & & & \\
\hline 50 & 92.35 & 1.540 & 1.00 & 4517089.00 & 0.99 & 0.985 & 39.7 & 0.581 & 0.899 & 12.6 & 0.443 \\
\hline 51 & 94.50 & 1.531 & 0.99 & 4369239.30 & 0.96 & & & & & & \\
\hline 52 & 95.24 & 1.532 & 0.99 & 4241302.50 & 0.93 & & & & & & \\
\hline 53 & 96.73 & 1.548 & 1.00 & 4504848.80 & 0.98 & 1.064 & 39.3 & 0.624 & 0.700 & 13.9 & 0.387 \\
\hline 54 & 98.24 & 1.481 & 0.95 & 4461709.90 & 0.97 & & & & & & \\
\hline 55 & 99.00 & 1.552 & 1.01 & 4373616.10 & 0.96 & & & & & & \\
\hline
\end{tabular}


Table 22 (Continued): $0.2 \mathrm{~mL} / \mathrm{min}$ Remediation Data, $60^{\circ} \mathrm{C}$ Activation

Data results for $0.2 \mathrm{~mL} / \mathrm{min}$ Remediation Data, $60^{\circ} \mathrm{C}$ Activation; samples $56-75$

\begin{tabular}{|c|c|c|c|c|c|c|c|c|c|c|c|}
\hline Sample & $\begin{array}{c}\text { Pore } \\
\text { Volume } \\
(\mathrm{mL})\end{array}$ & $\begin{array}{c}\text { UV-Vis } \\
\text { Abs (avg.) } \\
\text { TCE }\end{array}$ & $\begin{array}{c}\text { TCE C/C } C_{o} \\
\text { (UV) }\end{array}$ & $\begin{array}{c}\text { GC-FID } \\
\text { Area, TCE }\end{array}$ & $\begin{array}{l}\text { TCE C/Co } \\
\text { (GC-FID) }\end{array}$ & $\begin{array}{c}\text { UV-Vis } \\
\text { Abs (avg.) } \\
\text { PS }\end{array}$ & $\begin{array}{l}\text { Dilution } \\
\text { PS }\end{array}$ & $\mathrm{PS} C / \mathrm{C}_{0}$ & $\begin{array}{c}\text { UV-Vis } \\
\text { Abs (avg.) } \\
\text { SO4 }\end{array}$ & $\begin{array}{l}\text { Dilution } \\
\text { SO4 }\end{array}$ & $\mathrm{SO} 4 \mathrm{C} / \mathrm{C}_{\mathrm{o}}$ \\
\hline 56 & 101.24 & 1.535 & 0.99 & 4720028.80 & 1.03 & 1.030 & 39.7 & 0.610 & 0.700 & 12.7 & 0.355 \\
\hline 57 & 102.63 & 1.552 & 1.01 & 4303349.10 & 0.94 & & & & & & \\
\hline 58 & 104.38 & 1.530 & 0.99 & 4297712.70 & 0.94 & 1.035 & 39.7 & 0.611 & 0.671 & 14.1 & 0.377 \\
\hline 59 & 104.86 & & & 4087075.00 & 0.89 & & & & & & \\
\hline 60 & 117.07 & 1.321 & 0.80 & 3617399.20 & 0.79 & & & & & & \\
\hline 61 & 117.59 & & & 3777636.90 & 0.83 & & & & & & \\
\hline 62 & 118.27 & 1.352 & 0.83 & 2969916.20 & 0.66 & 1.027 & 39.2 & 0.600 & 0.540 & 17.4 & 0.383 \\
\hline 63 & 120.10 & 1.296 & 0.78 & 2827745.20 & 0.63 & & & & & & \\
\hline 64 & 120.81 & 1.241 & 0.73 & 2814566.50 & 0.62 & 1.012 & 39.3 & 0.592 & 0.845 & 12.4 & 0.413 \\
\hline 65 & 121.53 & 1.213 & 0.71 & 2037283.50 & 0.46 & 1.024 & 39.7 & 0.606 & 0.593 & 15.8 & 0.378 \\
\hline 66 & 122.27 & 1.212 & 0.71 & 2640213.80 & 0.59 & & & & & & \\
\hline 67 & 123.04 & 1.149 & 0.65 & 2468140.80 & 0.55 & & & & & & \\
\hline 68 & 123.75 & 1.152 & 0.65 & 2241140.40 & 0.50 & & & & & & \\
\hline 69 & 124.44 & 1.149 & 0.65 & 2386297.50 & 0.53 & & & & & & \\
\hline 70 & 125.83 & 1.080 & 0.59 & 2152847.60 & 0.48 & 1.041 & 39.8 & 0.618 & 0.737 & 12.4 & 0.365 \\
\hline 71 & 126.57 & 1.026 & 0.54 & 2349481.60 & 0.52 & & & & & & \\
\hline 72 & 127.27 & 0.992 & 0.51 & 1760173.00 & 0.40 & & & & & & \\
\hline 73 & 127.98 & 1.019 & 0.54 & 2013562.20 & 0.45 & & & & & & \\
\hline 74 & 129.00 & 1.001 & 0.52 & 1922265.00 & 0.43 & & & & & & \\
\hline 75 & 131.23 & 0.980 & 0.50 & 1125546.40 & 0.26 & 1.039 & 39.7 & 0.614 & 0.626 & 14.6 & 0.368 \\
\hline
\end{tabular}


Table 22 (Continued): $0.2 \mathrm{~mL} / \mathrm{min}$ Remediation Data, $60^{\circ} \mathrm{C}$ Activation

Data results for $0.2 \mathrm{~mL} / \mathrm{min}$ Remediation Data, $60^{\circ} \mathrm{C}$ Activation; samples 76-95

\begin{tabular}{|c|c|c|c|c|c|c|c|c|c|c|c|}
\hline Sample & $\begin{array}{c}\text { Pore } \\
\text { Volume } \\
\text { (mL) }\end{array}$ & $\begin{array}{c}\text { UV-Vis } \\
\text { Abs (avg.) } \\
\text { TCE }\end{array}$ & $\begin{array}{c}\text { TCE C/Co } \\
\text { (UV) }\end{array}$ & $\begin{array}{c}\text { GC-FID } \\
\text { Area, TCE }\end{array}$ & $\begin{array}{l}\text { TCE C/C } \\
\text { (GC-FID) }\end{array}$ & $\begin{array}{c}\text { UV-Vis } \\
\text { Abs (avg.) } \\
\text { PS }\end{array}$ & $\begin{array}{l}\text { Dilution } \\
\text { PS }\end{array}$ & $\mathrm{PS} \mathrm{C} / \mathrm{C}_{0}$ & $\begin{array}{c}\text { UV-Vis } \\
\text { Abs (avg.) } \\
\text { SO4 }\end{array}$ & $\begin{array}{l}\text { Dilution } \\
\text { SO4 }\end{array}$ & $\mathrm{SO} 4 \mathrm{C} / \mathrm{C}_{\mathrm{o}}$ \\
\hline 76 & 131.95 & 0.965 & 0.49 & 2055075.80 & 0.46 & & & & & & \\
\hline 77 & 132.65 & 0.952 & 0.48 & 1992533.50 & 0.45 & & & & & & \\
\hline 78 & 133.43 & 0.940 & 0.47 & 1721907.90 & 0.39 & & & & & & \\
\hline 79 & 134.15 & 0.920 & 0.45 & 1889466.80 & 0.42 & & & & & & \\
\hline 80 & 134.88 & 0.926 & 0.45 & 1720046.80 & 0.39 & 1.038 & 39.8 & 0.616 & 0.752 & 12.7 & 0.378 \\
\hline 81 & 135.94 & 0.923 & 0.45 & 1598867.20 & 0.36 & & & & & & \\
\hline 82 & 136.82 & 0.878 & 0.41 & 1716469.00 & 0.39 & & & & & & \\
\hline 83 & 138.73 & 0.913 & 0.44 & 1713711.20 & 0.39 & & & & & & \\
\hline 84 & 139.47 & 0.913 & 0.39 & 572712.00 & 0.14 & 1.039 & 38.8 & 0.601 & 0.777 & 12.6 & 0.386 \\
\hline 85 & 140.34 & 0.918 & 0.39 & 1553778.30 & 0.35 & & & & & & \\
\hline 86 & 141.10 & 0.903 & 0.38 & 1514767.10 & 0.34 & & & & & & \\
\hline 87 & 141.81 & 0.910 & 0.39 & 1453085.60 & 0.33 & & & & & & \\
\hline 88 & 142.46 & & & 1363152.90 & 0.31 & & & & & & \\
\hline 89 & 153.33 & 0.856 & 0.34 & 1253967.20 & 0.29 & 1.022 & 39.4 & 0.600 & 0.819 & 12.5 & 0.405 \\
\hline 90 & 154.04 & 0.850 & 0.33 & 1209701.60 & 0.28 & & & & & & \\
\hline 91 & 160.51 & 0.841 & 0.32 & 1135687.00 & 0.26 & 1.004 & 39.6 & 0.591 & 0.840 & 12.6 & 0.418 \\
\hline 92 & 161.21 & 0.864 & 0.34 & 947542.00 & 0.22 & & & & & & \\
\hline 93 & 161.97 & 0.842 & 0.33 & 961000.20 & 0.23 & & & & & & \\
\hline 94 & 169.47 & 0.782 & 0.27 & 876558.00 & 0.21 & & & & & & \\
\hline 95 & 170.21 & 0.795 & 0.28 & 740909.90 & 0.18 & & & & & & \\
\hline
\end{tabular}




\section{Table 22: $0.2 \mathrm{~mL} / \mathrm{min}$ Remediation Data, $60^{\circ} \mathrm{C}$ Activation}

Data results for $0.2 \mathrm{~mL} / \mathrm{min}$ Remediation Data, $60^{\circ} \mathrm{C}$ Activation; samples $95-119$

\begin{tabular}{|c|c|c|c|c|c|c|c|c|c|c|c|}
\hline Sample & $\begin{array}{c}\text { Pore } \\
\text { Volume } \\
\text { (mL) }\end{array}$ & $\begin{array}{c}\text { UV-Vis } \\
\text { Abs (avg.) } \\
\text { TCE }\end{array}$ & $\begin{array}{c}\text { TCE C/C } C_{0} \\
\text { (UV) }\end{array}$ & $\begin{array}{c}\text { GC-FID } \\
\text { Area, TCE }\end{array}$ & $\begin{array}{l}\text { TCE C/C } \\
\text { (GC-FID) }\end{array}$ & $\begin{array}{c}\text { UV-Vis } \\
\text { Abs (avg.) } \\
\text { PS }\end{array}$ & $\begin{array}{l}\text { Dilution } \\
\text { PS }\end{array}$ & $\mathrm{PS} C / \mathrm{C}_{0}$ & $\begin{array}{c}\text { UV-Vis } \\
\text { Abs (avg.) } \\
\text { SO4 }\end{array}$ & $\begin{array}{l}\text { Dilution } \\
\text { SO4 }\end{array}$ & $\mathrm{SO} 4 \mathrm{C} / \mathrm{C}_{0}$ \\
\hline 96 & 171.02 & 0.785 & 0.27 & 321224.60 & 0.09 & & & & & & \\
\hline 97 & 172.16 & 0.757 & 0.25 & 617123.20 & 0.15 & & & & & & \\
\hline 98 & 174.01 & 0.796 & 0.28 & 775193.00 & 0.19 & 0.997 & 39.8 & 0.590 & 0.818 & 12.5 & 0.403 \\
\hline 99 & 174.78 & 0.738 & 0.23 & 797034.60 & 0.19 & & & & & & \\
\hline 100 & 189.69 & 0.653 & 0.16 & 439368.80 & 0.11 & 1.012 & 39.5 & 0.596 & 0.851 & 12.5 & 0.419 \\
\hline 101 & 190.40 & 0.666 & 0.17 & 522119.90 & 0.13 & & & & & & \\
\hline 102 & 192.26 & 0.667 & 0.17 & 445513.80 & 0.12 & & & & & & \\
\hline 03 & 193.02 & 0.659 & 0.16 & 433464.20 & 0.11 & & & & & & \\
\hline 104 & 194.56 & 0.644 & 0.15 & 462905.30 & 0.12 & 1.013 & 39.2 & 0.591 & 0.832 & 12.5 & 0.409 \\
\hline 105 & 196.18 & 0.642 & 0.15 & 427430.80 & 0.11 & & & & & & \\
\hline 106 & 197.67 & 0.640 & 0.15 & 419524.70 & 0.11 & & & & & & \\
\hline 107 & 199.34 & 0.622 & 0.13 & 369053.10 & 0.10 & 1.022 & 39.3 & 0.599 & 0.807 & 12.6 & 0.403 \\
\hline 108 & 202.80 & 0.611 & 0.12 & 327355.60 & 0.09 & & & & & & \\
\hline 109 & 203.59 & 0.603 & 0.11 & 223165.50 & 0.07 & & & & & & \\
\hline 110 & 205.71 & 0.571 & 0.09 & 314830.20 & 0.09 & 1.020 & 39.7 & 0.603 & 0.827 & 12.5 & 0.407 \\
\hline 111 & 206.21 & & & 285211.20 & 0.08 & & & & & & \\
\hline 112 & 224.47 & 0.564 & 0.08 & 29806.30 & 0.01 & 1.018 & 39.6 & 0.601 & 0.823 & 12.5 & 0.406 \\
\hline 113 & 225.17 & 0.558 & 0.07 & 50281.00 & 0.02 & & & & & & \\
\hline 114 & 242.66 & 0.529 & 0.05 & 3888.60 & 0.00 & & & & & & \\
\hline
\end{tabular}


Table 22 (Continued): $0.2 \mathrm{~mL} / \mathrm{min}$ Remediation Data, $60^{\circ} \mathrm{C}$ Activation

Data results for $0.2 \mathrm{~mL} / \mathrm{min}$ Remediation Data, $60^{\circ} \mathrm{C}$ Activation; samples $115-125$

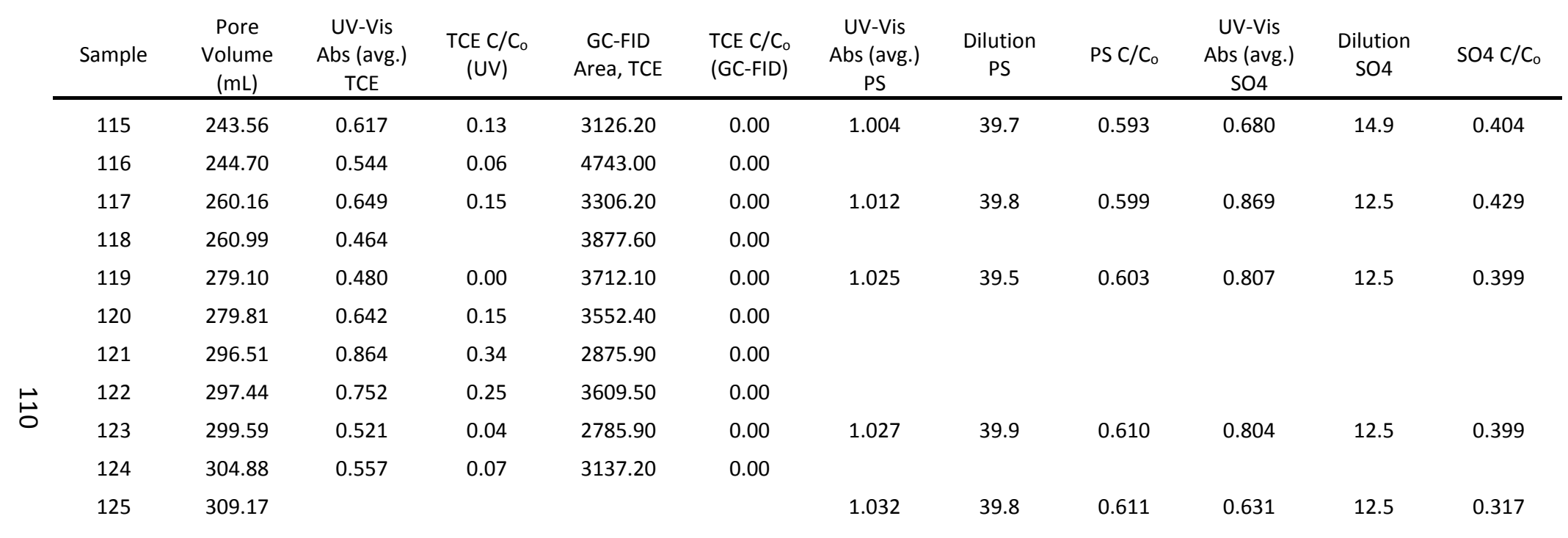




\section{Table 23: 100 mM Batch Studies}

Performed for control of persulfate interaction with Accusand, sampling containers, other mass loss effects

Asterisk $(*)$ indicates sample done without Accusand.

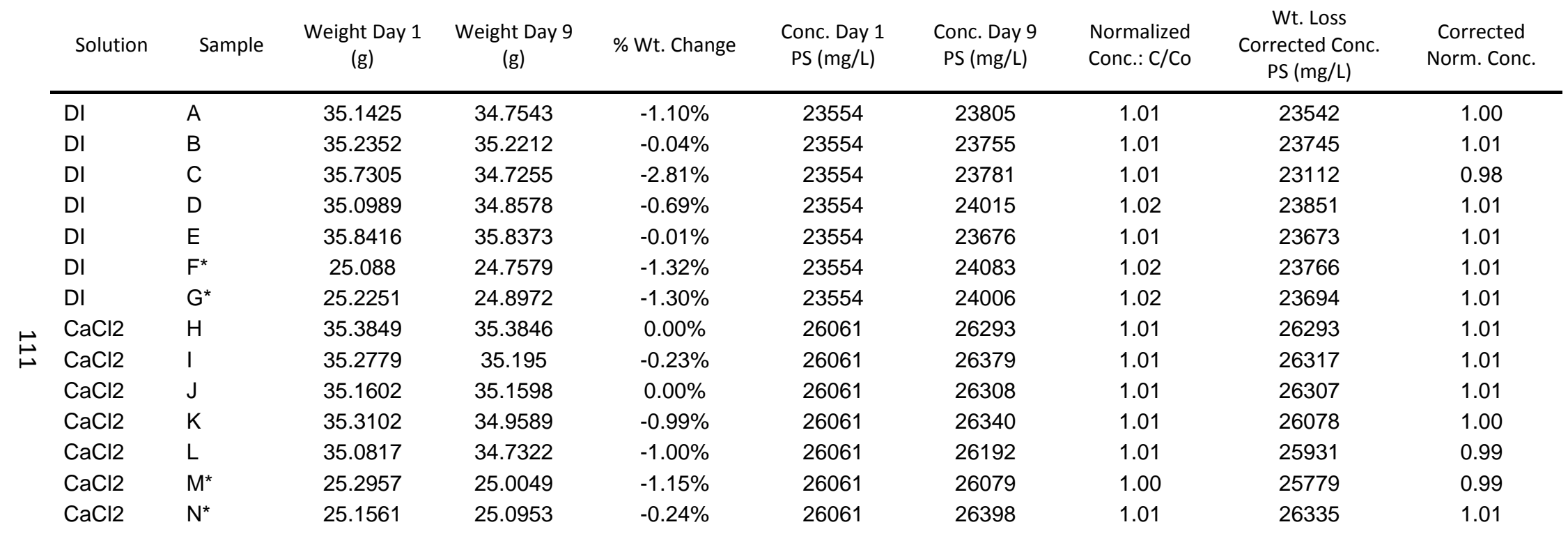




\section{Table 24: 10 mM Batch Studies}

Performed for control of persulfate interaction with Accusand, sampling containers, other mass loss effects

Asterisk $(*)$ indicates sample done without Accusand.

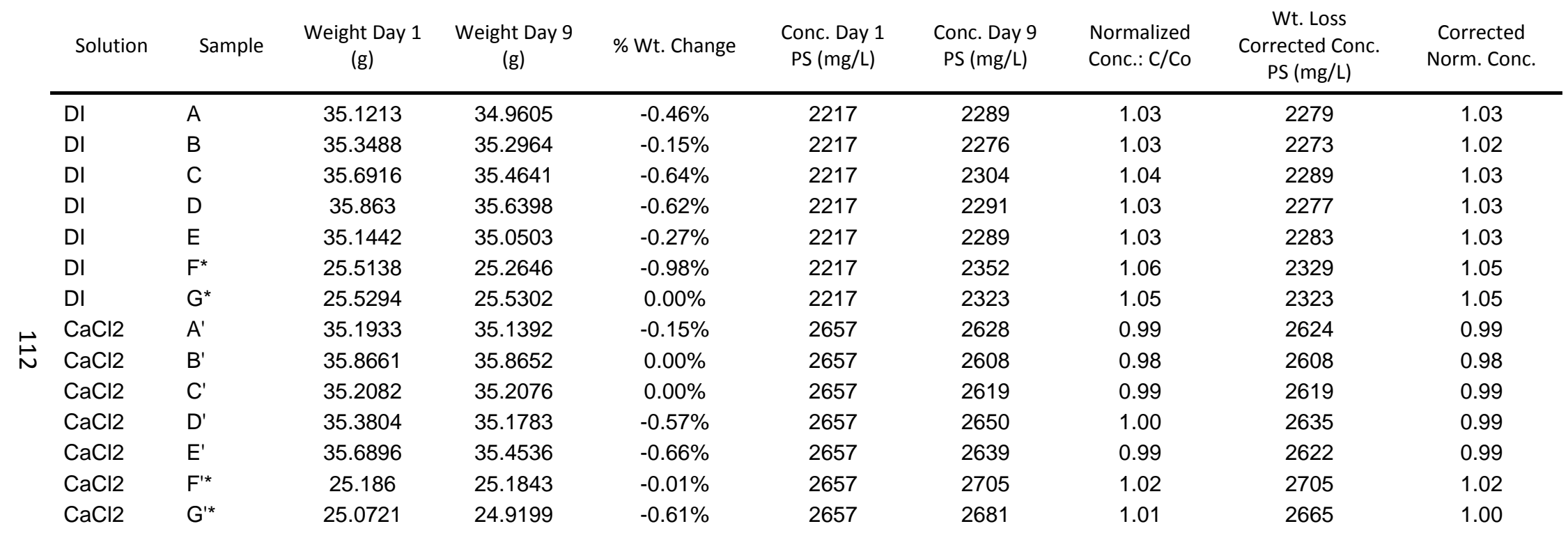




\section{Table 25: $60^{\circ} \mathrm{C}$ Batch Activation Study}

Performed for Heat-activation of persulfate kinetics Concentrations, $\mathrm{C}_{0}: 2393.6 \mathrm{mg} / \mathrm{L} \mathrm{Na}_{2} \mathrm{~S}_{2} \mathrm{O}_{8}$

Electrolyte: $0.01 \mathrm{~N} \mathrm{CaCl}_{2}$

Data results for $60^{\circ} \mathrm{C}$ Batch Activation of persulfate; samples 1-11

\begin{tabular}{|c|c|c|c|c|c|}
\hline Sample & Time (hr) & Dilution & $\begin{array}{c}\text { UV-Vis Abs. } \\
\text { (Avg.), PS }\end{array}$ & $C / C_{0}, P S$ & \\
\hline 1 & 0.0 & 104.9 & 0.618 & 0.975 & \\
\hline 2 & 12.9 & 104.5 & 0.325 & 0.498 & \\
\hline 3 & 24.7 & 103.2 & 0.150 & 0.213 & \\
\hline 4 & 36.8 & 62.4 & 0.121 & 0.101 & \\
\hline 5 & 48.8 & 61.9 & 0.065 & 0.047 & \\
\hline 6 & 60.8 & 62.0 & 0.036 & 0.019 & \\
\hline 7 & 73.0 & 61.7 & 0.023 & 0.006 & \\
\hline 8 & 86.8 & 20.0 & 0.041 & 0.008 & \\
\hline 9 & 95.3 & 20.1 & 0.022 & 0.007 & \\
\hline 10 & 99.5 & 20.1 & 0.018 & 0.001 & LDL \\
\hline 11 & 111.2 & 20.0 & 0.007 & -0.003 & LDL \\
\hline
\end{tabular}




\section{Table 26: $90^{\circ} \mathrm{C}$ Batch Activation Study}

Performed for Heat-activation of persulfate kinetics, and sulfate species mass balance

Concentrations, $\mathrm{C}_{0}: 2375.8 \mathrm{mg} / \mathrm{L} \mathrm{Na}_{2} \mathrm{~S}_{2} \mathrm{O}_{8}$

Electrolyte: $0.01 \mathrm{~N} \mathrm{CaCl}_{2}$

Data results for $90^{\circ} \mathrm{C}$ Batch Activation of persulfate; samples 1-17

\begin{tabular}{|c|c|c|c|c|c|c|c|}
\hline Sample & $\begin{array}{l}\text { Elapsed } \\
\text { Time }\end{array}$ & Dilution, PS & $\begin{array}{l}\text { UV-Vis Abs. } \\
\text { (avg.), PS }\end{array}$ & $C / C_{0}, P S$ & Dilution, $\mathrm{SO}_{4}$ & $\begin{array}{l}\text { UV-Vis Abs. (avg.), } \\
\mathrm{SO}_{4}\end{array}$ & $\mathrm{C} / \mathrm{C}_{\mathrm{o}}, \mathrm{SO}_{4}$ \\
\hline 1 & 0.13 & 59.8 & 1.103 & 0.999 & 13.7 & 0.020 & 0.020 \\
\hline 2 & 0.23 & 59.4 & 1.099 & 0.988 & 11.7 & 0.038 & 0.030 \\
\hline 3 & 0.33 & 59.4 & 0.971 & 0.870 & 19.8 & 0.163 & 0.142 \\
\hline 4 & 0.50 & 60.0 & 0.662 & 0.592 & 19.8 & 0.598 & 0.429 \\
\hline 5 & 0.69 & 59.1 & 0.459 & 0.398 & 19.7 & 0.877 & 0.611 \\
\hline 6 & 0.86 & 39.4 & 0.529 & 0.308 & 29.9 & 0.523 & 0.717 \\
\hline$\stackrel{⿱ ⺊ 口}{\bullet}$ & 1.03 & 19.7 & 0.833 & 0.246 & 29.7 & 0.596 & 0.785 \\
\hline 8 & 1.19 & 19.7 & 0.662 & 0.195 & 29.5 & 0.653 & 0.836 \\
\hline 9 & 1.36 & 19.7 & 0.530 & 0.154 & 29.7 & 0.683 & 0.870 \\
\hline 10 & 1.61 & 19.7 & 0.375 & 0.107 & 29.9 & 0.726 & 0.920 \\
\hline 11 & 1.86 & 19.8 & 0.272 & 0.076 & 29.6 & 0.783 & 0.967 \\
\hline 12 & 2.11 & 19.7 & 0.196 & 0.052 & 29.7 & 0.750 & 0.937 \\
\hline 13 & 2.37 & 19.7 & 0.141 & 0.035 & 31.8 & 0.738 & 0.981 \\
\hline 14 & 2.71 & 19.7 & 0.091 & 0.020 & 31.7 & 0.734 & 0.973 \\
\hline 15 & 3.03 & 19.7 & 0.062 & 0.015 & 31.8 & 0.730 & 0.972 \\
\hline 16 & 3.37 & 19.7 & 0.041 & 0.009 & 33.5 & 0.708 & 0.992 \\
\hline 17 & 3.74 & 19.6 & 0.031 & 0.006 & 33.5 & 0.707 & 0.990 \\
\hline 18 & 4.14 & 19.7 & 0.021 & 0.003 & 33.5 & 0.720 & 1.006 \\
\hline 19 & 4.49 & 19.9 & 0.017 & 0.002 & 33.6 & 0.716 & 1.003 \\
\hline 20 & 5.00 & 19.7 & 0.016 & 0.001 & 33.8 & 0.712 & 1.005 \\
\hline 21 & 6.56 & 19.8 & 0.016 & 0.001 & 33.4 & 0.719 & 1.002 \\
\hline
\end{tabular}

